\title{
Perspectives on neck pain
}

Citation for published version (APA):

Langenfeld Sickendieck, A. (2018). Perspectives on neck pain. [Doctoral Thesis, Maastricht University]. Gildeprint en Universitaire Pers Maastricht. https://doi.org/10.26481/dis.20180710al

Document status and date:

Published: 01/01/2018

DOI:

10.26481/dis.20180710al

Document Version:

Publisher's PDF, also known as Version of record

\section{Please check the document version of this publication:}

- A submitted manuscript is the version of the article upon submission and before peer-review. There can be important differences between the submitted version and the official published version of record.

People interested in the research are advised to contact the author for the final version of the publication, or visit the DOI to the publisher's website.

- The final author version and the galley proof are versions of the publication after peer review.

- The final published version features the final layout of the paper including the volume, issue and page numbers.

Link to publication

\footnotetext{
General rights rights.

- You may freely distribute the URL identifying the publication in the public portal. please follow below link for the End User Agreement:

www.umlib.nl/taverne-license

Take down policy

If you believe that this document breaches copyright please contact us at:

repository@maastrichtuniversity.nl

providing details and we will investigate your claim.
}

Copyright and moral rights for the publications made accessible in the public portal are retained by the authors and/or other copyright owners and it is a condition of accessing publications that users recognise and abide by the legal requirements associated with these

- Users may download and print one copy of any publication from the public portal for the purpose of private study or research.

- You may not further distribute the material or use it for any profit-making activity or commercial gain

If the publication is distributed under the terms of Article $25 \mathrm{fa}$ of the Dutch Copyright Act, indicated by the "Taverne" license above, 


\section{PERSPECTIVES ON NECK PAIN}

Anke Langenfeld 
Copyright Anke Langenfeld Sickendieck, Maastricht 2018

All rights reserved. No part of this publication my be reprinted or utilized in any form or by any electronic, mechanical or other means, now known, or hereafter invented, including photocopying and recording, or in any information storage or retrievel system, without permission from the copyright owner,

ISBN: 9789462339996

Layout and Printing by: Gildeprint I Universitaire Pers Maastricht 


\title{
PERSPECTIVES ON NECK PAIN
}

\author{
DISSERTATION \\ To obtain the degree of Doctor at Maastricht University, \\ on the authority of Rector Magnificus, \\ Prof. Dr. Rianne M. Letschert \\ In accordance with the decision of the Board of Deans, \\ to be defended in public on \\ Tuesday July $10^{\text {th }} 2018$ at 10.00 hours
}

by

Anke Langenfeld Sickendieck 


\section{Supervisor}

Prof. Dr. R.A. de Bie

\section{Co-supervisor}

Dr. Jaap Swanenburg, Balgrist Hospital, Zurich

Prof. em. B. Kim Humphreys, Zurich

\section{Assessment committee}

Prof. Dr. A.E. Boonen, (chair)

Prof. Dr. A.F. Lenssen

Prof. Dr. B. Koes, Erasmus MC, Rotterdam

Dr. B. Staal, HAN University, Radbound UMC, Nijmwegen

Dr. P.C. Willems

The research presented in this thesis was conducted at the School for Public Health and primary Care: CAPHRI, Department of Epidemiology, of Maastricht University. CAPHRI participates in the Netherlands School for Primary Care Research CaRe. CAPHRI was classified as excellent" by the external evaluation committee of leading international experts that reviewed CAPHRI in December 2010 


\section{Contents}

Chapter 1 General introduction 7

Chapter 2 Prognostic Factors for recurrences in neck pain patients up to 21 one year after chiropractic care. (published)

Chapter 3 Effect of manual versus mechanically assisted manipulations 37 of the thoracic spine in neck pain patients: study protocol of a randomized controlled trial. (published)

Chapter 4 Comparing manual and mechanically assisted manipulations of the thoracic spine in neck pain patients: A pilot study (published)

Chapter 5 Validity and reliability of a German version of the Neck Disability Index (NDI-G) (published)

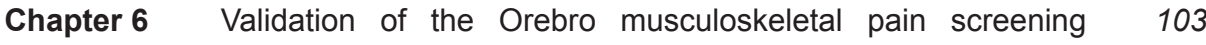
questionnaire in patients with chronic neck pain. (published)

Chapter 7 Development of a self-administered neck mobility assessment tool in chronic neck pain patients. (published)

$\begin{array}{lll}\text { Chapter } 8 & \text { Patient's subjective impression of cervical range of motion: A } & 139\end{array}$ mixed-methods approach (published)

$\begin{array}{lll}\text { Chapter } 9 & \text { General discussion } & 157\end{array}$

$\begin{array}{lll}\text { Addendum } & \text { Summary } & 167\end{array}$

Valorisation 173

Acknowledgments $\quad 177$

About the author $\quad 181$

List of publications 183 


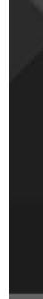



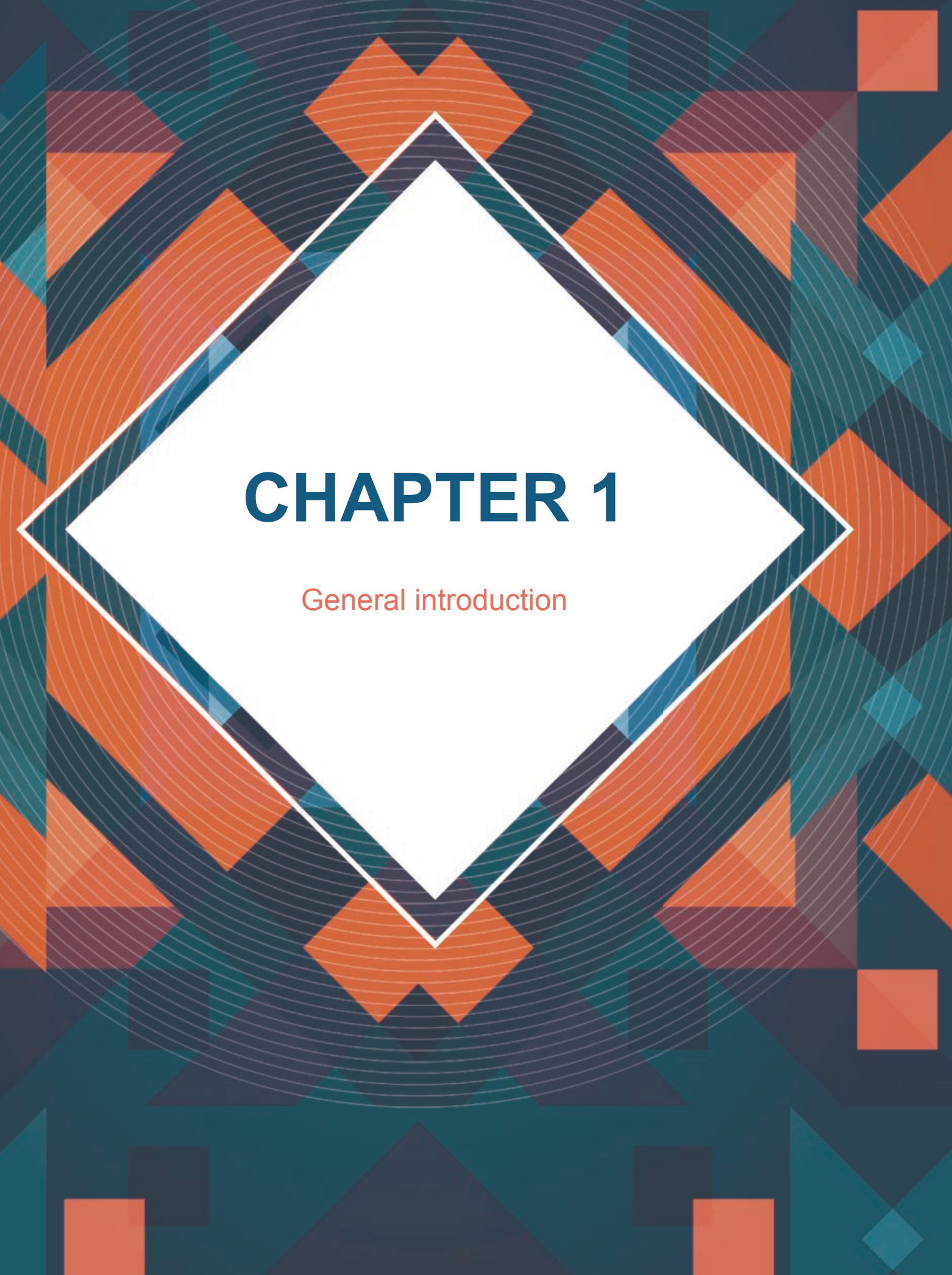



\section{General introduction}

This thesis deals with the perspectives of neck pain. The introduction provides an overview of the burden of neck pain in the general society (1.1); the onset, risk factors, course, the prognostic factors of neck pain (1.2), and the current treatment options for neck pain (1.3). In addition, the pros and cons for the use of questionnaires in physical therapy practice (1.4) have been presented. Explanations of why a patient's perspective should always be considered in the assessment and why it needs to be integrated into the management of neck pain (1.5) have also been provided. Finally, the objectives and outlines of my thesis have been presented (1.6 and 1.7).

\section{Neck pain and its prevalence}

Neck pain, in adjunction with low back pain, was the most common cause of disability in 2015, especially in high-income countries ${ }^{1}$. The prevalence and burden (financial and human) of neck pain are high globally ${ }^{2}$. Anatomically, neck pain is defined as pain perceived in the posterior region of the cervical spine, anywhere between the superior nuchal line and the spinous process of the first thoracic vertebra ${ }^{3}$. Interestingly, the definition of neck pain does not presuppose or imply that the underlying cause of this complaint has its origin in the neck area. It simply indicates the area where the patient experiences pain ${ }^{4}$. In 2008, the Task Force on Neck Pain and Its Associated Disorders provided the following classification for neck pain: Grade I, no major pathology and no or little interference with daily activities; Grade II, no major pathology, but possible interference with daily activities, and clinical interventions might be required to help reduce the symptoms; Grade III, additional neurological symptoms, which may require specific tests and treatments; Grade IV, neck pain due to major pathologies, such as spinal infection and serious instability ${ }^{5}$.

\section{Onset, risk factors, course, and prognostic factors of neck pain}

Neck pain is commonly associated with a multifactorial etiology ${ }^{6}$, and it is often accompanied by concomitant pain, such as headache, shoulder pain, upper limb pain, upper back pain, jaw pain, and low back pain ${ }^{7-9}$. Furthermore, patients with neck pain may often report dizziness, lightheadedness, or nausea ${ }^{9}$. Usually, acute neck pain is resolved in days to weeks ${ }^{10}$, but more than half of the individuals experiencing neck pain $(50 \%-$ $85 \%$ ) do not report complete cure and develop a chronic course with frequent relapses ${ }^{11-13}$. If a person experiences neck pain once, it is likely that another episode of neck pain will be experienced in the next one to five years ${ }^{13}$. 
Some factors can influence either the onset of neck pain (risk factors) or its course and recovery (prognostic factors). Usually, to identify the risk factors of neck pain, studies enroll healthy individuals without neck pain at the beginning of the measurement period. These individuals are followed for a previously defined period of time. During this period, data are collected and later statistically analyzed to determine the factors that influence the development of neck pain (risk factors) ${ }^{13}$. Currently, the known risk factors for the onset of neck pain are age, genetics, psychological distress, reduced general health, female sex, previous history of neck injury, high number of children, smoking, and exposure to tobacco ${ }^{14,15}$. Furthermore, high quantitative job demands (e.g., working under time pressure and working with deadlines) and low coworker support are additional risk factors for neck pain ${ }^{16}$. The risk factors for leave due to a new episode of neck pain in a male-dominated industrial setting are several earlier episodes of neck and back pain, few positive challenges at work, leave for any duration not associated with neck or low back pain, uncertainty about own working ability in two years, absence of daily physical activity during leisure time (e.g., cleaning and gardening), and repetitive work procedures. The risk of leave because of neck or back pain was shown to be higher in blue collar workers than in white-collar workers ${ }^{17}$. Additionally, occupational, psychological, and social factors have been shown to be predictors for new-onset and persistent neck pain ${ }^{18}$. Christensen and Knardahl (2014) identified strong influences of quantitative demand, role conflict, social climate, decision control, and empowering leadership over time as a risk for a newonset and persistent neck pain ${ }^{18}$.

A different approach is followed for identifying prognostic factors. In this assessment, the focus is on people who already experience neck pain. Prognostic factors that influence the recovery of neck pain either positively or negatively are identified among patients with neck pain ${ }^{13}$. The common prognostic factors are age, psychological health, advice and referral of a healthcare practitioner, duration of symptoms, high baseline pain intensity, high self-reported neck disability, history of other musculoskeletal disorders, and patient expectations ${ }^{13,19-22}$. It appears that young age at the first onset of neck pain is associated with a better prognosis and a faster recovery ${ }^{13}, 20$. Furthermore, a better psychological health status and greater social support have been shown to be associated with better outcomes in a primary care setting ${ }^{13}$. A long duration of symptoms and a high severity of pain in addition to increased functional limitations at the first visit may influence the recovery negatively with regard to short-term outcomes. With regard to long-term outcomes, the duration of symptoms at the first visit to a healthcare professional was a predictor of recovery, and it has been found that a longer duration of neck pain before 
visiting a clinician was associated with a worse prognosis ${ }^{19}$. Additionally, high pain intensity and high self-reported neck disability at the baseline assessment have been found to be associated with a poor prognosis ${ }^{20}$. If a patient has a history of musculoskeletal disorders other than neck pain, shoulder pain, headache, and low back pain, the prognosis of neck pain is more likely to be poor.

It has always been considered that being active could positively influence the onset and course of neck pain. A recent study by Palmlöf et al. (2016) found that being active during leisure time can reduce the risk of developing long duration neck pain, but only if there was no incident of neck pain initially ${ }^{21}$. Once neck pain has occurred, being active during leisure time does not have any influence on neck pain. Similar observations were made for work-related physical activity ${ }^{21}$.

\section{Current treatment options for neck pain}

There are several reviews and guidelines on neck pain and its possible effective treatments 23-47. A recent guideline update of the work performed by the Task Force on Neck Pain and its Associated Disorders in 2008 has focused on the management of neck pain and any associated disorders ${ }^{47}$. These guidelines focus on adults with neck pain of grades I-III for less than six months. Eight recommendations were made, and they are considered to support healthcare professionals in the treatment of patients with neck pain. The recommendations are as follows:

1. Clinicians should rule out any structural pathologies or diseases, which could cause neck pain, e.g., arterial dissection. Furthermore, the pain should be graded (grades I-III). Grade IV pain should be treated by another type of health professional, and it is therefore not mentioned in this section.

2. Clinicians should be aware of any factors that could cause delayed recovery.Patients need to be educated and reassured that neck pain is benign and self- limited, depending on the grading, and that they should stay active and move around. Nevertheless, patients with maintenance of pain, worsening of pain, or new physical or psychological symptoms should be referred to a physician.

3. Patients with symptoms for less than three months and a grade of I or II should receive structured patient education, in combination with a range of motion exercises, multimodal care that includes a range of motion exercises and manipulation or mobilization, or muscle relaxants. Treatments for which questions have been raised include structured patient education alone, strain-counterstrain therapy, relaxation massage, cervical collar, electroacupuncture, and clinic-based heat. 
4. If a patient experiences pain for more than three months, structured patient education in combination with a range of motion and strengthening exercises, qigong, yoga, clinical massage, low-level laser therapy, or non-steroidal anti- inflammatory drugs may be useful. Treatments without supporting evidence include strengthening exercise alone, strain-counterstrain therapy, relaxation massage, relaxation therapy for pain or disability, electrotherapy, shortwave diathermy, clinic-based heat, electroacupuncture, and botulinum toxin injections.

5. For the treatment of grade III complaints, supervised strengthening exercises in addition to structured patient education are recommended. No effectiveness has been found for structured patient education alone, cervical collar, low-level laser therapy, or traction.

6. If the pain duration is longer than three months and is associated with disability and neurological signs, the patient should be referred to a physician for further tests and assessments.

7. The patient should be reassessed at every visit, and improvement or deterioration should be monitored ${ }^{47}$.

\section{The use of questionnaires in research}

There are several questionnaires targeting disability associated with neck pain ${ }^{48,} 49$. In general, questionnaires are a research method to collect data, and they are usually completed by the patient ${ }^{50}$. Furthermore, questionnaires are cost effective, and nowadays, they can even be sent via email ${ }^{51,52}$. Additionally, they can provide a better understanding of treatment from the patient's perspective by translating clinical improvement into patientcentered outcomes ${ }^{53}$.

There are known advantages of using questionnaires to gather data. First, they provide anonymity and therefore may capture more honest answers ${ }^{50,52}$. Furthermore, the target audience can be clearly defined, but the participants can be from different locations. The majority of patients will be aware of the information requested from them, and the data analysis can be performed statistically ${ }^{50}$. The main disadvantage is that patients with poor literacy, visual impairments, and language issues may not be able to fill out the questionnaire. Additionally, the researcher cannot be sure that each patient has independently filled out the questionnaire ${ }^{50}$. Furthermore, if patients have any confusion with regard to the questionnaire, the researcher might not be able to clarify the issues. This is because there is limited flexibility for patient responses, as the questions are usually rigid, unless they are open-ended ${ }^{50}$. 
If questionnaires are used in the research design, they should fulfill three main characteristics, which are described as domains that contain measurement properties ${ }^{54}$. These are validity, reliability, and responsiveness ${ }^{54,55}$. Validity is defined as the degree to which an instrument truly measures the construct(s) it purports to measure ${ }^{54}$. Furthermore, validity can be divided into content validity (including face validity), construct validity (including structural validity, hypothesis testing, and cross-cultural validity), and criterion validity ${ }^{54}$. Reliability is defined as the degree to which a measurement is free from measurement error ${ }^{54}$. It can be divided into internal consistency, reliability, and measurement error ${ }^{54}$. Responsiveness is defined as the ability of an instrument to assess change over time in the construct to be measured ${ }^{54}$.

\section{Patient's perspective and expectations}

As a multidimensional phenomenon, neck pain is associated with physical and psychological parameters, which affect measurement ${ }^{49}$. This is especially true in the case of chronic neck pain, which may need more than one index to obtain a complete health profile of the patient ${ }^{55}$. Considering that not a single mechanism appears to explain all variances in selfreported disability, it is clear that neck-related disability is not a one-dimensional construct. Instead, it should be assessed from a variety of perspectives across different disciplines, and perhaps, the most important is the patient's own perspective of the condition ${ }^{56}$. Additionally, clarity with regard to the patient's perspective provides insights into how the treatment should be tailored to target patient requirements ${ }^{57}$. In fact, patient expectation can greatly influence the therapy's outcome. If a patient has high expectations that the therapy will be beneficial, recovery is more likely ${ }^{22,58}$. Patient expectations of physical therapy are usually diverse ${ }^{59}$. Patients expect a proper dialog and clear communication, and they prefer to be referred to as a person and not as a number. Furthermore, they prefer to receive an explanation about the problem and a tailored exercise program that addresses their requirements ${ }^{59}$.

\section{Objectives of the thesis}

The general aim of the thesis was to investigate the clinician's and patient's perspectives on the outcomes of treatments in patients with neck pain. First, possible prognostic factors, which could be associated with recurrence of neck pain after patients had been treated with general chiropractic care, were investigated. Second, a newly developed treatment technique for the thoracic spine and its influence on neck pain were assessed. This technique was compared to standard treatment and focused on short- and long-term outcomes. A valuable insight from these initial studies was that the patient's perspective 
was missing with regard to neck pain, especially range of motion. The incorporation of the patient's perception of neck pain is related to their activities of daily living, and it should be an important part of treatment. To our knowledge, currently, no instrument covers the patient's perspective with regard to the cervical range of motion. Therefore, the final objective of this thesis was to develop and test a measure that focuses on the patient's perspective with regard to the range of motion of the cervical spine (S-ROM-Neck).

\section{Outline of the thesis}

The chapters of this thesis present findings from six different studies. They investigate the different aspects of neck pain. Initially, I focused on the possible prognostic factors in patients with neck pain (chapter 2). I then developed a randomized clinical trial protocol, where I compared manual manipulations to mechanically assisted manipulations directed to the thoracic spine (chapter 3). Additionally, I conducted a pilot study evaluating the mentioned protocol (chapter 4). Furthermore, I assessed the use and verification of the different outcome measures adopted in the previous studies, especially the Neck Disability Index, which is a well- known and widely used measurement tool (chapter 5), and the Örebro Questionnaire. The questionnaire is commonly used to identify patients who might develop persistent back pain. I was interested as to whether the questionnaire could be used in patients with neck pain (chapter 6). Additionally, I developed another tool to evaluate the patient's perspective with regard to the cervical range of motion (S- ROMNeck) (chapter 7 ) and finally compared the ratings of the patient and clinician with respect to the cervical range of motion devices (CROM) (chapter 8). 


\section{REFERENCES}

1. Vos T, Allen C, Arora M, et al. Global, regional, and national incidence, prevalence, and years lived with disability for 310 diseases and injuries, 1990???2015: a systematic analysis for the Global Burden of Disease Study 2015. Lancet. 2016;388(10053):1545-1602. doi:10.1016/ S0140- 6736(16)31678-6.

2. Hoy D, March L, Woolf A, et al. The global burden of neck pain: estimates from the global burden of disease 2010 study. Ann Rheum Dis. 2014;73(7):1309- 1315. doi:10.1136/ annrheumdis-2013-204431.

3. Bogduk N, McGuirk B. Management of Acute and Chronic Neck Pain: An Evidence-Based Approach. 1st ed. Edinburgh, London, New York, Oxford, Philadelphia, St. Louis, Sydney, Toronto: Elsevier; 2006.

4. Bogduk N. The Anatomy and Pathophysiology of Neck Pain. Phys Med Rehabil Clin N Am. 2011;22(3):367-382. doi:10.1016/j.pmr.2011.03.008.

5. Guzman J, Haldeman S, Carroll LJ, et al. Clinical practice implications of the Bone and Joint Decade 2000-2010 Task Force on Neck Pain and Its Associated Disorders: from concepts and findings to recommendations. J Manipulative Physiol Ther. 2008;32(2 Suppl):S227-S243. doi:10.1016/j.jmpt.2008.11.023.

6. Alexander EP. History, Physical Examination, and Differential Diagnosis of Neck Pain. Phys Med Rehabil Clin N Am. 2011;22(3):383-393. doi:10.1016/j.pmr.2011.02.005.

7. Rao R. Neck Pain, Cervical Radiculopathy, and. J Bone Jt Surg. 2002;84- A(10):479-488. http:// www.ncbi.nlm.nih.gov/pubmed/21137285.

8. Ferrari R, Russell AS. Neck pain. Best Pract Res Clin Rheumatol. 2003;17(1):57-70. doi:10.1053/ yberh.2003.269.

9. Leaver AM, Maher CG, McAuley JH, Jull GA, Refshauge KM. Characteristics of a new episode of neck pain. Man Ther. 2013;18(3):254-257. doi:10.1016/j.math.2012.05.008.

10. Binder Al. Cervical spondylosis and neck pain. Br Med J. 2007;334:527-531. doi:10.1136/ bmj.39127.608299.80.

11. Walton DM, Eilon-Avigdor $\mathrm{Y}$, Wonderham M, Wilk P. Exploring the clinical course of neck pain in physical therapy: A longitudinal study. Arch Phys Med Rehabil. 2014;95(2):303-308. doi:10.1016/j.apmr.2013.09.004.

12. Hoy DG, Protani M, De R, Buchbinder R. The epidemiology of neck pain. Best Pract Res Clin Rheumatol. 2010;24(6):783-792. doi:10.1016/j.berh.2011.01.019.

13. Carroll LJ, Hogg-johnson S, Velde G Van Der, et al. Course and prognostic factors for neck pain in the general population neck pain and its associated disorders. Spine (Phila Pa 1976). 2008;33(4S):75-82.

14. Croft PR, Lewis M, Papageorgiou a C, et al. Risk factors for neck pain: a longitudinal study in the general population. Pain. 2001;93(3):317-325. http://www.ncbi.nlm.nih.gov/pubmed/11514090.

15. Hogg-Johnson S. Differences in reported psychometric properties of the Neck Disability Index: patient population or choice of methods? Spine J. 2009;9(10):854-856. doi:10.1016/j. spinee.2009.07.001.

16. Ariëns G a, Bongers PM, Hoogendoorn WE, Houtman IL, van der Wal G, van Mechelen W. High quantitative job demands and low coworker support as risk factors for neck pain: results of a prospective cohort study. Spine (Phila Pa 1976). 2001;26(17):1896-901-3. doi:10.1097/00007632-200109010-00016.

17. Bergström G, Bodin L, Bertilsson H, Jensen IB. Risk factors for new episodes of sick leave due to neck or back pain in a working population. A prospective study with an 18-month and a threeyear follow-up. Occup Environ Med. 2007;64(4):279-287. doi:10.1136/oem.2006.026583.

18. Christensen JO, Knardahl S. Time-course of occupational psychological and social factors as predictors of new-onset and persistent neck pain: A three- wave prospective study over 4 years. Pain. 2014;155(7):1262-1271. doi:10.1016/j.pain.2014.03.021. 
19. Bruls VE, Bastiaenen $\mathrm{CH}$, de Bie R a. Prognostic Factors of Complaints of Arm, Neck And/or Shoulder.; 2015. doi:10.1097/j.pain.0000000000000117.

20. Walton DM, Carroll LJ, Kasch H, et al. An overview of systematic reviews on prognostic factors in neck pain: Results from the International Collaboration on Neck Pain (ICON) Project. Open Orthop J. 2013;7(Suppl 4: M9):494-505. doi:10.2174/1874325001307010494.

21. Palmlöf L, Holm LW, Alfredsson L, Magnusson C, Vingård E, Skillgate E. The impact of work related physical activity and leisure physical activity on the risk and prognosis of neck pain - a population based cohort study on workers. BMC Musculoskelet Disord. 2016;17(1):219. doi:10.1186/s12891-016-1080-1.

22. Palmlöf L, Holm LW, Alfredsson L, Skillgate E. Expectations of recovery: A prognostic factor in patients with neck pain undergoing manual therapy treatment. Eur J Pain (United Kingdom). 2016;20(9):1384-1391. doi:10.1002/ejp.861.

23. Bervoets DC, Luijsterburg PAJ, Alessie JJN, Buijs MJ, Verhagen AP. Massage therapy has shortterm benefits for people with common musculoskeletal disorders compared to no treatment: $A$ systematic review. J Physiother. 2015;61(3):106-116. doi:10.1016/j.jphys.2015.05.018.

24. Cross KM, Kuenze C, Grindstaff TL, Hertel J. Thoracic spine thrust manipulation improves pain, range of motion, and self-reported function in patients with mechanical neck pain: a systematic review. J Orthop Sports Phys Ther. 2011;41(9):633-642. doi:10.2519/jospt.2011.3670.

25. Gross AR, Paquin JP, Dupont G, et al. Exercises for mechanical neck disorders: A Cochrane review update. Man Ther. 2016;24:25-45. doi:10.1016/j.math.2016.04.005.

26. Gross A, Miller J, D'Sylva J, et al. Manipulation or mobilisation for neck pain: a Cochrane Review. Man Ther. 2010;15(4):315-333. doi:10.1016/j.math.2010.04.002.

27. Huisman $\mathrm{P}$ a, Speksnijder CM, de Wijer A. The effect of thoracic spine manipulation on pain and disability in patients with non-specific neck pain: a systematic review. Disabil Rehabil. 2013;35(20):1677-1685. doi:10.3109/09638288.2012.750689.

28. van der Velde $G, Y u H$, Paulden $M$, et al. Which interventions are cost-effective for the management of whiplash-associated and neck pain-associated disorders? A systematic review of the health economic literature by the Ontario Protocol for Traffic Injury Management (OPTIMa) Collaboration. Spine J. 2016;16(12):1582-1597. doi:10.1016/j.spinee.2015.08.025.

29. Yamato TP, Saragiotto BT, Maher C. Therapeutic exercise for chronic non- specific neck pain: PEDro systematic review update. Br J Sports Med. 2015;49(20):1350. doi:10.1136/ bjsports-2014-093874.

30. Vincent K, Maigne JY, Fischhoff C, Lanlo O, Dagenais S. Systematic review of manual therapies for nonspecific neck pain. Jt Bone Spine. 2013;80(5):508- 515. doi:10.1016/j.jbspin.2012.10.006.

31. Yu H, C??t?? P, Southerst D, et al. Does structured patient education improve the recovery and clinical outcomes of patients with neck pain? A systematic review from the Ontario Protocol for Traffic Injury Management (OPTIMa) Collaboration. Spine J. 2016;16(12):1524-1540. doi:10.1016/j.spinee.2014.03.039.

32. Kroeling P, Gross A, Ch G, et al. Electrotherapy for neck pain (Review). Cochrane Database Syst Rev. 2013;(8). doi:10.1002/14651858.CD004251.pub5.www.cochranelibrary.com.

33. D'Sylva J, Miller J, Gross A, et al. Manual therapy with or without physical medicine modalities for neck pain: a systematic review. Man Ther. 2010;15(5):415-433. doi:10.1016/j.math.2010.04.003.

34. Schroeder J, Kaplan L, Fischer DJ, Skelly AC. The outcomes of manipulation or mobilization therapy compared with physical therapy or exercise for neck pain: a systematic review. Evid Based Spine Care J. 2013;4(1):30-41. doi:10.1055/s-0033-1341605.

35. Bronfort G, Haas M, Evans RL, Bouter LM. Efficacy of spinal manipulation and mobilization for low back pain and neck pain: a systematic review and best evidence synthesis. Spine $J$. 2004;4(4):335-356. doi:10.1016/j.spinee.2003.06.002.

36. Miller J, Gross A, D'Sylva J, et al. Manual therapy and exercise for neck pain: A systematic review. Man Ther. 2010;15(4):334-354. doi:10.1016/j.math.2010.02.007.

37. Haines T, Gross AR, Burnie S, Goldsmith CH, Perry L, Graham N. A Cochrane review of patient education for neck pain. Spine J. 2009;9(10):859-871. doi:10.1016/j.spinee.2009.04.019.

38. Southerst D, Nordin MC, C??t?? P, et al. Is exercise effective for the management of neck pain and associated disorders or whiplash-associated disorders? A systematic review by the Ontario 
Protocol for Traffic Injury Management (OPTIMa) Collaboration. Spine J. 2016;16(12):15031523. doi:10.1016/j.spinee.2014.02.014.

39. Bryans R, Decina P, Descarreaux M, et al. Evidence-based guidelines for the chiropractic treatment of adults with neck pain. J Manipulative Physiol Ther. 2014;37(1):42-63. doi:10.1016/j. jmpt.2013.08.010.

40. Anderson-PeacockE, Blouin J-S, Bryans R, et al. Chiropractic clinical practice guideline: evidencebased treatment of adult neck pain not due to whiplash. J Can Chiropr Assoc. 2005;49(3):158209. http://www.pubmedcentral.nih.gov/articlerender.fcgi?artid=1978453\&tool=pmce ntrez\&rendertype $=$ abstract.

41. Wong JJ, Shearer HM, Mior S, et al. Are Manual Therapies, Passive Physical Modalities, or Acupuncture Effective for the Management of Patients with Whiplash-Associated Disorders or Neck Pain and Associated Disorders? An Update of the Bone and Joint Decade Task Force on Neck Pain and Its Ass. Vol 16. Elsevier Inc.; 2016. doi:10.1016/j.spinee.2015.08.024.

42. Graham N, Gross AR, Carlesso LC, et al. An ICON Overview on Physical Modalities for Neck Pain and Associated Disorders. Open Orthop J. 2013;7(SEPTEMBER 2013):440-460. doi:10.2 174/1874325001307010440.

43. Plastaras CT, Schran S, Kim N, et al. Complementary and Alternative Treatment for Neck Pain: Chiropractic, Acupuncture, TENS, Massage, Yoga, Tai Chi, and Feldenkrais. Phys Med Rehabil Clin N Am. 2011;22(3):521-537. doi:10.1016/j.pmr.2011.02.011.

44. Pangarkar S, Lee PC. Conservative Treatment for Neck Pain: Medications, Physical Therapy, and Exercise. Phys Med Rehabil Clin N Am. 2011;22(3):503-520. doi:10.1016/j.pmr.2011.04.001.

45. Childs JD, Cleland JA, Elliott JM, et al. Neck pain: Clinical practice guidelines linked to the International Classification of Functioning, Disability, and Health from the Orthopedic Section of the American Physical Therapy Association. J Orthop Sports Phys Ther. 2008;38(9):A1-A34. doi:10.2519/jospt.2008.0303.

46. Costello J, Jull G. Evidence-based Clinical Statement Neck Pain. Pain. 2002;(November):6-45.

47. Cote P, Wong JJ, Sutton D, et al. Management of neck pain and associated disorders: A clinical practice guideline from the Ontario Protocol for Traffic Injury Management (OPTIMa) Collaboration. Eur Spine J. 2016;25(7):2000- 2022. doi:10.1007/s00586-016-4467-7.

48. Schellingerhout JM, Verhagen AP, Heymans MW, Koes BW, De Vet HC, Terwee CB. Measurement properties of disease-specific questionnaires in patients with neck pain: A systematic review. Qual Life Res. 2012;21(4):659- 670. doi:10.1007/s11136-011-9965-9.

49. Petala E, Kapoukranidou D, Christos K. Assessment of Patients with Neck Pain: The Most Valid Measurement Tools. Res Rev J Med Heal Sci. 2015;4(4):19-25.

50. Marshall G. The purpose, design and administration of a questionnaire for data collection. Radiography. 2005;11(2):131-136. doi:10.1016/j.radi.2004.09.002.

51. Wiitavaara $B$, Heiden M. Content and psychometric evaluations of questionnaires for assessing physical function in people with neck disorders: a systematic review of the literature. Disabil Rehabil. 2017;0(0):1-9. doi:10.1080/09638288.2017.1334096.

52. Miller NJ. Questionnaires - The Handbook for Economics Lecturers. The Handbook for Economic Lecturers. http://www.economicsnetwork.ac.uk/handbook/printable/questionnaires_v5.pdf. Published 2002. Accessed December 4, 2017.

53. Wiklund I. Assessment of patient-reported outcomes in clinical trials: The example of healthrelated quality of life. Fundam Clin Pharmacol. 2004;18(3):351-363. doi:10.1111/j.14728206.2004.00234.x.

54. Mokkink LB, Terwee CB, Patrick DL, et al. The COSMIN study reached international consensus on taxonomy, terminology, and definitions of measurement properties for health-related patientreported outcomes. J Clin Epidemiol. 2010;63(7):737-745. doi:10.1016/j.jclinepi.2010.02.006.

55. Misailidou V, Malliou P, Beneka A, Karagiannidis A, Godolias G. Assessment of patients with neck pain: a review of definitions, selection criteria, and measurement tools. $J$ Chiropr Med. 2010;9(2):49-59. doi:10.1016/j.jcm.2010.03.002.

56. Walton DM, Balsor B, Etruw E. Exploring the Causes of Neck Pain and Disability as Perceived by Those Who Experience the Condition: A Mixed- Methods Study. Int Sch Res Netw Rehabil. 2012;2012:1-7. doi:10.5402/2012/971328. 
57. Bostick GP, Brown CA, Carroll LJ, Gross DP. If they can put a man on the moon, they should be able to fix a neck injury: a mixed-method study characterizing and explaining pain beliefs about WAD. Disabil Rehabil. 2012;34(19):1617-1632. doi:10.3109/09638288.2012.656791.

58. Bishop MD, Mintken PE, Bialosky JE, Cleland JA. Patient expectations of benefit from interventions for neck pain and resulting influence on outcomes. $J$ Orthop Sports Phys Ther. 2013;43(7):457-465. doi:10.2519/jospt.2013.4492.

59. Calner T, Isaksson G, Michaelson P. "I know what I want but I'm not sure how to get it"-Expectations of physiotherapy treatment of persons with persistent pain. Man Ther. 2016;25(3):e142-e143. doi:10.1016/j.math.2016.05.274. 



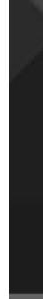




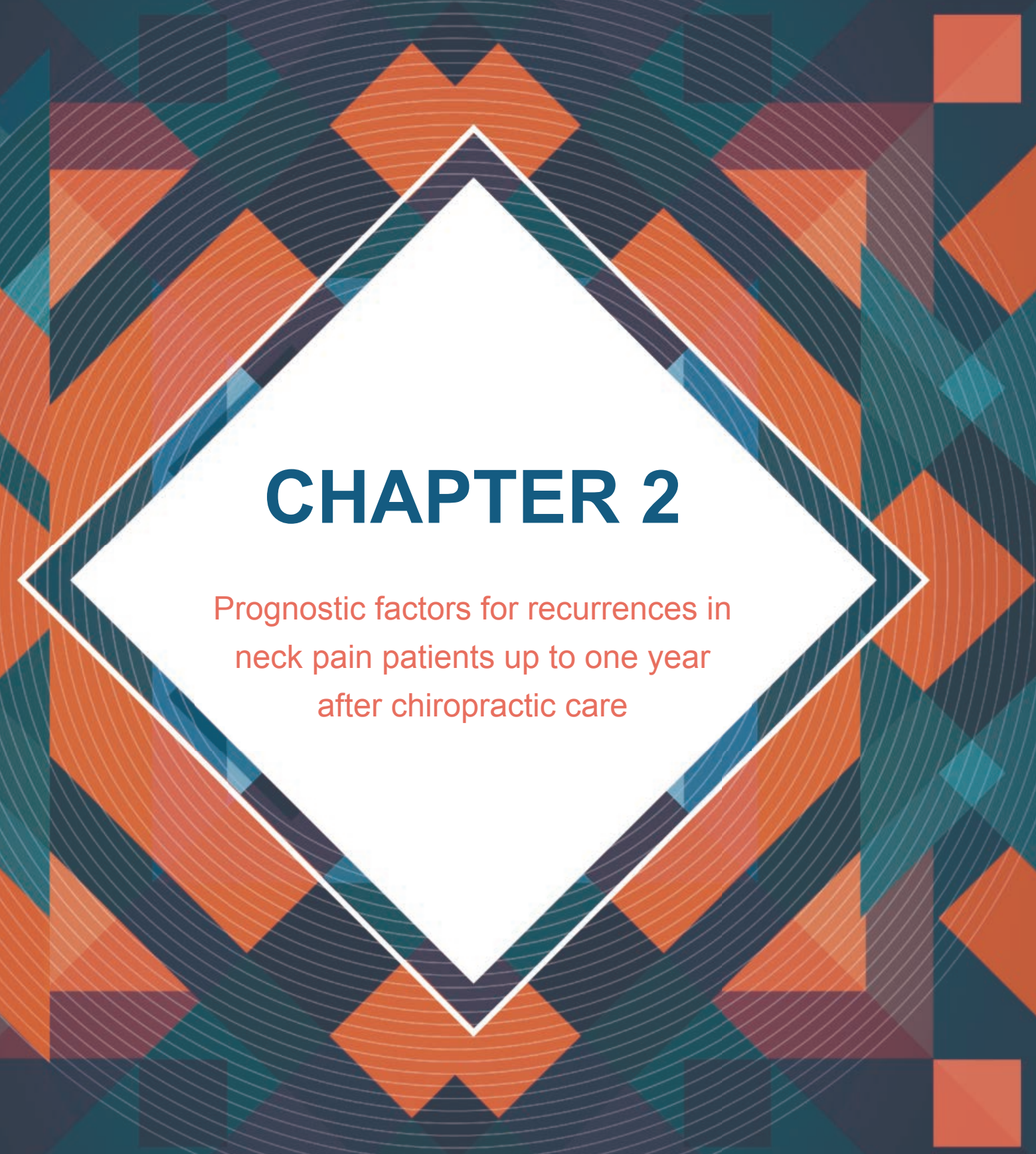

Anke Langenfeld, B. Kim Humphreys, Jaap Swanenburg, and Cynthia K. Peterson

Published: J Manipulative Physiol Ther 2015;38:458-464 


\begin{abstract}
Objective: Information about recurrence and prognostic factors is important for patients and practitioners to set realistic expectations about the chances of full recovery and to reduce patient anxiety and uncertainty. Therefore, the purpose of this study was to assess recurrence and prognostic factors for neck pain in a chiropractic patient population at 1 year from the start of the current episode.
\end{abstract}

Methods: Within a prospective cohort study, 642 neck pain patients were recruited by chiropractors in Switzerland. After a course of chiropractic therapy, patients were followed up for 1 year regarding recurrence of neck pain. A logistic regression analysis was used to assess prognostic factors for recurrent neck pain. The independent variables age, pain medication usage, sex, work status, duration of complaint, previous episodes of neck pain and trauma onset, numerical rating scale, and Bournemouth questionnaire for neck pain were analyzed. Prognostic factors that have been identified in previous studies to influence recovery of neck pain are psychologic distress, poor general health at baseline, and a previous history of pain elsewhere. Results: Five hundred forty five patients (341 females), with a mean age of 42.1 years (SD, 13.1) completed the 1-year follow-up period. Fifty-four participants (11\%) were identified as "recurrent." Prognostic factors associated with recurrent neck pain were previous episodes of neck pain and increasing age.

Conclusion: The results of this study suggest that recurrence of neck pain within 1 year after chiropractic intervention in Swiss chiropractic patients presenting from varied onsets is low. This study found preliminary findings that older age and a previous episode of neck may be useful predictors of neck pain recurrence within 1 year.

Key Indexing Terms: Neck Pain; Recurrence; Chiropractic; Forecasting 
Neck pain is a common reason for patients seeking health care. ${ }^{1}$ Most people will see a medical practitioner or another health care provider at least once in their lifetime due to neck pain. ${ }^{2}$ Those who have experienced an episode of neck pain are likely to have another onset within the next 1 to 5 years. ${ }^{3}$ Consequently, The Neck Pain Task Force has described neck pain as an episodic occurrence over one's lifetime with variable degrees of recovery between episodes. ${ }^{2}$ Hush et al ${ }^{4}$ reported that a new episode of neck pain appears to recover during the acute phase. Nevertheless, the prognosis for a complete recovery is quite poor. ${ }^{4}$ In an observational study, it was shown that patients with a new episode of neck pain in primary care setting typically have high pain scores that improve rapidly during the 3 months after treatment. However, those who do not recover within the 3 months after the intervention have reported relatively low residual pain and disability. ${ }^{5}$ There are known prognostic factors for the onset of neck pain such as computer work, heavy physical work, psychosocial variables, psychologic variables (eg, catastrophizing and kinesiophobia), duration of complaint, age, sex, and previous neck injury. ${ }^{6-11}$ Although several previous studies have made observations regarding neck pain (onset/recovery), no studies prospectively attempted to determine prognostic factors for recurrence of neck pain as a primary outcome.

Information about the possible development of the condition is crucial in shaping patients' expectations about recovery. ${ }^{5}$ It is important that a neck pain patient knows what to expect after a chiropractic treatment and for the therapist to be able to distinguish those with neck pain who will recover and those who will not. The first purpose of this study was to assess the number of episodes of self-reported recurrences over a 1-year period. The second purpose was to identify prognostic factors for the recurrence of neck pain after a chiropractic intervention. 


\section{METHODS}

\section{Study Sample}

Patients with neck pain of any duration age older than 18 years, who had not undergone chiropractic care or manual therapy within the previous 3 months, and agreed to participate, were included in the study. Patients were excluded if they had signs of severe pathology of the cervical spine that are contraindications for chiropractic manipulative treatment such as tumor, severe trauma, acute inflammation, rheumatic conditions, and any signs of possible adverse events, for example, cervical artery dysfunction. All members of the Association of Swiss Chiropractors (Chirosuisse) were invited to participate by recruiting patients. Each chiropractor received notifications, instructions, and the study protocol by e-mail. Patients who were deemed eligible for the study were given, by the individual practice secretaries, the information on participating and the informed consent form to sign. All data from those who consented to participate were sent to a secure fax machine at the Department of Chiropractic Medicine, University Hospital of Balgrist. The participating chiropractors were asked to provide normal and usual treatment for their neck pain patients. No efforts were made to standardize the treatment or the number of treatments. It is known from a study done by Humphreys et al ${ }^{12}$ and a recent article by Bryans et al ${ }^{13}$ that chiropractic treatment is diversified. Commonly used techniques are spinal manipulation, trigger point therapy, therapeutic exercises, mobilization techniques, and advice on the activities of daily living. 12,13 The attending chiropractor was not informed if any of their patients withdrew from the study. Ethics approval was obtained from the Canton of Zurich, Switzerland Ethics Committee (EK-19/2009), and written informed consent was obtained from all participants.

\section{Study Design}

This study conducted a secondary analysis of prospectively collected data that were gathered during another research project with a 1-year follow-up. ${ }^{14}$ Before the start of the study, a literature search was conducted to identify relevant articles. The following databases were checked for relevant article: Medline, CINAHL, Embase, Cochrane, and PEDro. The key terms were neck pain, prognostic factor(s), and recurrence. These were used as single terms and then linked. The identified abstracts were then screened for eligibility. None of the articles was found to match the aim of the article. At baseline, the following variables were collected: age, sex, work status, traumatic onset, duration of complaint, previous episodes, and the use of pain medication. In addition, the Bournemouth questionnaire for neck pain (BQN) and the numeric rating scale (NRS) were used. The BQN is a short form, multidimensional questionnaire that was developed on 
the biopsychosocial model. The BQN includes 7 items on psychosocial issues as well as pain intensity and physical disablility. ${ }^{15,16}$ The NRS is an 11-point rating scale to assess the patient's perception of pain intensity. It ranges from 0 ("no pain at all") to 10 ("the worst imaginable pain"). ${ }^{17}$ To score the questionnaire, the individual items were added up for a total score of 70 . A higher score reflects more psychosocial complaints related to the neck pain experience..$^{18,19}$ The patient data were collected at baseline, 3, 6, and 12 months after the initial treatment. Trained research assistants using a standardized script called each patient by telephone at the appointed data collection time. The following definition of recurrence was used to quantify participants as recurrent: recurrent neck pain is defined as pain that occurred at least 2 times over the past year with each episode of neck pain lasting at least 24 hours, with a pain intensity of greater than 2 on an 11-point NRS and at least a 30 day pain-free episode between episodes. ${ }^{20}$ In addition, patients were deemed to be "recurrent" if they were attending additional treatment for their neck pain such as acupuncture, physiotherapy, osteopathy, or surgery. This was the primary outcome measure. Patients were deemed to be "nonrecurrent" if they reported no new episodes of neck pain. If a patient withdrew from the study, the associated data set was marked.

\section{Database}

The database for this study was formulated, structured, and categories were identified before the start of the study. Research assistants not involved in the study checked the database as well as the informed consent. A quality assurance check of the data was done at different intervals by both the assistant that entered the data as well as by another research assistant who was not involved in the data entry. They both independently checked the accuracy of the data compared with the original questionnaires. During the time the study was conducted, all participants' files were stored and locked in a secure room, to which only the research assistants had access. The files of participants who dropped out of the study were removed, stored, and locked away. Only the principal investigator had access to them.

\section{Statistical Analysis}

The data were stored and analyzed using the IBM SPSS 21 statistical software package (SPSS, Inc, Chicago, IL). Descriptive statistics were used to describe patient characteristics. Logistic regression (stepwise: backward) was applied to test prognostic factors for recurrent neck pain. The dichotomous dependent variable was coded as 0 , nonrecurrent; and 1, recurrent. The independent variables were dichotomized and included 
age ( 0 , below45; 1 , above 45), use of pain medication (no, 0 ; yes, 1 ), sex (male, 0 ; female, 1 ), work status (not working, 0 ; working, 1 ), duration of complaint ( 0 , acute/subacute up to 90 days; 1 , chronic N90 days), previous episodes of neck pain (no, 0 ; yes, 1), and trauma onset (no, 0 ; yes, 1). As well, pain measured by using the NRS and disability measured by the BQN were 2 of the independent variables. All variables were checked for correlation before they were entered into the model. In the case of correlation between variables ( $r$ $>0.20$ ), one of the correlating variables was selected for the logistic regression based on fewer correlations with the other independent variables. The selection criterion for removal for the analysis was set at $\alpha=.05$, and $P<.05$ was considered significant. To judge the quality of the model, a receiver operating characteristics curve was conducted. The area ranges from 0.5 to 1.0 .5 equals no discrimination; and 1 , perfect discrimination. ${ }^{21}$ 


\section{RESULTS}

\section{Study Sample}

Of the 280 members of the ChiroSuisse Association from the 2 largest geographic regions (German and French), 29\% participated in this study. A total of 642 patients were recruited, and $97(15 \%)$ withdrew from the study during the 1-year follow-up. Five hundred forty-five neck pain patients (204 men and 341 women) provided complete data during the 1-year follow-up period. Of the 545 participants, the mean age was 42.1 years (SD, 13.1). At baseline, the mean NRS score for pain intensity was 5.67 (SD, 2.19) and the mean total score for the BQN was 30.92 (SD, 14.82). Thirty-two participants stated during follow-up that they no longer want to participate. Five, 1 week after the initial treatment; 6 , after 1 month; 9 at 3 months; 12 at 6 months; and 2 at 12 months. Two participants could not be recontacted. See the Table for a more detailed account of the baseline sociodemographic and clinical characteristics of the participants.

\section{Recurrence of Neck Pain Complaint}

At 1 year after treatment, a total of 491 participants were classified as "nonrecurrent," as they had not experienced a new episode of neck pain. Fifty-four (11\%) patients were identified as "recurrent" of which 33 began another treatment (physiotherapy, osteopathy, and acupuncture), and 6 patients underwent surgery.

\section{Prognostic Factors for Recurrence of Neck Pain}

Nine independent variables were entered into the model, namely age, use of pain medication, sex, work status, duration of complaint, previous episodes of neck pain, trauma onset, NRS, and BQN. The logistic regression model with recurrence as the dependent variable $(0$, nonrecurrent; 1 , recurrence) revealed age (odds ratio, 2.310; $\mathrm{P}$ $=.004$; confidence interval, 1.299-4.108) and a previous history of neck pain (odds ratio, $0.503 ; \mathrm{P}=.019$; confidence interval, $0.284-0.893$ ) as statistically significant risk factors (Nagelkerke, 0.05). An increase in age was associated with recurrence. Patients older than 45 years are twice as likely to experience a neck pain recurrence within 1 year after the start of chiropractic treatment. If a participant did not experience an episode of neck pain before, the risk of recurrence reduced 0.503. The area under the curve analysis (Figs 1 and 2 ) showed that the full multivariable model is not able to discriminate well. ${ }^{22}$ 
Table 1: Baseline characteristics of all participants

\begin{tabular}{lc}
\hline \multicolumn{1}{c}{ Variable } & Total $(\mathrm{n}=545)$ \\
\hline Age (yrs) & $42.10(\mathrm{SD} 13.10)$ \\
Age groups (yrs) & \\
- $18-29$ & $98(18.0 \%)$ \\
- $30-44$ & $223(40.9 \%)$ \\
- $60-59$ & $156(28.6 \%)$ \\
Gender & $68(12.5 \%)$ \\
- male & \\
- female & $204(37.4 \%)$ \\
Duration of complaints & $341(62.6 \%)$ \\
- acute (<30 days) & \\
- cubacute (>30<90 days) & $242(44.4 \%)$ \\
Profession & $110(20.2 \%)$ \\
- working & $193(35.4 \%)$ \\
- not working & \\
Pain medication & $452(82.9 \%)$ \\
- no & $93(17.1 \%)$ \\
Trauma onset & \\
- no & $372(68.3 \%)$ \\
- yes & $174(31.7 \%)$ \\
Previuos episodes & \\
- no & $469(86.1 \%)$ \\
Numes & $76(13.9 \%)$ \\
Bournemouth Questionnaire (BQN) & $30.92(\mathrm{SD} 14.82)$ \\
\hline
\end{tabular}




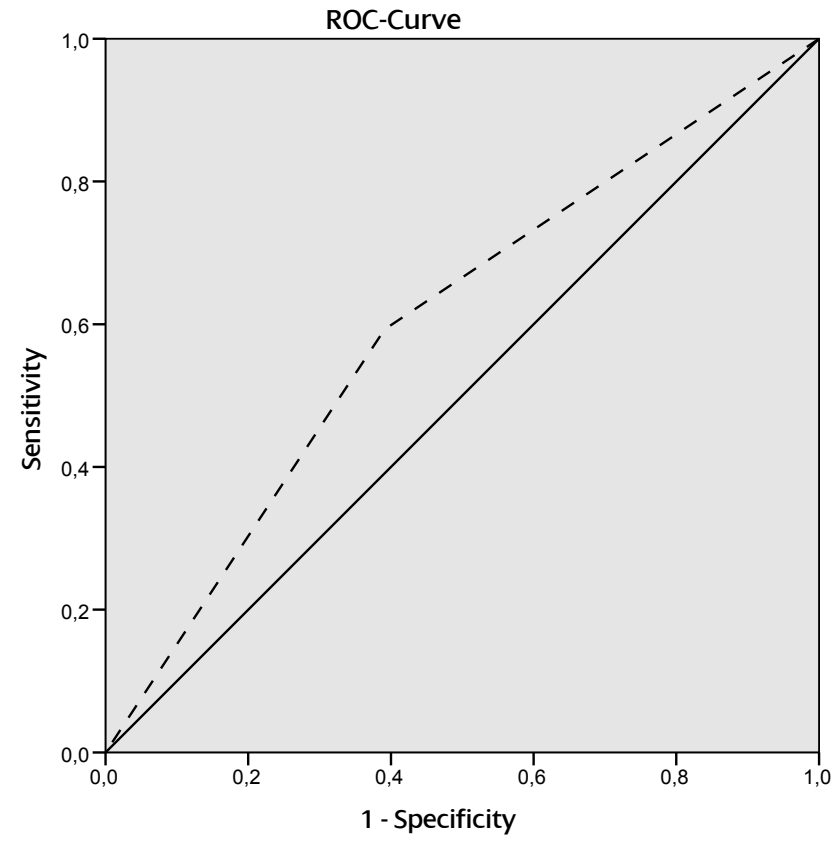

Fig 1. Receiver operating characteristics curve age older than 45 years (0.601).

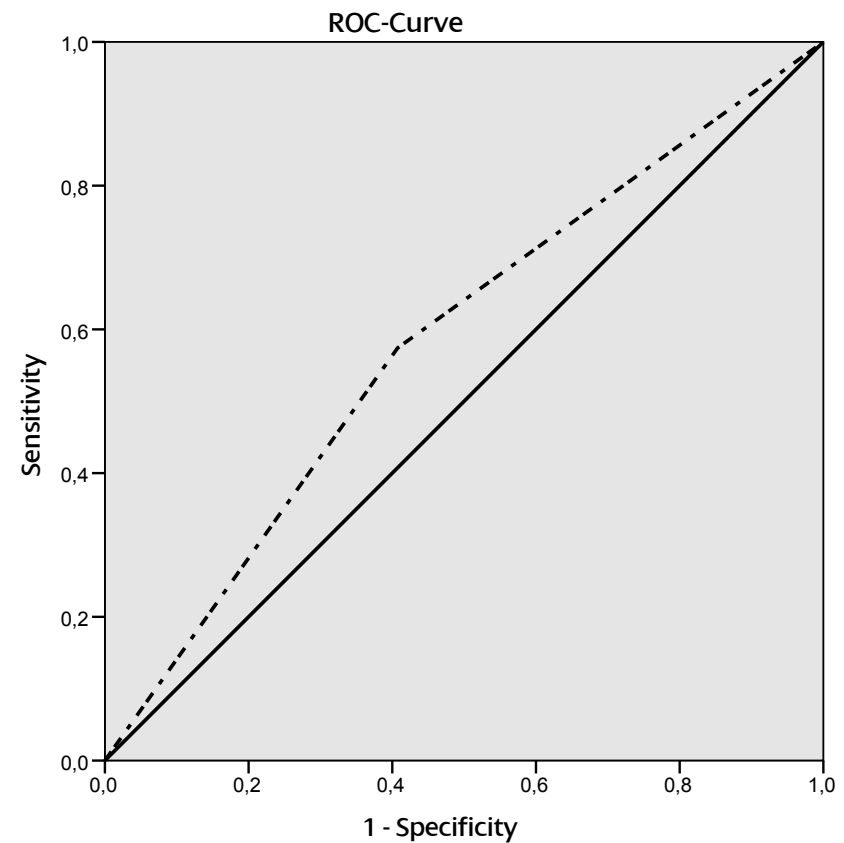

Fig 2. Receiver operating characteristics curve previous episodes (0.583). 


\section{DISCUSSION}

Information about recurrence and prognostic is important for patients and practitioners to set realistic expectations about the chances of a full recovery and to reduce patient anxiety and uncertainty.

\section{Recurrence of Neck Pain Complaint}

The results of this study revealed that $89 \%$ of neck pain patients had recovered from their neck pain episode up to 1 year after receiving chiropractic care. Therefore, $11 \%$ of patients reported a new episode or recurrence of their neck pain or had the need for an additional neck pain intervention. Although an age of older than 45 years and a series of previous complaints were labeled as a significant prognostic factor during the statistical analyses, the Nagelkerke of 0.05 and the receiver operating characteristics curve of 0.601 and 0.583 revealed that the model is overall a poor predictor of the individual's risk of recurrence. Because of the fact that, in a literature search, no other study could be identified that focused on recurrence as a primary outcome, studies that worked with recovery and the clinical course of recovery are used to integrate our findings into recent research. In the study by Leaver et al ${ }^{5}$ that focused the clinical course of a new episode of neck pain and on clinical factors that are associated with faster recovery rates, $22 \%$ of the participants included reported recurrences of their neck pain at 3 months. ${ }^{5}$ There are differences in these 2 studies, which make it difficult to compare the outcomes. First of all, Leaver et al ${ }^{5}$ focused not on recurrence as a primary outcome. They included patients with a new episode of neck pain of less than 3 months' duration that was preceded by at least 4 weeks without complaints. There was no clear definition of the problems being either acute or chronic, and they did not dichotomize the participants into acute or chronic. We chose to include participants with any duration of neck pain and subgrouped them. Another key point in our study was that participants did not have had any treatment in the previous 3 months by a chiropractor or physical therapist. In the study of Leaver et al ${ }^{5}$, the patients received either physical therapy or chiropractic at 4 treatment sessions over 2 weeks. During each session, patients received manual therapy that could have been a high-velocity thrust manipulation or mobilization. The selection of treatment methods was at the discretion of the treating therapist. In addition, they received exercises, advice about activity, and electrotherapy. In the current study, only chiropractic care was given that typically would include spinal manipulation, advice on the activities of daily living, trigger point therapy, therapeutic exercises, and mobilization techniques. ${ }^{12}$ The type of 
intervention was not standardized, although normal and usual chiropractic care was applied, which in our opinion, reflects the reality of daily chiropractic practice.

\section{Prognostic Factors for Recurrence of Neck Pain}

Age and a previous episode of neck pain were found to be prognostic factors for recurrence using logistic regression. However, we have to point out that also, these 2 variables were significant; however, further statistical analyses revealed that, overall, the model is a poor predictor. In particular, Croft et $\mathrm{al}^{8}$ showed that previous episodes of neck pain are prognostic factors for recurrence of another neck pain episode, ${ }^{8}$ and Leaver et al ${ }^{5}$ and Croft et al ${ }^{8}$ found that increasing age leads to a higher risk of recurrence. Although it is tempting to explain the relationship based on increased spinal degeneration with increasing age, however, the research literature is equivocal on this issue. ${ }^{23-26}$ More research is needed to understand the likely reasons for age as a predictor for recurrence of neck pain. On the other hand, factors such as injury $8,27,28$ and female sex ${ }^{6,8,11}$ could not be confirmed, although the literature shows that women are more likely to develop neck pain problems. ${ }^{6,8,11,29}$ Furthermore, women have twice the prevalence and incidence for nonspecific neck pain compared with males. ${ }^{30}$ However, this did not appear to influence the recurrence rate in the present study, although most of our participants were female (62.7\%). Neck injury has also been connected with the onset of neck pain, ${ }^{7,8,28}$ although our study could not find a relationship between a previous neck injury and recurrence of neck pain. One reason for this could be the small number of patients in our study with a previous neck injury (13.9\%). Croft et $\mathrm{al}^{8}$ used a different approach to investigate this issue using a longitudinal survey design. Participants were only included if they were free of any neck pain at the start and surveyed again after 1 year. ${ }^{8}$ Of the total number of 1708 participants, $305(17.8 \%)$ reported neck pain within the previous year, and 104 of these recalled a prior injury. ${ }^{8}$ We cannot make a direct comparison, as our participants started with neck pain and were treated for this complaint. An additional factor that is mentioned in the literature is duration of complaint. ${ }^{31,32}$ Rubinstein et al ${ }^{31}$ used the same inclusion and exclusion criteria as this current study, but they were focused on identifying predictors of a favorable outcome, not prognostic factors for a recurrence. Rubinstein et al ${ }^{31}$ state that subjects who have less than 30 days of neck pain are more likely to recover compared with patients with a duration of complaint more than 60 days. A previous study done by Peterson et al ${ }^{14}$ focusing on the predictors of "improvement" revealed that acute patients have higher pain levels and disability before treatment but improve quicker than chronic patients. ${ }^{14}$ That study worked with time points at 1 week, 1 month, and 3 months and 
focused on "improvement" using the Patient's Global Impression of Change scale. ${ }^{14}$ Using the same patients from that database, this current study used a follow-up period of 12 months but focused only on whether the patients reported recurrences of their neck pain or were recovered. The results of this current study were not able to confirm that the duration of complaints before the first treatment influenced the onset of new episodes of neck pain. However, this could be caused by the duration of the follow-up; it might have been too short to include patients who had a recurrence more than 12 months after finishing the study. Kjellman et al ${ }^{32}$ focused on prognostic factors for perceived pain and function, and they found that duration of the current complaint was a prognostic factor for neck pain recurrence at the 12-month follow-up time. ${ }^{32}$ However, there are a number of differences compared with our study. In particular, Kjellman et al ${ }^{32}$ compared different treatment settings. One hundred twenty-three participants were recruited at physiotherapy units to which they had been referred. The second group of 70 patients was recruited during a randomized controlled trial that compared physiotherapy and chiropractic. ${ }^{32}$ The patients participating in the randomized controlled trial did not have any treatment during the month before the start of the study. However, that rule was not applied to the patients recruited by the physiotherapy units. ${ }^{32}$ In our opinion, that could have influenced the outcome, because 2 different study samples were used. Our study sample only included participants who had not undergone manual therapy treatment or chiropractic treatment previously and therefore make the outcome more generalizable. Consequently, caution should be used in comparing the study of Kjellmann et $\mathrm{al}^{32}$ with the present one because of the different treatment and baseline settings. It is clear that much more standardized research is needed in this area. Identifying the likelihood of recurrences in neck pain patients as well as prognostic factors for recurrence is important for patients and practitioners. The results of this study revealed that recurrence of another episode of neck pain within a year after the start of chiropractic care is low. However, having had a previous episode as well as increasing age is increased risk factors for predicting a subsequent new episode of neck pain within a year. This information may help patients understand and reduce their fear or anxiety related to their neck pain condition and help them recover by providing realistic information about their chance of a full recovery. ${ }^{5,29-31,33-35}$

\section{Limitations}

There are limitations to the generalizability of our study. Ninety-seven patients (15\%) withdrew from the study. We do not know if the dropout group was representative of the remaining participants. Of the remaining patients, $89 \%$ showed no recurrence, and this imbalanced group size could have influenced the logistic regression analysis. ${ }^{33}$ Psychologic 
factors are also known to influence the recovery of pain patients..$^{3,5,8,10}$ However, we did not analyze this for the current study. In addition, it would be reasonable to analyze the data with a more differentiated subgrouping, for example, (1) chronic patients who did not seek additional care and (2) chronic patients who did seek additional care. Those patients may not necessarily be recurrent because they may have a persistent neck problem. Because of the limiting factors of the study, a confirmatory study is required.

\section{CONCLUSION}

The results of this study suggest that recurrence of neck pain within 1 year after chiropractic intervention in Swiss chiropractic patients presenting from varied onsets is low. It provides a better understanding of recurrent neck pain as well as prognostic risk factors for a subsequent episode of neck pain. Older age and a previous episode of neck may be useful predictors of neck pain recurrence within 1 year; however, additional studies are needed.

\section{FUNDING SOURCES AND POTENTIAL CONFLICTS OF INTEREST}

The Uniscientia Foundation funded this study. No funding conflicts of interest were reported for this study 


\section{REFERENCES}

1. Global Year Against Musculoskeletal Pain. Int Assoc Study Pain 2009 [http://www.iasp-pain. org/files/Content/ContentFolders/GlobalYearAgainstPain2/MusculoskeletalPainFactSheets/ NeckPain_Final.pdf].

2. Haldeman S, Carroll LJ, Cassidy JD. The empowerment of people with neck pain : introduction and its associated disorders. Spine (Phila Pa 1976) 2008;33:8-13.

3. Carroll LJ, Hogg-johnson S, Van Der Velde G, et al. Course and prognostic factors for neck pain in the general population neck pain and its associated disorders. Spine (Phila Pa 1976) 2008;33:75-82.

4. Hush JM, Lin CC, Michaleff ZA, et al. Prognosis of acute idiopathic neck pain is poor: a systematic review and metaanalysis. Arch Phys Med Rehabil 2011;92:824-9.

5. Leaver AM, Maher CG, McAuley JH, Jull G, Latimer J, Refshauge KM. People seeking treatment for a new episode of neck pain typically have rapid improvement in symptoms: an observational study. J Physiother 2013;59:31-7.

6. Skillgate E, Magnusson C, Lundberg M, Hallqvist J. The ageand sex-specific occurrence of bothersome neck pain in the general population—results from the Stockholm public health cohort. BMC Musculoskelet Disord 2012;13:185.

7. Bohman T, Côté P, Boyle E, Cassidy JD, Carroll LJ, Skillgate E. Prognosis of patients with whiplash-associated disorders consulting physiotherapy: development of a predictive model for recovery. BMC Musculoskelet Disord 2012;13:264.

8. Croft PR, Lewis M, Papageorgiou AC, et al. Risk factors for neck pain: a longitudinal study in the general population. Pain 2001;93:317-25.

9. Feleus A, Bierma-Zeinstra SMA, Miedema HS, et al. Prognostic indicators for non-recovery of non-traumatic complaints at arm, neck and shoulder in general practice- 6 months follow-up. Rheumatology (Oxford) 2007;46:169-76.

10. Karels CH, Bierma-Zeinstra SMA, Burdorf A, Verhagen AP, Nauta AP, Koes BW. Social and psychological factors influenced the course of arm, neck and shoulder complaints. J Clin Epidemiol 2007;60:839-48.

11. Vos CJ, Verhagen AP, Passchier J, Koes BW. Clinical course and prognostic factors in acute neck pain: an inception cohort study in general practice. Pain Med 2008;9:572-80.

12. Humphreys BK, Peterson CK, Muehlemann D, Haueter P. Are Swiss chiropractors different than other chiropractors? Results of the job analysis survey 2009. J Manipulative Physiol Ther 2010;33:519-35.

13. Bryans $R$, Decina $P$, Descarreaux $M$, et al. Evidence-based guidelines for the chiropractic treatment of adults with neck pain. J Manipulative Physiol Ther 2014;37:42-63.

14. Peterson C, Bolton J, Humphreys BK. Predictors of outcome in neck pain patients undergoing chiropractic care: comparison of acute and chronic patients. Chiropr Man Ther 2012;20:27.

15. Bolton JE, Humphreys BK. The Bournemouth questionnaire: a short-form comprehensive outcome measure. II. Psychometric properties in neck pain patients. J Manipulative Physiol Ther 2002;25:141-8.

16. Soklic M, Peterson C, Humphreys BK. Translation and validation of the German version of the Bournemouth questionnaire for neck pain. Chiropr Man Ther 2012;20:2.

17. Childs JD, Piva SR, Fritz JM. Responsiveness of the numeric pain rating scale in patients with low back pain. Spine (Phila Pa 1976) 2005;30:1331-4.

18. Gay RE, Madson TJ, Cieslak KR. Comparison of the Neck Disability Index and the neck Bournemouth questionnaire in a sample of patients with chronic uncomplicated neck pain. $J$ Manipulative Physiol Ther 2007;30:259-62.

19. Longo UG, Loppini M, Denaro L, Maffulli N, Denaro V. Rating scales for low back pain. Br Med Bull 2010;94:81-144.

20. Stanton TR, Latimer J, Maher CG, Hancock MJ. A modified Delphi approach to standardize low back pain recurrence terminology. Eur Spine J 2011;20:744-52. 
21. Cook NR.Use andmisuse of the receiver operating characteristic curve in risk prediction. Circulation 2007;115:928-35.

22. Pepe MS, Janes H, Longton G, Leisenring W, Newcomb P. Limitations of the odds ratio in gauging the performance of a diagnostic, prognostic, or screening marker. Am J Epidemiol 2004;159:882-90.

23. Borghouts JA, Koes BW, Bouter LM. The clinical course and prognostic factors of non-specific neck pain: a systematic review. Pain 1998;77:1-13.

24. Hogg-Johnson S, van der Velde G, Carroll LJ, et al. The burden and determinants of neck pain in the general population: results of the Bone and Joint Decade 2000-2010 Task Force on Neck Pain and Its Associated Disorders. J Manipulative Physiol Ther 2009;32:S46-60.

25. Peterson C, Bolton J, Wood AR, Humphreys BK. A crosssectional study correlating degeneration of the cervical spine with disability and pain in United Kingdom patients. Spine (Phila Pa 1976) 2003;28:129-33.

26. Childs JD, Cleland JA, Elliott JM, et al. Neck pain: clinical practice guidelines linked to the International Classification of Functioning, Disability, and Health from the Orthopedic Section of the American Physical Therapy Association. J Orthop Sports Phys Ther 2008;38:A1-A34.

27. Paksaichol A, Janwantanakul P, Purepong N, Pensri P, van der Beek AJ. Office workers' risk factors for the development of non-specific neck pain: a systematic review of prospective cohort studies. Occup Environ Med 2012;69:610-8.

28. Hill J, Lewis M, Papageorgiou AC, Dziedzic K, Croft P. Predicting persistent neck pain: a 1-year follow-up of a population cohort. Spine (Phila Pa 1976) 2004;29:1648-54.

29. Malchaire J, Cock N, Vergracht S. Review of the factors associated with musculoskeletal problems in epidemiological studies. Int Arch Occup Environ Health 2001;74:79-90.

30. Cassou B, Derriennic F, Monfort C, et al. Chronic neck and shoulder pain, age, and working conditions: Iongitudinal results from a large random sample in France. Occup Environ Med 2002;59:537-44.

31. Rubinstein SM, Knol DL, Leboeuf-Yde C, de Koekkoek TE, Pfeifle CE, van Tulder MW. Predictors of a favorable outcome in patients treated by chiropractors for neck pain. Spine (Phila Pa 1976) 2008;33:1451-8.

32. Kjellman G, Skargren E, Oberg B. Prognostic factors for perceived pain and function at one-year follow-up in primary care patients with neck pain. Disabil Rehabil 2002;24:364-70.

33. Buitenhuis $\mathrm{J}$, de Jong PJ. Fear avoidance and illness beliefs in post-traumatic neck pain. Spine (Phila Pa 1976) 2011;36:S238-43.

34. Meulders A, Vlaeyen JWS. Fear reduction in subacute whiplash-associated disorders: the royal road to recovery? Pain 2013;154:330-1.

35. Sterling M. Does knowledge of predictors of recovery and nonrecovery assist outcomes after whiplash injury? Spine (Phila Pa 1976) 2011;36:S257-62. 


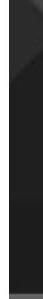




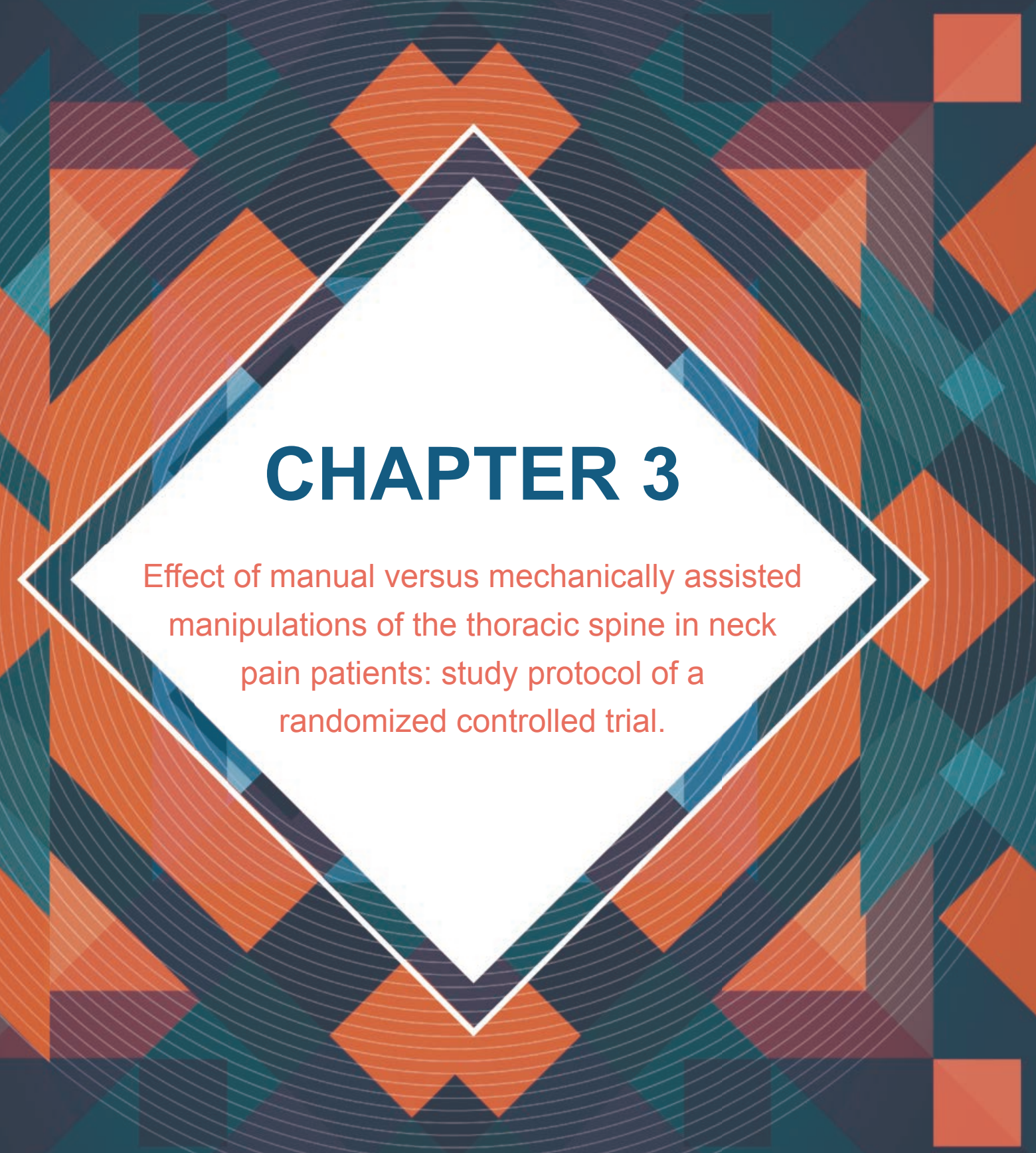

Anke Langenfeld, B. Kim Humphreys, Rob A. de Bie and Jaap Swanenburg

Published: Trials (2015) 16:233 DOI 10.1186/s13063-015-0763-5 


\begin{abstract}
Background: Neck pain is a common musculoskeletal condition with a point prevalence of around $15 \%$ in males and $23 \%$ in females that often presents in physiotherapy practice. Physical therapy and/or manipulation therapy is generally the first management option for patients with mechanical neck pain. Physical therapists treat mechanical neck pain with a number of interventions including joint mobilization and/or manipulation, therapeutic exercises or education. However, manipulation of the cervical spine carries some risks. Treating the thoracic spine for neck pain is an alternative approach. Emerging evidence suggests that it may be effective for treating neck pain without the risks associated with cervical spine manipulation. A new electromechanical device has recently been developed and tested for delivering multiple high velocity, low amplitude thrust manipulations to the spine. This device incorporates both auditory and visual systems that provide real time feedback on the applied treatment. The objective of this study is to compare the short- and long-term effects of manual versus mechanically assisted manipulations of the thoracic spine for neck pain patients.
\end{abstract}

Methods/Design: A 6-month, randomized controlled trial consisting of 54 patients with acute or chronic neck pain patients will be conducted. Patients with no signs of major pathology and with little or no interference with daily activities will be recruited. Three treatment sessions with 4-day intervals will be carried out. The patients will be randomly assigned to receive either manually performed manipulations or electromechanical manipulations at the thoracic spine. The primary outcome is pain intensity as measured by the Visual Analogue Pain Rating Scale. The secondary outcome measures are neck physical disability using the Neck Disability Index, quality of life measured by the European Quality of Life 5 Dimensions 5 Levels and patients' improvement using the Patient's Global Impression of Change Scale.

Discussion: It is expected that both interventions will improve neck pain. This would be a significant finding, as thoracic spine manipulation for neck pain does not carry the same risk of injury as cervical spine manipulation. In addition, the results may provide useful information about therapeutic options for health care providers and patients for the problem of neck pain.

Trial registration: Current Controlled Trials ISRCTN88585962, registered January 2013

Keywords: Neck pain, Spinal manipulation, Impulse $\mathrm{iQ} \otimes$, Thoracic spine 


\section{Background}

The burden of musculoskeletal disorders is increasing rapidly, using a high percentage of health care resources ${ }^{1}$. Neck pain is a musculoskeletal disorder and is a common cause for patients seeking treatment from health care providers ${ }^{2}$. Most people will see a medical practitioner or another health care provider at least once in their lifetime due to neck pain 1 . Alarmingly, 30 to $50 \%$ of the general population suffer from neck pain annually, with a point prevalence of around $15 \%$ in males and $23 \%$ in females; and these numbers are increasing ${ }^{1,3}$. Even more concerning is the fact that someone who has experienced one episode of neck pain is likely to have another episode within the next 1 to 5 years ${ }^{4}$, and can be expected to suffer for several years, with a low chance of full resolution. Neck pain is generally described as pain perceived in the posterior region of the cervical spine. It is distributed between the superior nuchalline down to the first thoracic spinous process and may radiate into the head, shoulders, arms and chest ${ }^{5}$. The Task Force on Neck Pain and its Associated Disorders proposed the following classification for neck pain patients:

- Grade I: no signs of major pathology and little or no interference with daily activities. This is frequently the case.

- Grade II: no signs of major pathology, but with an interference with daily activities. This occurs less frequently.

- Grade III: neck pain with neurological signs or symptoms (radiculopathy).

- Grade IV: neck pain with signs of major pathology (for example, serious instability or spinal infection) ${ }^{6}$.

Current opinion regarding the etiology and onset of neck pain and how it is best managed varies widely, andoften seems to be associated with the background and beliefs of the clinician ${ }^{6,7}$. Treatments that have been recommended for neck pain within physical therapy settings so far are exercise therapy, manipulation therapy and a combination of exercise and cervical spinal manipulation as well as education: they seem to have the highest level of evidence ${ }^{8}$. There are also other treatment options: for example, acupuncture, cognitive/behavioural therapy, and electro-physical modalities, but so far there is conflicting evidence about their benefit ${ }^{8}$. Although cervical spinal manipulation is still recommended for the treatment of neck pain, there is a small risk of possible serious side-effects such as cervical artery dysfunction (CAD), lesions of the brain stem, Wallenberg syndrome or ischemic stroke ${ }^{9-11}$. Although these presentations are rare they should be considered as part of the patient's assessment ${ }^{11}$. The literature is equivocal on a link between the use of 
cervical spinal manipulation and serious risks ${ }^{9,10,12-14}$. Studies show no clear relationship between cervical spinal manipulation and an arterial dissection although the manipulation process is capable of triggering such an event, because cervical spinal manipulations are comparable to minor mechanical events, which might cause arterial dissection ${ }^{15}$ 16. Furthermore, literature suggests that the dissection of the vertebral or carotid artery may have already been in progress before the manipulation is given due to the fact that the dissection causes pain similar to mechanical neck pain and, therefore, patients visit a chiropractor or a primary care physician because of these complaints ${ }^{17,18}$. However, there is still a debate in the current research whether manipulation of the cervical spine in patients with neck pain is harmless ${ }^{10}$. Pre-manipulative testing and screening procedures were introduced to minimize the risk of side-effects in cervical spinal manipulations ${ }^{10}$. Unfortunately these procedures have shown a lack of sensitivity, specificity, and feasibility $8,10,15,17,18$. To address the issues of the risk of a serious adverse event and a lack of useful testing/screening procedures, a different treatment strategy has been utilized ${ }^{19}$ : spinal manipulation directed at the thoracic spine instead of to the cervical spine ${ }^{20}$. The justification for using thoracic spinal manipulations for the treatment of neck pain is based on the biomechanical link between cervical and thoracic spine ${ }^{21-23}$. Normal functioning of the cervical spine depends on normal biomechanics of the upper thoracic spine. If there is any functional disturbance in the upper thoracic spine, the capacity of the muscles decreases and the range of motion of the cervical spine is impaired ${ }^{23}$.

Within the last few years several intervention studies, systematic reviews, and metaanalyses have been conducted investigating thoracic spinal manipulations ${ }^{20,24-30}$. The majority of these intervention studies were focused on patients with acute or a primary complaint of neck pain and they reported short-term outcomes ${ }^{20,24,26}$. Thus far, only 1 study has investigated patients suffering from chronic neck pain over a long-term outcome of 6 months ${ }^{27}$. Nevertheless, the Orthopaedic Section of the American Physical Therapy Association (APTA) included the use of thoracic spinal manipulations as a possible treatment option in their guidelines for the treatment of patients with neck pain and neckrelated arm pain, although this is based on weak evidence ${ }^{25}$. Young and colleagues (2014) state that there is a significant amount of evidence to recommend thoracic manipulation for the treatment of mechanical neck pain, especially for short-term improvement of range of motion and disability ${ }^{31}$. 


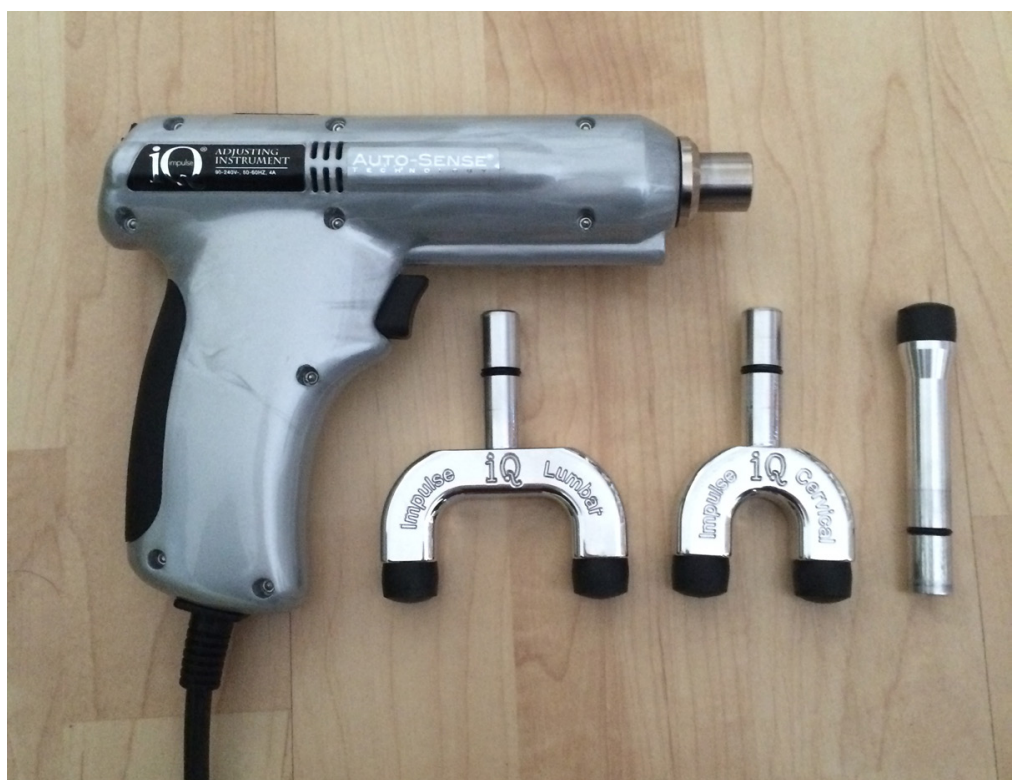

Fig. 1 Impulse IQ尺. Picture of the device that was used to conduct the mechanical manipulations

A manipulation may be delivered manually (high velocity, low amplitude) or mechanically using spring-loaded orelectromechanical devices (mechanical force, manuallyassisted) ${ }^{32-35}$. Forces applied during a manual spinal manipulation may vary somewhat from manipulation to manipulation given by one practitioner as well as between practitioners ${ }^{36}$. Therefore, a mechanical instrument may have less force variation and, therefore, more consistency ${ }^{32}$. Mechanical devices may be useful in reducing the variations in the practitioner's performance of spinal manipulation ${ }^{34}$. Two randomized controlled trials have been conducted so far, comparing the outcome of manual and mechanically delivered manipulations in patients with neck pain and patients with sacroiliac joint pain ${ }^{34,35}$. One study used manual manipulations compared to mechanical force, using a springloaded device. The manipulations were applied to the cervical spine ${ }^{34}$. The other study also compared manual manipulation to a mechanical-force, manually-assisted instrument (Activator Adjusting Instrument) (Activator Methods International, Ltd, Phoenix, Arizona, USA). In this study the manipulations were applied to the sacroiliac joint ${ }^{35}$. Both studies concluded that both methods of applying manipulations are beneficial for the patient in terms of pain reduction, range of motion and disability of the treated area ${ }^{34,35}$. Although there are only two studies using different body regions and mechanical and manual manipulations in comparison, both ways of applying a manipulation seem to be beneficial. A new electromechanical device for manipulations has recently been developed, which 
purports to give objective feedback to the practitioner, using an audible sign (beep) (Fig. 1). The device contains a motion sensor and a microcomputer. While the thrusts are delivered, the amount of spinal motion and the frequency of motion are identified in real time. As the vertebra rebounds, data is sent to the microcomputer. Auto-Sense Technology ${ }^{\circledR}$ (Neuromechanical Innovations, Chandler, AZ, USA) consequently adapts the amount of the subsequent thrusts. If the acceleration response has been maximized, the treatment stops automatically ${ }^{37}$. However, the exact effect remains unclear if this electromechanical device does what it purports to do, and if it has the same effect as manually performed manipulations. Therefore, the purpose of this study is to compare the effects of manually performed manipulations and electromechanical manipulations to the thoracic spine in neck pain patients. Short- and long-term clinical outcomes, such as neck pain and function and overall improvement, will be assessed.

\section{Study aim}

The aim of this study is to compare the short and long-term treatment outcomes for neck pain patients using an instrument-assisted mechanical manipulation with feedback versus manual manipulations of the thoracic spine. 


\section{Methods/Design}

This study is a randomized trial comparing the treatment effects of manual versus instrument- assisted mechanical manipulations of the thoracic spine for neck pain patients. The study has received ethical approval from the Ethics Commission of the Canton of Zurich (2012-0248).

\section{Enrollment and eligibility criteria}

Participants will be recruited by registered chiropractors and physical therapists in private practices in the canton of Zurich. A test group of 54 participants will be recruited based on the following inclusion criteria: 1) presence of acute or chronic neck pain, Grade I or II ${ }^{6}$; 2) aged 18 or older; 3) able to speak and read German or English; 4) no previous manual therapy applied to the thoracic spine; and 5) interested in participating in the study. Potential participants will be excluded from the study if they suffer from the following conditions: 1) severe disorders of the cervical spine such as disc prolapse, spinal stenosis, postoperative conditions in neck and shoulder areas; 2) history of severe trauma; 3) spasmodic torticollis; 4) frequent migraine headaches; 5) peripheral nerve entrapment; 6) fibromyalgia; 7) shoulder diseases (causing reduced mobility of the joint: for example, fractures, adhesive capsulitis); 8) inflammatory rheumatic diseases; 9) osteoporosis; 10) cancer and 11) be currently undergoing legal procedures resulting from their neck pain. If and when the participant qualifies based on the above criteria and has signed the informed consent form, the recruiting chiropractor or physical therapist will inform the research assistant of their suitability for the study. The research assistant will verify the inclusion and exclusion criteria and invite the participant for the baseline assessments.

\section{Design}

There will be 3 treatment sessions and an additional training program for 6 weeks. Followup assessments will take place after 6 weeks, 3 months and 6 months. The 3 treatment session will always be 4 days apart. At baseline the participant will fill out the Visual Analogue Pain Rating Scale (VAS), the Neck Disability Index (NDI) and the European Quality of Life 5 Dimensions 5 Levels (EQ-5D-5 L) [38- 45]. At two subsequent treatment sessions, the patient will be asked to fill out the NDI, VAS, EQ-5D-5 L, and the Patients Global Impression of Change Scale (PGIC) before the treatment ${ }^{46}$. The VAS will be repeated after each treatment. For the follow-up assessments the participants will receive the same questionnaires (Fig. 2). 


\section{History taking and physical examination}

Baseline measurements as stated above, will be followed by a history taking and physical examination $(\mathrm{P} / \mathrm{E})$. History taking includes questions referring to the onset, episode, nature and location, as well as factors that increase or decrease the pain, medication use, occupation, sick leave and other treatments that have already been tried. The P/E will start with a neurological screening (motor, reflex and sensory testing) followed by Spurling' s test, cervical distraction test and neurodynamic upper limb test ${ }^{47-50}$. These evaluations are added to confirm that the patient is eligible to participate in the study. If one of the previous tests is positive the patient will be excluded from the study at this point. Next the segmental mobility of the entire thoracic spine will be tested. In this study a dysfunctional segment is defined as a painful segment, that is produced using prone springing palpation for pain provocation ${ }^{51,52}$. We define the painful segment as the treatment segment ${ }^{53}$. The testing and marking of the thoracic spine will be carried out by an orthopedic manual therapy (OMT)-trained physical therapist, who will also be applying the manipulations. The most painful segment is marked with a waterproof marker and then photographed; followed by the randomized treatment of the painful thoracic segment. Other painful and/or hypomobile segments will be marked and reported but they will not be treated. 


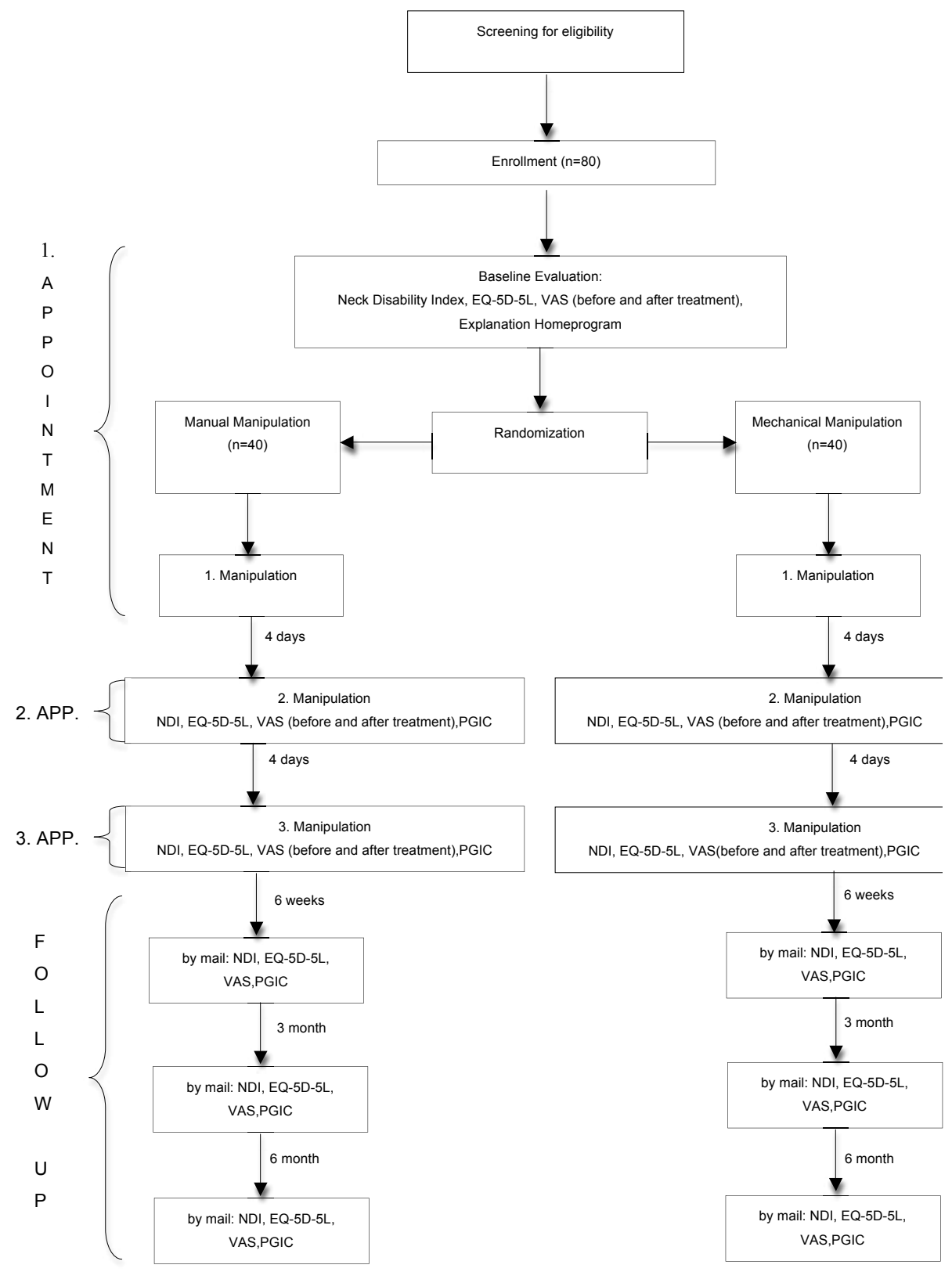

Fig. 2 Flowchart of the trial. Flowchart of the trial showing how the participants were allocated to the different groups and the follow-up 


\section{Randomization}

A clinician, who is not involved in the study, will independently conduct the randomization procedure. A block randomization (20 blocks of 4 ) using a computer-based randomization program will be conducted. The original randomization list will be stored in an opaque and sealed envelope not accessible to the therapist conducting the manipulations. Eighty sequentially numbered, sealed, opaque envelopes, containing the randomized group allocation will be prepared. At the time of treatment, these envelopes will be given to the therapist applying the manipulation, immediately prior to the execution of the manipulation. The patient will be unaware of the technique that will be applied, only that the technique may either be delivered manually or with an electromechanical instrument (Impulse $\mathrm{iQ} \otimes$, Neuromechanical Innovations, Chandler, AZ, USA). To minimize any possible effects of expectations of treatment, each participant will be asked prior to the first treatment about their expectations regarding new and conventional treatments.

\section{Blinding}

To minimize performance bias, the therapist who is conducting the treatment will be kept unaware of the treatment method until the manipulation is applied. Additionally, the questionnaires that are filled out by the patient are put inside sealed, opaque envelopes. The therapist is unaware of the patient-assessed outcome. When data is entered into the database the researcher will be unaware of the associated participant due to depersonalization/anonymity of the questionnaires. Additionally, the expectations of the patient regarding the new and conventional treatments are retrieved beforehand and taken into consideration during the evaluation of the data.

\section{Treatment}

After the initial $P / E$ the first manipulation will be applied to the thoracic spine either manually or by using the Impulse $\mathrm{iQ} \otimes$ (Neuromechanical Innovations, Chandler, AZ, USA) and the training program, consisting of four different exercises, will be instructed.

\section{Manual}

For the manually performed manipulations the patient is lying supine. The therapist' $s$ hand is under the thoracic spine using a pistol grip (the fingers are positioned with the index finger straightened and fingers 3 to 5 flexed). The patient's forearms are crossed in front of their chest. The force is applied against the therapist's flexed fingers, the thenar eminence and slightly cranial to the transverse process of the caudal vertebra of the treatment segment ${ }^{53}$ (Figs. 3 and 4 ). 


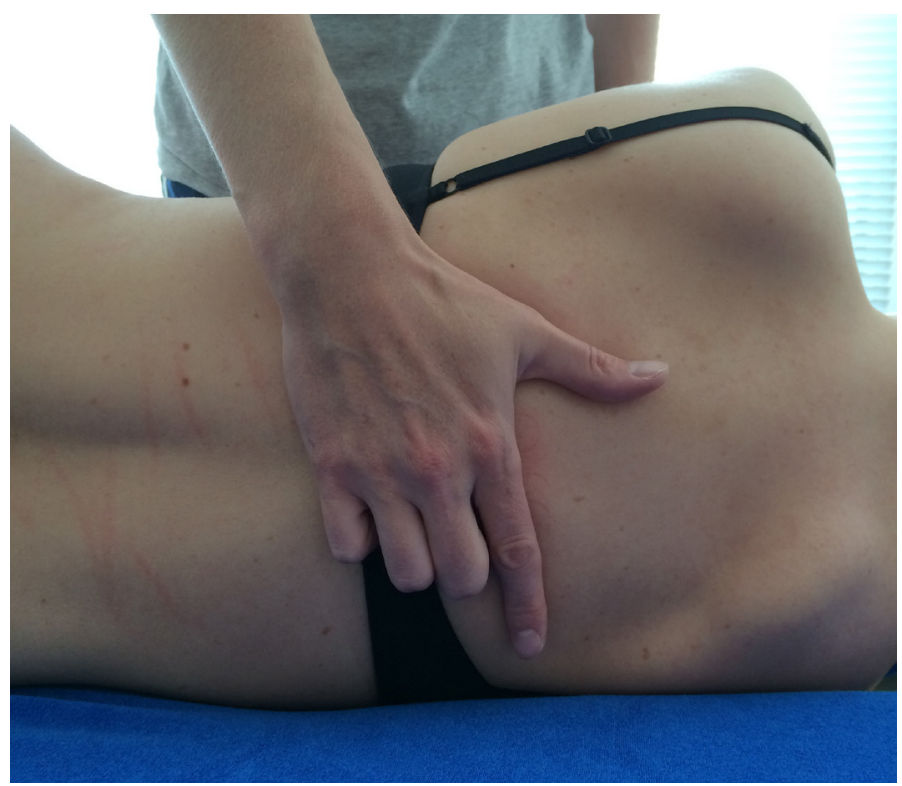

Fig. 3 Hand position. This picture shows how the hand of the therapist has to be positioned during the manual manipulation

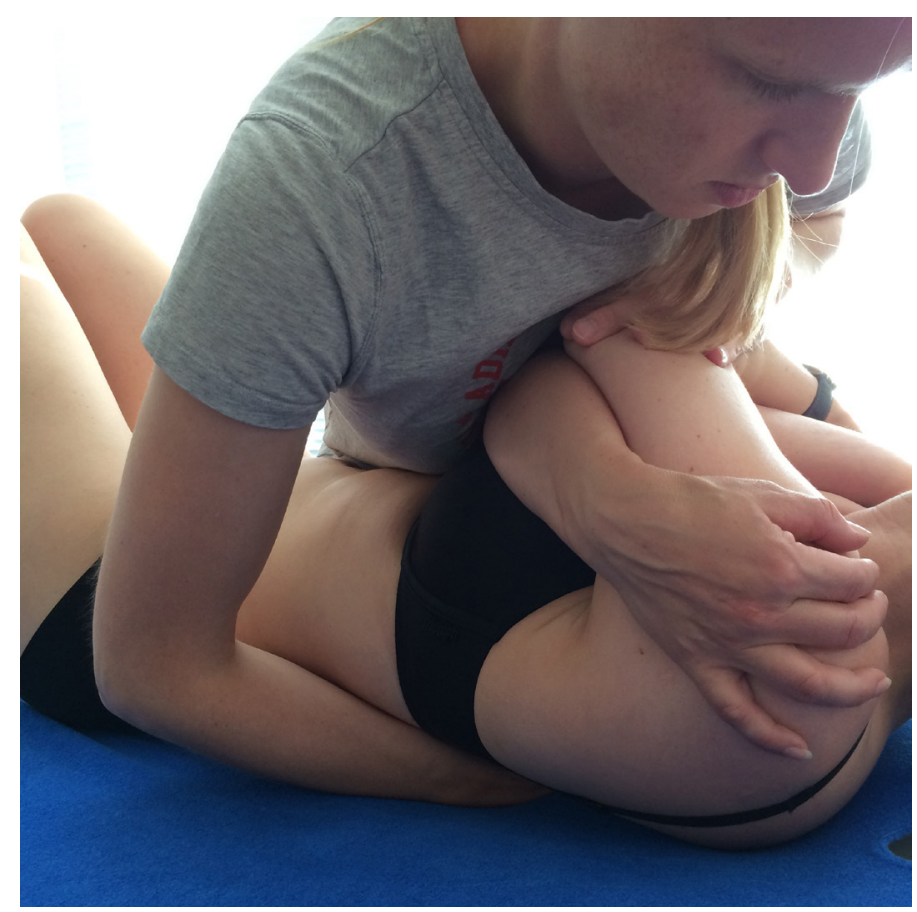

Fig. 4 Manual manipulations. Positioning of the patient and therapist's body during the manual manipulation 


\section{Mechanical}

For the Impulse $\mathrm{iQ} \otimes$ (Neuromechanical Innovations, Chandler, AZ, USA) the patient lies prone on a treatment table, with arms next to the body, in a relaxed position. Before the treatment begins, the patient is instructed that they will hear a rattling sound that indicates the thrusts conducted by the device and a beep at the end of the treatment. The Impulse $\mathrm{iQ} \otimes$ (Neuromechanical Innovations, Chandler, AZ, USA) is then put onto the vertebra that has been identified as a painful segment. A double stylus and middle force setting (peak force $=200 \mathrm{~N}$ ), as recommended by the manufacturer for the treatment of the thoracic spine, will be used ${ }^{54}$. The device records and analyzes the spinal acceleration response each time a thrust is delivered using the built-in firmware. The machine then produces a series of repetitive thrusts monitoring the acceleration response and, if the response is improving, treatment continuous up to $3 \mathrm{~s}$. If the acceleration response is negative (flat line or decrease) the thrust delivered by the instrument ceases (Figs. 5 and 6).

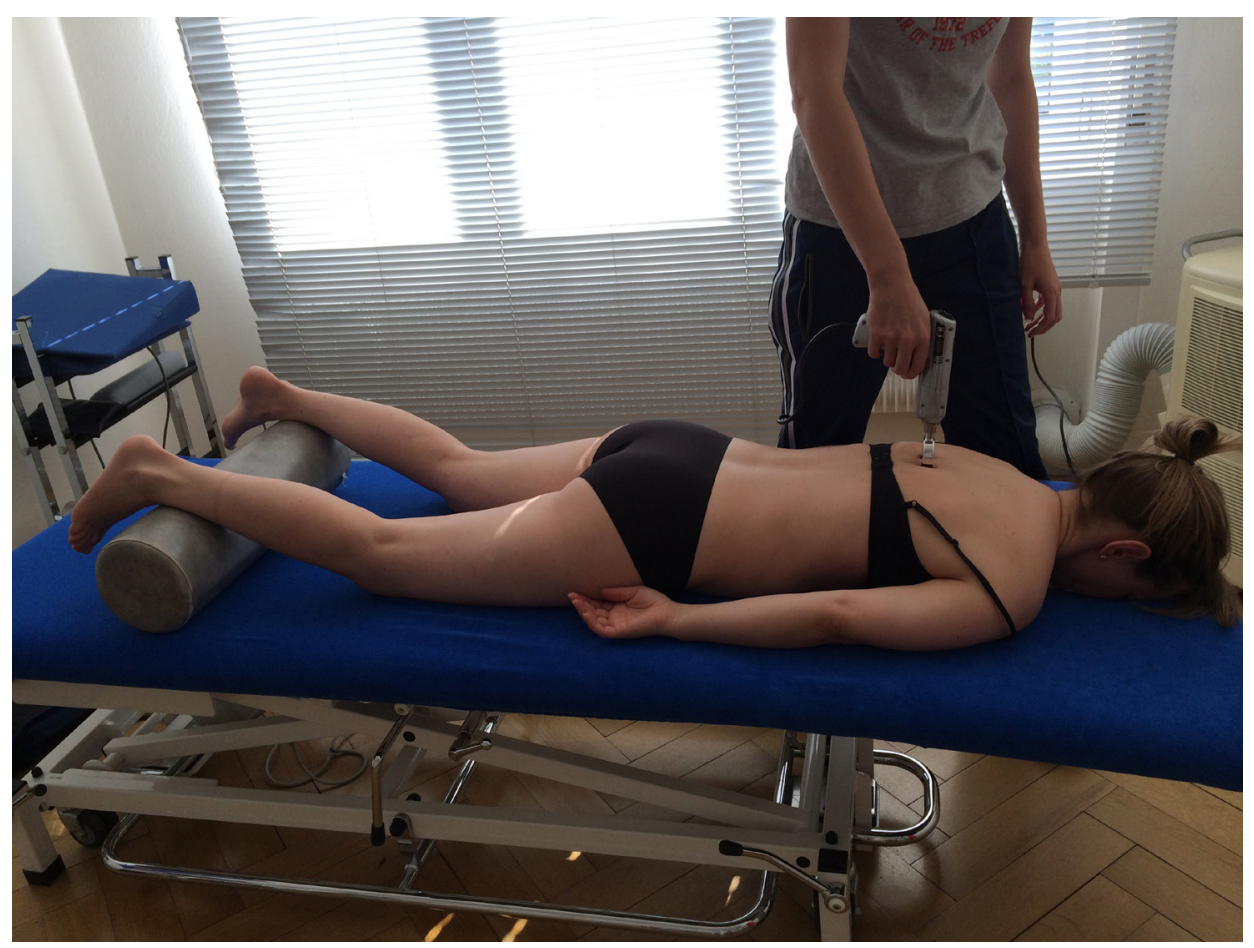

Fig. 5 Patient position during mechanical manipulation. The patient lies prone, arms next to the body in a relaxed position. 


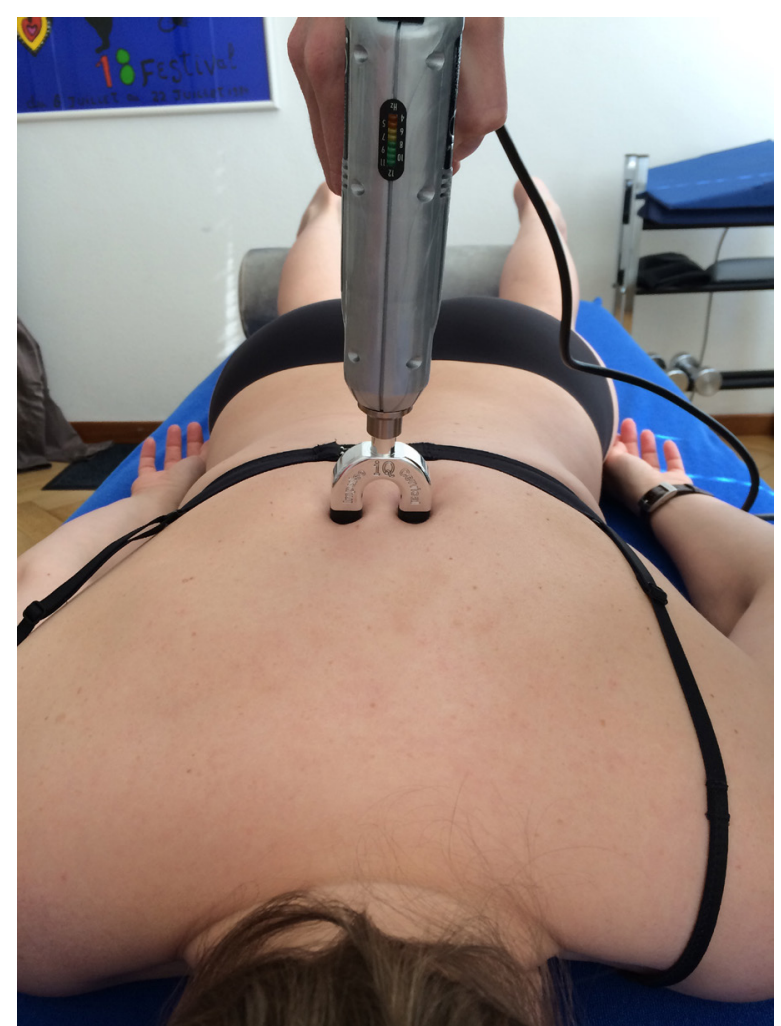

Fig. 6 Positioning of the double stylus. The double stylus is positioned directly on the treatment segment.

\section{Training program}

After the first treatment session the patients will all be introduced to the home exercise program and asked to perform this program once a day for 6 weeks, while compliance with the home exercise program is assessed using a training journal:

1) Retraining the cranio-cervical muscles

a) Training the holding capacity of the deep neck flexors ${ }^{55}$

b) Head Lift ${ }^{56}$

2) Retraining scapular muscles ${ }^{55}$

3) Eye/Head coordination ${ }^{55}$

A detailed exercise-program may be found in Additional file 1. 


\section{Exercise Program: Neck}

\section{1a) Training Deep Neckflexors}

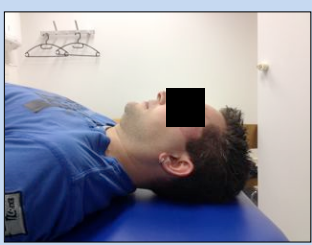

Starting Position

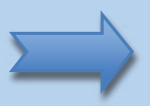

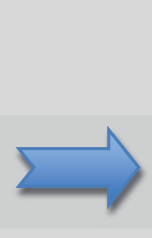

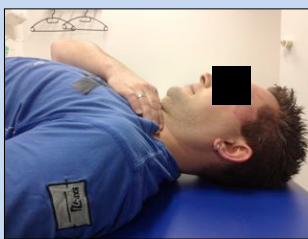

End Position

Supine, leggs bend. No pillow underneath your head. Place one hand on your throat. Now start to look down towards your chin, the head follows with a small and slow movement (nodding). The back of your head should glide over the surface. Just move your head as far down as you start feeling some tention under your fingers. Keep this position for ten seconds.

Repetitions: 10

\section{1b) Training Deep Neckflexors}

Starting Position

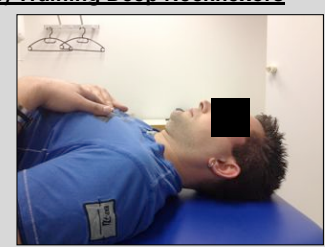

Supine, hooklying, hands on your chest. No pillow underneath your head. Now tuck your chin in and lift your head about $1 \mathrm{~cm}$. The position of your chin should be stable. You are allowed to have a $60-90 \mathrm{sec}$. break between the repetitions. If you are able to do 12 repititions without a problem it is ok to increase up to 15 or even 20 .

Repetitions: 3 Series of 12 (15/20) Length: 1 Sec / Break $2 \mathrm{Sec}$

\section{Ferquency: $1 / d$}

\section{2) Training Shouldergirdle}

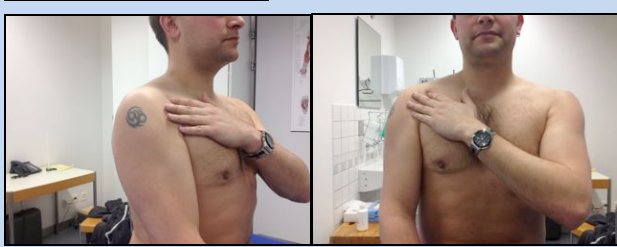

Starting Position

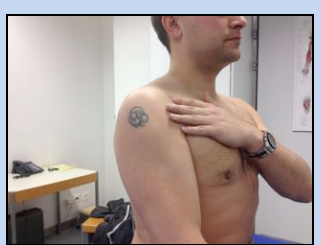

End Position

Sitting on a chair, in front of a mirror. The left hand is placed on the front of your right shoulder. Your index finger is on the coracoid process. Now try to move the bone away from your hand in a longitudinal axis. Keep this position for ten seconds. Now do the same with the left shoulder. Later it is also ok to train both shoulders at the same time. If this exercise is to easy for you, put both hands on your thigh and, while you keep your shoulder in a good position, push down with your hands into your thigh.

Repititions: 10 
3) Head-Eye-Coordination

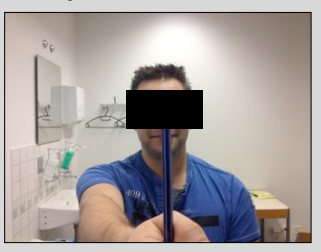

Starting Position

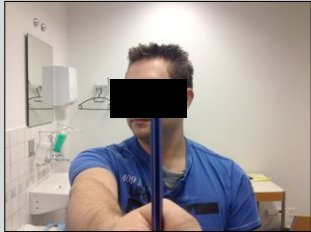

Position 1

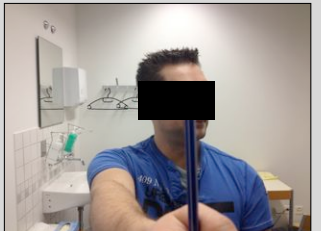

Position 2

Sitting on a chair, you could either have a steady spot on the wall or hold a pen in your hand. If you chose a pen, put it into one hand and straighten the arm out, so that you can see the pen. Look at the pen. Now move your head and your eyes to the right and then back to the pen. Do the same to the left. If this exercise is to easy you can increase the level as follows.

- First move your eyes then the head to the target.

- Head and eyes move into opposite directions

- Do the exercise while standing

Repetitions: 3 Series of 5 to each side

Frequency: $1 / d$

If you feel dizzy or light headed while exercising, please take a break!! 


\section{Outcomes}

\section{Primary outcome measure}

The primary outcome measure is the VAS before and after every treatment, after 6 weeks, 3 months and 6 months. The VAS has shown to be a valid and reliable outcome measure ${ }^{38-41}$. The VAS tries to assess a person's pain intensity level. The patient is asked to place a mark on a 100-mm long line with the question 'how much pain do you have at this moment'. The beginning of the line illustrates 'no pain' the end of the line 'extreme pain'. To extract the data the researcher measures the distance in millimeters between 'no pain' and the mark set by the participant.

\section{Secondary outcome measures}

Secondary outcome measures are the NDI, EQ-5D-5 L and the PGIC. The German version of NDI is a questionnaire to assess self-rated disability in neck pain patients. It is a short paper-pencil instrument, which is based on a similar instrument used for patients with lower back pain, the Oswestry Low Back Pain Questionnaire. It consists of ten items: for example, working and driving. Each item has a score up to 5 with a total score of 50 . The lower the score the less the self-rated disability ${ }^{42,43}$. The EQ-5D-5 L is a valid and reliable self-report questionnaire that measures patient's health status for clinical and economic appraisal using a descriptive system and a VAS ${ }^{44,45}$. The descriptive system assesses mobility, self-care, usual activities, pain, discomfort and anxiety/depression and patients choose the most appropriate option from 'no problem' to 'extreme problem'. The digits for the five dimensions can be combined in a five-digit number, which describes the health status. The VAS is vertical and $20 \mathrm{~cm}$ long and the endpoint options range from ' the best health you can imagine' to ' the worst health you can imagine'. The participant is asked to mark the scale with a ' $X$ ' and write the corresponding number in a box ${ }^{57}$. The PGIC is a valid outcome measure that is based on a seven-point Likert scale ${ }^{58}$. The purpose of the PGIC is to obtain a patient's report of their improvement over time during treatment. The scale ranges from ' much better', 'better', ' somewhat better', ' no change', 'somewhat worse', 'worse' and ' much worse' . 'Much better' is rated as 7 and ' much worse' as 1 on the PGIC ${ }^{59}$. With this scale it is possible to dichotomize the participants into 2 groups; namely those that have 'improved' (ratings of 6 and 7 ) and those that have 'not improved' (ratings 1 to 5 ). 


\section{Statistical methods}

\section{Number of test subjects}

The sample size was calculated with the formula:

$n=f(\alpha, \beta / 2) * 2 * \alpha^{2} / d^{2}$

Therefore: $2 \times\left[(1.96+0.842)^{2} \times 15^{2}\right] / 12^{2}=24.53{ }^{60}$. The significance level alpha was chosen at $5 \%$ and the power of $80 \%$. From the literature, an expected standard deviation of $15 \mathrm{~mm}$ of a VAS can be determined ${ }^{19}$. For the expected mean difference the minimal clinically significant difference $(12 \mathrm{~mm})$ on the VAS was determined ${ }^{61}$. To be able to accomplish all needed participants, 2 patients per group will be added addressing possible withdrawals, missing data, and losses to follow up ${ }^{62}$. Therefore, a total of 54 patients will be recruited (27 per arm).

\section{Statistical analyzes}

Descriptive statistics will be used to illustrate the empirical data and research population. The Shapiro-Wilk test will be used to assess whether all the variables are normally distributed. If the data is normally distributed the changes of VAS will be analyzed using analysis of variance (ANOVA) (repeated measures) to explore possible significant interaction (group $\mathrm{x}$ time) effects ( $\left.\alpha^{1} 0.05\right)$. Secondary outcome variables will be compared using the Wilcoxon test for matched pairs including confidence intervals. Participants will be sub-grouped into acute and chronic to compare the outcomes. To analyze the outcome of the PGIC, patients will be split into 2 groups (dichotomized): improved ( 6 and 7 ) and not improved ( 1 to 5). With the help of logistic regression, the predicted probability of the outcome will be assessed using the PGIC as dependent variables (improved/not improved). Independent variables will be age, sex, expectations, manipulation and duration of complaints. Missing data will be analyzed using an intention-to-treat method. The data will be collected, stored and analyzed in the IBM-SPSS 22 (PASW, Chicago, IL,USA) statistics program.

\section{Ethics and data security}

This trial has been approved by the Ethics Committee of the Canton of Zurich (KEK-ZHnumber 2012-0248). All patients will be asked to provide written informed consent prior to participating in this study. This trial is registered at Current Controlled Trials (ISRCTN 88585962). The collected data will be locked in a secure cabinet and saved at Balgrist University Hospital for 20 years. 


\section{Discussion}

The purpose of this study is to compare treatment outcomes for neck pain patients using manual versus instrument-assisted mechanical manipulation at the thoracic spine. For this aim, a randomized clinical trial is the appropriate study. There are already existing trials and reviews that have investigated the treatment of the thoracic spine in neck pain patients 20, 24-30. Although there are trials that have compared mechanical and manual manipulations ${ }^{34,35}$, no study has worked with the Impulse $\mathrm{iQ} \otimes$ (Neuromechanical Innovations, Chandler, AZ, USA). There are several factors, which will support the outcome of the study. These are based on the latest knowledge about the treatment of neck pain. First, patients will receive a treatment using an interval of 4 days between each manipulation. This is recommended in the clinical prediction guideline rules for the use of thoracic manipulations in neck pain patients. Second, we added a home exercise program. It is recommended to combine manipulations of the spine with exercises, to have the strongest benefit for patients with neck pain ${ }^{8}$. Third, all outcome measures that are used (VAS, NDI, EQ-5D-5 L) are valid and reliable and have been often used in research. Fourth, to minimize selection bias, a person not involved in the study conducted the randomization of the participants using a computer program. The outcome of the data sheet was then written on cards and put inside opaque, sequentially numbered and sealed envelopes. One of the trial's weaknesses might be regarding blinding. We addressed this issue in different ways. To minimize performance bias, the therapist who is conducting the treatment will be unaware of the treatment method until the manipulation is applied. Additionally, the filled-in questionnaires are put inside a sealed, opaque envelop by the patient. The therapist is unaware of the outcome. When the data is put into the database the therapist will be unaware of the associated participant due to de-personalization/anonymity of the questionnaires. Additionally, the expectations of the patient regarding the new and conventional treatment are retrieved beforehand and taken into consideration during the evaluation of the data. The results of this study may provide useful information for clinicians and patients in terms of effective therapeutic options for treating neck pain patients without the risk of cervical spine manipulation. The outcomes of the research will be published in a timely manner after the completion of this study.

\section{Trial status}

Recruitment of study participants is currently ongoing. 


\section{Consent section}

Written informed consent was obtained from the patient(s) for publication of this manuscript and accompanying images. A copy of the written consent is available for review by the Editor-in-Chief of this journal 


\section{References}

1. Haldeman S, Carroll L, Cassidy JD, Schubert J, Nygren A. The bone and joint decade 2000 2010 task force on neck pain and its associated disorders: executive summary. J Manipulative Physiol Ther. 2008;32 Suppl 2:S7-9.

2. Leaver AM, Maher CG, McAuley JH, Jull G, Latimer J, Refshauge KM. People seeking treatment for a new episode of neck pain typically have rapid improvement in symptoms: an observational study. J Geophys Res. 2013;59:31-7.

3. Hogg-Johnson S, van der Velde G, Carroll LJ, Holm LW, Cassidy JD, Guzman J, et al. The burden and determinants of neck pain in the general population: results of the bone and joint decade 2000-2010 task force on neck pain and its associated disorders. J Manipulative Physiol Ther. 2009;32 Suppl 2:S46-60.

4. Carroll LJ, Hogg-Johnson S, Van Der VG, Haldeman S, Holm LW, Carragee EJ,et al. Course and prognostic factors for neck pain in the general population neck pain and its associated disorders. Spine (Phila Pa 1976). 2008;33:75-82.

5. Bogduk N, McGuirk B. Management of acute and chronic neck pain: an evidence-based approach. 1st ed. Edinburgh, London, New York, Oxford, Philadelphia, St. Louis, Sydney, Toronto: Elsevier; 2006.

6. Guzman J, Haldeman S, Carroll LJ, Carragee EJ, Hurwitz EL, Peloso P, et al. Clinical practice implications of the bone and joint decade 2000-2010 task force on neck pain and its associated disorders: from concepts and findings to recommendations. J Manipulative Physiol Ther. 2008;32 Suppl 2:S227-43.

7. Walton DM, Macdermid JC, Santaguida PL, Gross A, Carlesso L. Results of an international survey of practice patterns for establishing prognosis in neck pain: the ICON project. Open Orthop J. 2013;7:387-95.

8. Costello J, Jull G. Evidence-based clinical statement neck pain. Pain.2002;6:45.

9. Haneline MT, Rosner AL. The etiology of cervical artery dissection. J Chiropr Med. 2007;6:11020.

10. Clinical Guidelines for Assessing Vertebrobasilar Insufficiency in the Management of Cervical Spine Disorders.http://almacen-gpc.dynalias.org/publico/Valoracion\%20Insuficiencia\%20 vertebrobasilar\%20APA\%202006.pdf. Accessed 11 Feb 2015.

11. International Framework for the Examination of the Cervical Region for Potential Cervical Arterial Dysfunction prior to Orthopaedic Manual Therapy Intervention.http://www.ifompt.com/site/ ifompt/IFOMPT\%20Examination\%20cervical\%20spine \%20doc\%20September\%202012\%20 definitive.pdf.Accessed 11 Feb 2015.

12. Sweeney A, Doody C. Manual therapy for the cervical spine and reported adverse effects: a survey of Irish manipulative physiotherapists. Man Ther. 2010;15:32-6.

13. Thiel HW, Bolton JE, Docherty S, Portlock JC. Safety of chiropractic manipulation of the cervical spine: a prospective national survey. Spine (Phila Pa 1976). 2007;32:2375-8. discussion 2379.

14. Miley ML, Wellik KE, Wingerchuk DM, Demaerschalk BM. Does cervical manipulative therapy cause vertebral artery dissection and stroke? Neurologist. 2008;14:66-73.

15. Thomas LC, Rivett DA, Attia JR, Parsons M, Levi C. Risk factors and clinical features of craniocervical arterial dissection. Man Ther. 2011;16:351-6.

16. Cassidy JD, Boyle E, Coté P, He Y, Hogg-Johnson S, Silver FL, et al. Risk of vertebrobasilar stroke and chiropractic care: results of a population based case control and case-crossover study. Spine. 2008;36:92. author reply 92.

17. Marx P, Püschmann H, Haferkamp G, Busche T, Neu J. Manipulative treatment of the cervical spine and stroke. Fortschr Neurol Psychiatr. 2009;77:83-90.

18. Murphy DR. Current understanding of the relationship between cervical manipulation and stroke: what does it mean for the chiropractic profession? Chiropr Osteopat. 2010;18:22.

19. Fernández-de-las-Peñas C, Palomeque-del-Cerro L, Rodríguez-Blanco C, Gómez-Conesa A, Miangolarra-Page JC. Changes in neck pain and active range of motion after a single thoracic spine manipulation in subjects presenting with mechanical neck pain: a case series. $\mathrm{J}$ 
Manipulative Physiol Ther. 2007;30:312-20.

20. Cleland JA, Childs JD, McRae M, Palmer JA, Stowell T. Immediate effects of thoracic manipulation in patients with neck pain: a randomized clinical trial. Man Ther. 2005;10:127.

21. Norlander S, Gustavsson B, Lindell J, Nordgren B. Reduced mobility in the cervico-thoracic motion segment - a risk factor for musculoskeletal neck-shoulder pain: a two-year prospective follow-up study. Scand J Rehabil Med. 1997;29:167-74.

22. Norlander S, Nordgren B. Clinical symptoms related to musculoskeletal neck-shoulder pain and mobility in the cervico-thoracic spine. Scand J Rehabil Med. 1998;30:243-51.

23. Norlander S, Aste-Norlander U, Nordgren B, Sahlstedt B. Mobility in the cervico-thoracic motion segment: an indicative factor of musculo-skeletal neck-shoulder pain. Scand J Rehabil Med. 1996;28:183-92.

24. González-Iglesias J, Fernández-de-las-Peñas C, Cleland JA, Alburquerque-Sendín F, Palomeque-del-Cerro L, Méndez-Sánchez R. Inclusion of thoracic spine thrust manipulation into an electro-therapy/thermal program for the management of patients with acute mechanical neck pain: a randomized clinical trial. Man Ther. 2009;14:306-13.

25. Childs JD, Cleland JA, Elliott JM, Teyhem DS, Wainner RS, Whitman JM, et al. Neck pain: clinical practice guidelines linked to International Classification of Functioning, Disability, and Health from the Orthopaedic Section of the American Physical Therapy Association. J Orthop Sports Phys Ther. 2008;38:A1-34.

26. Cleland JA, Glynn P, Whitman JM, Eberhart SL, MacDonald C, Childs JD. Short-term effects of thrust versus nonthrust mobilization/manipulation directed at the thoracic spine in patients with neck pain: a randomized clinical trial. Phys Ther. 2007;87:431-40.

27. Lau HMC, Wing Chiu TT, Lam T-H. The effectiveness of thoracic manipulation on patients with chronic mechanical neck pain - a randomized controlled trial. Man Ther. 2011;16:141-7.

28. Walser RF, Meserve BB, Boucher TR. The effectiveness of thoracic spine manipulation for the management of musculoskeletal conditions: a systematic review and meta-analysis of randomized clinical trials. J Man Manip Ther. 2009;17:237-46.

29. Cross KM, Kuenze C, Grindstaff TL, Hertel J. Thoracic spine thrust manipulation improves pain, range of motion, and self-reported function in patients with mechanical neck pain: a systematic review. J Orthop Sports Phys Ther. 2011;41:633-42.

30. Gross A, Miller J, D'Sylva J, Burnie S, Goldsmith C, Graham N, et al. Manipulation or mobilisation for neck pain (Review). Cochrane Libr. 2010;5:1-110.

31. Young JL, Walker D, Snyder S, Daly K. Thoracic manipulation versus mobilization in patients with mechanical neck pain: a systematic review. J Man Manip Ther. 2014;22:141-53.

32. Kawchuk GN, Prasad NG, McLeod RC, Liddle T, Li T, Zhu Q. Variability of force magnitude and force duration in manual and instrument-based manipulation techniques. J Manipulative Physiol Ther. 2006;29:611-8.

33. Colloca CJ, Keller TS, Black P, Normand MC, Harrison DE, Harrison DD. Comparison of mechanical force of manually assisted chiropractic adjusting instruments. J Manipulative Physiol Ther. 2005;28:414-22.

34. Wood TG, Colloca CJ, Matthews R. A pilot randomized clinical trial on the relative effect of instrumental (MFMA) versus manual (HVLA) manipulation in the treatment of cervical spine dysfunction. J Manipulative Physiol Ther.2001;24:260-71.

35. Shearar KA, Colloca CJ, White HL. A randomized clinical trial of manual versus mechanical force manipulation in the treatment of sacroiliac joint syndrome. J Manipulative Physiol Ther. 2005;28:493-501.

36. Herzog W. The biomechanics of spinal manipulation. J Bodyw Mov Ther.2010;14:280-6.

37. Neuromechanical Innovations. http://www.neuromechanical.com/iq/. Accessed 11 February 2015.

38. Price $D$, McGrath $P$, Rafii A, Buckingham $B$. The validation of visual analogue scales as ratio scale measures for chronic and experimental pain. Pain. 1983;17:45-56.

39. Price D, Bush F, Long S, Harkins S. A comparison of pain measurement characteristics of mechanical visual analogue and simple numerical rating scales. Pain. 1994;56:217-26.

40. Deloach LJ, Stiff JL, Caplan AB. The Visual Analog Scale in the immediate postoperative period: intrasubject variability and correlation with a numeric scale. Anesth Analg. 1998;86:102-6. 
41. Williamson A, Hoggart B. Pain: a review of three commonly used pain rating scales. J Clin Nurs. 1994;2005:798-804.

42. Swanenburg J, Humphreys K, Langenfeld A, Brunner F, Wirth B. Validity and reliability of a German version of the Neck Disability Index (NDI-G). Man Ther. 2013;19(1):52-8. doi:10.1016/j. math.2013.07.004.

43. Vernon H. The Neck Disability Index: state-of-the-art, 1991-2008. J Manipulative Physiol Ther. 2008;31:491-502.

44. Kim SH, Kim HJ, Lee S-I, Jo M-W. Comparing the psychometric properties of the EQ-5D-3L and EQ-5D-5L in cancer patients in Korea. Qual Life Res. 2012;21:1065-73.

45. Janssen MF, Pickard AS, Golicki D, Gudex C, Niewada M, Scalone L, et al. Measurement properties of the EQ-5D-5L compared to the EQ-5D-3L across eight patient groups: a multicountry study. Qual Life Res. 2013;22:1717-27.

46. Swanenburg J, Gruber C, Brunner F, Wirth B. Patients' and therapists' perception of change following physiotherapy in an orthopedic hospital's outpatient clinic. Physiother Theory Pract. 2014;3985:1-6.

47. Spurling R, Scoville W. Lateral rupture of the cervical intervertebral discs: a common cause of shoulder and arm pain. Surgery, Gynecol Obstet.1944;78:350-8.

48. Wainner RS, Fritz JM, Irrgang JJ, Boninger ML, Delitto A, Allison S. Reliability and diagnostic accuracy of the clinical examination and patient self-report measures for cervical radiculopathy. Spine. 2003;28:52-62.

49. Cleland JA, Koppenhaver S. Cervical Spine. In: Netter's orthopaedic clinical examination: an evidence-based approach. 2nd ed. Philadelphia: Saunders, an imprint of Elsevier Inc; 2011. p. 66-128.

50. Shacklock M. Clinical neurodynamics: a new system of musculoskeletal treatment. 1st ed. Edinburgh, London, New York, Oxford, Philadelphia, St. Louis, Sydney, Toronto: ButterworthHeinemann, an imprint of Elsevier Inc; 2005.

51. Seffinger MA, Najm WI, Mishra SI, Adams A, Dickerson VM, Murphy LS, et al. Reliability of spinal palpation for diagnosis of back and neck pain: a systematic review of the literature. Spine. 2004;29:E413-25.

52. Schneider M, Erhard R, Brach J, Tellin W, Imbarlina F, Delitto A. Spinal palpation for lumbar segmental mobility and pain provocation: an interexaminer reliability study. J Manipulative Physiol Ther. 2008;31:465-73.

53. Krauss JR, Evjenth O, Creighton D. Translatoric spinal manipulation for physical therapists. 1st ed. A Lakeview Media L.L.C: Publication; 2006.

54. Colloca CJ. Neuromechanical Innovations: impulse adjusting system. 1st ed. Chandler, Arizona: Neuromechanical Innovations; 2012.

55. Jull GA, Falla D, Treleaven J, Sterling M, O'Leary S. A therapeutic exercise approach for cervical disorders. In: Boyling JD, Jull GA, editors. Grieves Mod Man Ther vertebral Column. 3rd ed. Edinburgh, London, New York, Oxford, Philadelphia, St. Louis, Sydney, Toronto: Elsevier, Churchill, Livingston; 2004. p. 451-71.

56. O'Leary S, Jull G, Kim M, Vicenzino B. Specificity in retraining craniocervical flexor muscle performance. J Orthop Sports Phys Ther. 2007;37:3-9.

57. EQ-5D-5L User Guide. http://www.euroqol.org/fileadmin/user upload/Documenten/PDF/ Folders Flyers/UserGuide EQ-5D-5L v2.0 October 2013.pdf. Accessed 11 Feb 2015.

58. Farrar JT, Young JP, Lamoreaux L, Werth JL, Poole RM. Clinical importance of changes in chronic pain intensity measured on an 11-point numerical pain rating scale. Pain. 2001;94:149 58.

59. Hurst $\mathrm{H}$, Bolton J. Assessing the clinical significance of change scores recorded on subjective outcome measures. J Manipulative Physiol Ther. 2004;27:26-35.

60. Noordzij M, Tripepi G, Dekker FW, Zoccali C, Tanck MW, Jager KJ. Sample size calculations: basic principles and common pitfalls. Nephrol Dial Transplant. 2010;25:1388-93.

61. Kelly AM. The minimum clinically significant difference in visual analogue scale pain score does not differ with severity of pain. Emerg Med J. 2001;18:205-7.

62. Whitley E, Ball J. Statistics review 4: sample size calculations. Crit Care. 2002;6:335-41. 



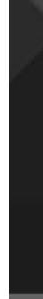




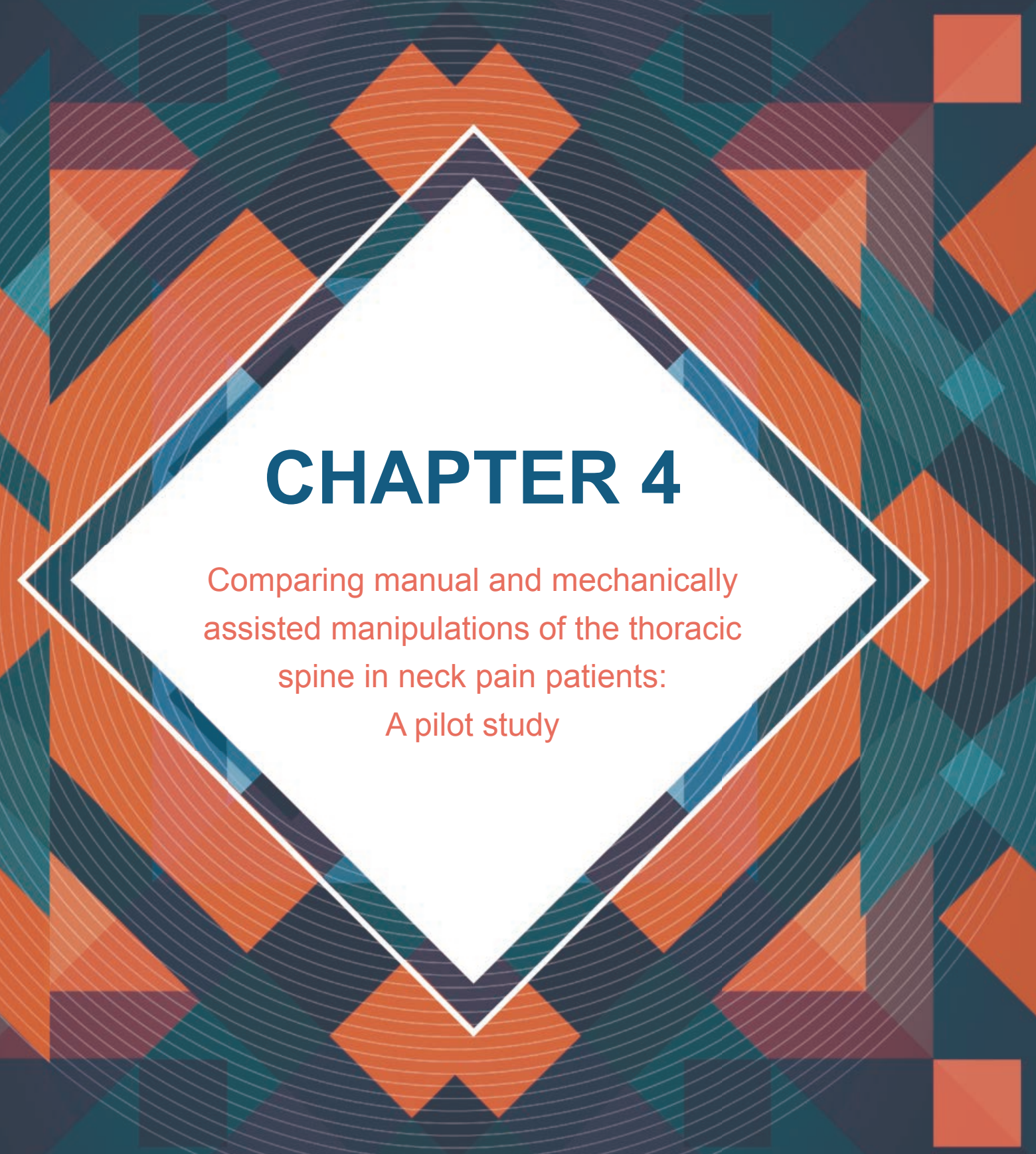

Anke Langenfeld , B. Kim Humphreys, Rob A. de Bie and Jaap Swanenburg

Published: F1000Research 2018, 7:156 (doi: 10.12688/f1000research.13780.1) 


\begin{abstract}
Background: Manipulations of the thoracic spine are a common treatment option in patients with neck pain. This approach avoids the risk of cervical arterial dissection. Currently there are different options available, which have been evaluated for their efficacy. The aim of this study was to assess short- and long-term effects of two different methods of manipulating the thoracic spine in combination with a standardized exercise program for neck pain.
\end{abstract}

Methods: This pilot study included patients who were over 18 years of age, able to speak and read German or English, had acute or chronic neck pain, and had not previously undergone manual therapy for the thoracic spine. Patients were recruited from private physical therapy practices. Patients were randomly assigned to two treatment groups by using block randomization. The objective was to compare the effects of manually performed manipulations and electromechanical manipulations on the thoracic spine in patients with neck pain. Primary outcome was the visual analogue pain rating scale. Secondary outcomes included Neck Disability Index, European Quality of Life scale, and Patients' Global Impression of Change Scale.

Results: Ten patients were recruited. Five patients received manual manipulations, and five received electromechanical manipulations. Both groups showed an improvement in pain scores (VAS) $(X(5)=14.161, p=0.015)$ with no difference between the groups. There were no significant changes in the secondary outcomes. The electromechanical (Impulse $\mathrm{iQ} \otimes$ ) manipulations group showed a clinically relevant reduction in the neck disability index.

Conclusion: Both manual and electromechanical manipulations are well tolerated, and show that they can be both successful treatments for neck pain in combination with exercises. Thoracic manipulations seem to be beneficial for the patient's complaint of neck pain, while electromechanical manipulations seem to be able to reduce neck disability.

Trial registration: Current Controlled Trials ISRCTN88585962, registered in January 2013. 


\section{Introduction}

Neck pain ranks fourth among the most common musculoskeletal complaints worldwide ${ }^{1}$. Although often not disabling, most patients with neck pain will not experience a complete resolution of their problem ${ }^{2}$. Furthermore, various possible causes for neck pain exist ${ }^{2}$. Neck pain symptoms are often temporary and can be treated successfully with nonsurgical care such as medication, physical therapy, and manipulations ${ }^{3-5}$. Best studied treatments are cervical spine manipulations in conjunction with exercise therapy ${ }^{6,7}$. Although there is conflicting evidence, cervical spinal manipulations are suspected to cause serious adverse events such as cervical artery dissection (CAD) (see The International Federation of Orthopaedic Manipulative Physical Therapists (IFOMPT) cervical framework) ${ }^{8-11}$. An alternative approach to cervical manipulations, which has been reviewed extensively, is manipulations of the thoracic spine ${ }^{12-23}$. Manipulations may be delivered either manually (high velocity low amplitude) or mechanically using different spring-loaded or electromechanical devices ${ }^{24-27}$. However, manual forces given by the same practitioner may vary somewhat for each manipulation session and between practitioners ${ }^{28}$. Forces applied by an electromechanical device are more consistent ${ }^{24}$. Thus far, only three studies have compared between manual and mechanical manipulations ${ }^{26,27,29}$. In 2001, Wood and colleagues evaluated neck pain patients. They compared mechanical force, manually assisted (MFMA) adjustments (activator II adjusting instrument) to high velocity, and lowamplitude manipulation directed to a dysfunctional cervical spinal motion unit ${ }^{26}$. Shearar et al. (2005) evaluated patients with recent low back pain who were diagnosed with sacroiliac joint syndrome at the initial assessment. Patients were either treated with manually delivered chiropractic adjustments or an MFMA adjustment using an activator adjusting instrument ${ }^{27}$. Schneider et al. worked with acute low back pain patients in which one group received treatment by activator method proficiency-certified chiropractors while the other two groups used side posture thrust manipulation ${ }^{29}$. The above mentioned studies suggest that both ways of delivering manipulations are beneficial to reduce the patients' pain and disability. The latest technical development of such an electromechanical device, the Impulse $\mathrm{iQ}$., incorporates a feedback loop to adjust the manipulation force to the resonance of the patient's spine. Yet, no studies have investigated the effectiveness of this device.

The objective of our pilot study was to compare short- and long-term effects of two different ways of manipulating the thoracic spine in combination with a standardized exercise program for neck pain. 


\section{Methods}

\section{Study design}

A pilot study was conducted to compare the effects of two different methods of manipulation (manual manipulation vs. electromechanical manipulation) on the thoracic spine for patients with neck pain. A complete study protocol for a randomized controlled trial was published in May $2015^{30}$. The study received ethical approval from the Ethics Commission of the Canton of Zurich (2012-0248) and was registered at Current Controlled Trials (ISRCTN88585962). A completed CONSORT checklist can be found in Supplementary File 1.

\section{Participants}

Every participant received all relevant patient information in advance. When a potential participant had read the information and was willing to participate, he or she signed the informed consent form. Participants were recruited from, May 2013 until August 2015, in private physical therapy practices in Zurich, Switzerland. Inclusion criteria were the presence of acute or chronic neck pain grade I or II ${ }^{31}$, age 18 years or older, able to speak and read German or English, no previous manual therapy of the thoracic spine, and interest in participating in the study. Patients were excluded if they had severe disorders of the cervical spine, such as disk prolapse, spinal stenosis, postoperative conditions in neck and shoulder areas, a history of severe trauma, spasmodic torticollis, frequent migraine headaches, peripheral nerve entrapment, fibromyalgia, shoulder diseases (causing reduced mobility of the joint, e.g., fractures, adhesive capsulitis), inflammatory rheumatic diseases, osteoporosis, or cancer or if they were currently undergoing legal procedures related to their neck pain. Additional evaluations (history taking and physical examination) of the participant were added after baseline measurements to confirm eligibility of the participant to be included in the study population ${ }^{30}$.

\section{Randomization}

Aclinician not involved in the study randomized the participants independently into one of the two groups. Block randomization (20 blocks of 4 ) was carried out using a computer-based randomization program. The original list was stored in an opaque and sealed envelope, not accessible to the therapist delivering the manipulations. To reduce intervention bias, 80 individually numbered opaque and sealed envelopes were prepared, and the therapist received the assigned envelope immediately before each participant was to receive the manipulation. Additionally, after the participants completed the questionnaires, they were 
put into an opaque envelope that was individually and immediately sealed by the patient. The therapist was unaware of the outcome. The anonymous data were entered into the database and were untraceable to the participating patient.

\section{Intervention}

Each patient underwent three treatment sessions, with 4 days interval between each session. Additionally, during the first session, all participants were instructed to participate in an exercise program, which was to be completed as soon as possible. To evaluate compliance of the participants, they received a journal and were asked to mark the days that they had completed the required exercises. Follow-up assessments were conducted at 6 weeks, 3 months, and 6 months after the initial treatment.

Patients received the questionnaires by mail, including prepaid envelopes, to facilitate return of the completed forms. An extensive explanation of the treatments can be found elsewhere ${ }^{30}$.

\section{Manual manipulations}

For the manually performed manipulations, the patient was supine. The therapist's hand was placed under the thoracic spine using a pistol grip (the fingers positioned with the index finger straightened and fingers 3 to 5 flexed). The patient's forearms were crossed in front of their chest. The force was applied against the therapist's flexed fingers and the thenar eminence and slightly cranial to the transverse process of the caudal vertebrae of the segment to be treated ${ }^{32}$.

\section{Electromechanical manipulations}

For the electromechanical manipulations, the Impulse iQ. (Neuromechanical Innovations, Chandler, AZ, USA) was used. The patient was prone on a treatment table, with arms parallel to the body, in a relaxed position. Before the treatment began, the patient was instructed that they would hear a rattling sound that indicated the treatment thrusts conducted by the device and a beep to signify the end of treatment. The Impulse $\mathrm{iQ}$ was placed onto the vertebrae previously identified as the painful segment. A double stylus and middle force setting (peak force $=200 \mathrm{~N}$ ), as recommended by the manufacturer for the treatment of the thoracic spine, was used ${ }^{33}$. The device recorded and analyzed the spinal acceleration response each time a thrust was delivered by using the in-built firmware. To begin, the machine produced a series of repetitive thrusts while monitoring the acceleration response. If the response improved, the treatment thrusts continued up 
to 3 more seconds. If the acceleration response was negative (flat line or decrease), the thrusts delivered by the instrument ceased.

\section{Exercise program}

After the first treatment session, all patients were introduced to the home exercise program and asked to perform this program once a day for 6 weeks. Compliance with the home exercise program was assessed using a training journal as follows:

1) retraining the craniocervical muscles (e.g., training the holding capacity of the deep neck flexors and head lift),

2) retraining the scapular muscles, and

3) eye/head coordination ${ }^{34,35}$.

For a complete overview of the study`s course see Figure 1

\section{Outcome measures}

Baseline measures included age, weight, height, and the European Quality of Life 5 Dimensions 5 Levels (EQ-5D-5L). Furthermore, each patient's expectation of treatment outcome (the treatment he or she expected to be more beneficial) was assessed the beginning of the study. The primary outcome measure was the Visual Analogue Pain rating scale (VAS) that assesses pain intensity level ${ }^{36-39}$. The VAS was completed before and after every treatment session and at all follow-up points. Secondary outcomes were the Neck Disability Index (NDI) and the Patients Global Impression of Change Scale (PGIC) 40-44. The NDI is a self-reported questionnaire to evaluate disability. It consists of 10 items that score from zero to five. The higher the total score, the higher is the disability level of the patient ${ }^{41}$. The NDI's minimal clinical important difference (MCID) in patients with neck pain ranges from 3.5 to 9.5 , which mainly depends on the patient characteristics ${ }^{45-47}$. Pereira et al. (2015) state that in patients with chronic neck pain, the score has to be above 5.5 points, otherwise it is clinically irrelevant $45,48,49$. Before the second, third treatments and all follow-up assessment, the patients were asked about their global impression of change, using the PGIC ${ }^{50}$. The PGIC is a valid outcome measure that is based on a seven-point Likert scale ${ }^{51}$. Its purpose is to obtain a patient's report of improvement over time during treatment. The scale ranges from much better, better, somewhat better, no change, somewhat worse, worse, and much worse. Much better is rated as 7 and much worse as $1^{44}$. It can be used to dichotomize participants into two groups: improved (ratings of 6 and 7 ) and not improved (ratings 1 to 5). 


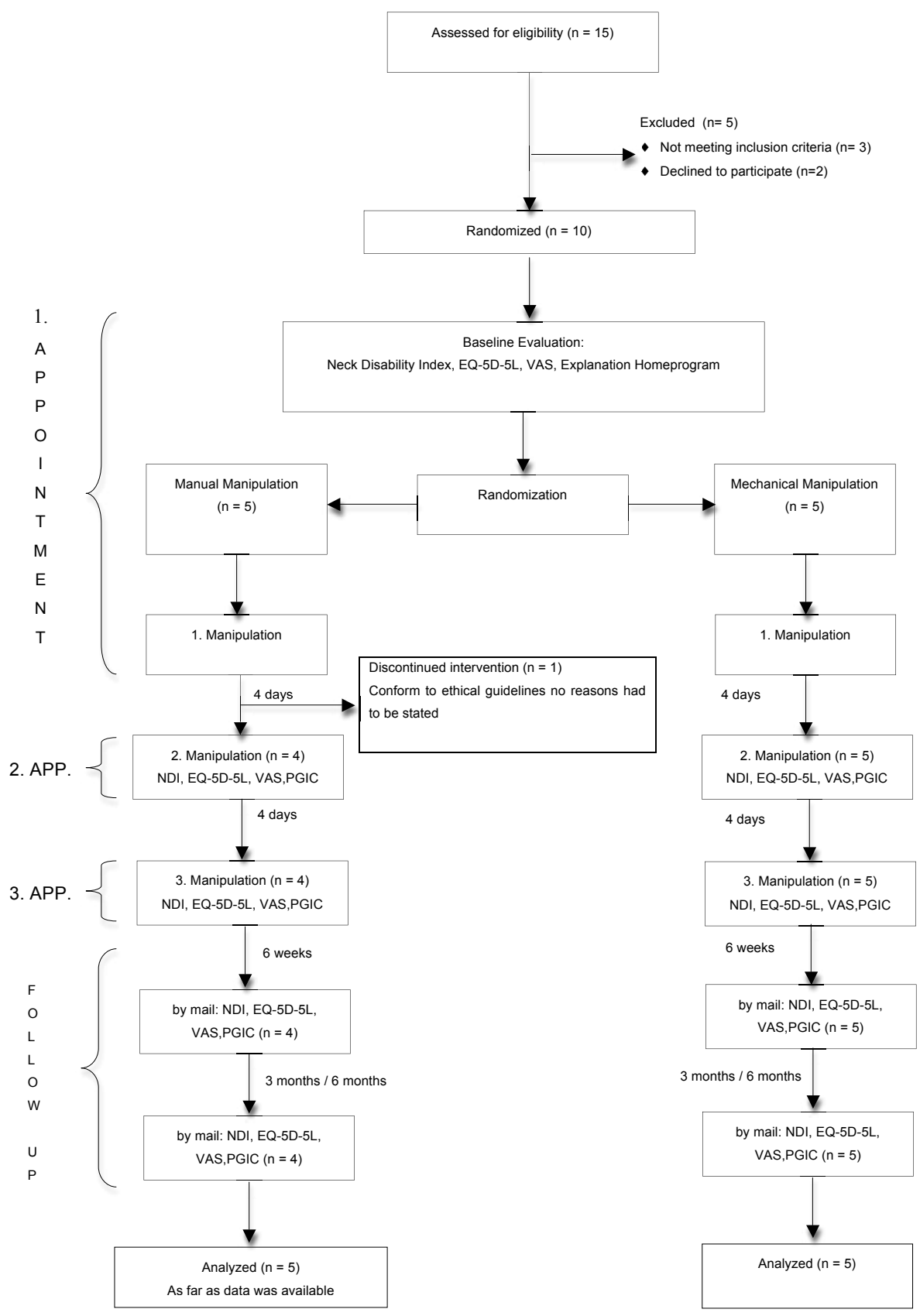

Figure 1. Flowchart of the trial, describing the process of randomization, evaluation and treatment 


\section{Statistics}

The data were stored and analyzed using the IBM SPSS 21 statistical software package (SPSS, Inc., Chicago, IL). Descriptive statistics were used to describe patient characteristics. Collected data were checked for normal distribution using the Shapiro-Wilk Test. The test identified that the scores for VAS and NDI were normally distributed. Because of outliers, the Friedman test was used as a nonparametric statistical test to retain all data points. The goal was to determine whether there were any statistically significant differences between the distributions of three or more related groups. Furthermore, pairwise comparisons were performed (SPSS Statistics, 2012) with a Bonferroni correction for multiple comparisons. 


\section{Results}

The study included two male and eight female participants. Because of unknown causes, one participant dropped out of the study after the first treatment. Nine participants had experienced chronic neck pain problems (>90 days), and one patient had acute problems (<90 days) (please see Table 4). Two participants had co-morbidities such as low back pain and coccydynia. Six participants believed that the conventional (manual) manipulation would be more successful, while four believed the electromechanical manipulation would be superior. Five participants received a manual treatment, and the remaining five received an electromechanical treatment. Three participants identified the third thoracic vertebra as the most painful and two identified the seventh thoracic vertebra. The second, fourth, fifth, sixth, and the tenth thoracic vertebrae were named by one patient as the most painful ones. Table 1 presents the demographic data and baseline measurements.

Table 1: Demographic Data and Baseline Measurements.

\begin{tabular}{lccccc}
\hline & $\mathrm{N}$ & Minimum & Maximum & Mean & Standard Deviation \\
\hline Age $(\mathrm{y})$ & 10 & 21 & 72 & 50.50 & 16.88 \\
Height $(\mathrm{cm})$ & 10 & 145.0 & 193.0 & 166.40 & 13.05 \\
Weight $(\mathrm{kg})$ & 10 & 50.0 & 91.0 & 69.63 & 13.80 \\
VAS $(\mathrm{mm})$ & 10 & 5 & 51 & 27.70 & 13.54 \\
NDI-G & 10 & 3 & 15 & 10.20 & 3.5 \\
EQ-5D-5L & 8 & 0.72 & .091 & 0.87 & 0.069 \\
EQ-5D-5L-1VAS & 10 & 20 & 95 & 71.50 & 23.22 \\
\hline
\end{tabular}

\section{Primary outcome}

Both groups showed a significant improvement in pain scores (Friedman test, VAS X2 (5) $=14.161, p=0.015)$. There were no statistically significantly differences between the two treatment groups: electromechanical $X^{2}(5)=7.701, p=0.174 /$ manual $X^{2}(5)=7.774, p=$ 0.169 . Bonferroni correction post hoc analysis revealed statistical differences in the rating from follow-up measurements at 3 months (median $=6.00$ ) from the first appointment $($ median $=26.00)(p=0.008)$. VAS scores at the baseline reduced by $11 \%$ at second treatment, $27 \%$ at third treatment, $54 \%$ after 6 weeks, $77 \%$ after 3 months, and $42 \%$ after 6 months. The \% change of pain is shown in Table 2. 
Table 2: Visual Analogue Pain Rating Scale (VAS) and \% change over a period of 6 months in all participants.

\begin{tabular}{|c|c|c|c|c|c|c|}
\hline \multirow[t]{3}{*}{ Manipulation } & \multicolumn{6}{|c|}{ VAS } \\
\hline & \multicolumn{3}{|c|}{ Treatment } & \multicolumn{3}{|c|}{ Follow up } \\
\hline & 1 & 2 & 3 & 6 weeks & 3 months & 6 months \\
\hline All (Change \%) & 26.00 & $\begin{array}{l}23.00 \\
(-11 \%)\end{array}$ & $\begin{array}{c}19.00 \\
(-27 \%)\end{array}$ & $\begin{array}{c}12.00 \\
(-54 \%)\end{array}$ & $\begin{array}{c}6.00 \\
(-77 \%)\end{array}$ & $\begin{array}{c}15.00 \\
(-42 \%)\end{array}$ \\
\hline Electromechanical Group & 17.00 & $\begin{array}{c}19.50 \\
(+14 \%)\end{array}$ & $\begin{array}{c}13.00 \\
(-23 \%)\end{array}$ & $\begin{array}{c}10.00 \\
(-41 \%)\end{array}$ & $\begin{array}{c}5.50 \\
(-68 \%)\end{array}$ & $\begin{array}{c}13.00 \\
(-28 \%)\end{array}$ \\
\hline Manual Group & 26.00 & $\begin{array}{l}25.00 \\
(-4 \%)\end{array}$ & $\begin{array}{c}19.00 \\
(-27 \%)\end{array}$ & $\begin{array}{c}12.00 \\
(-54 \%)\end{array}$ & $\begin{array}{c}15.50 \\
(-40 \%)\end{array}$ & $\begin{array}{c}15.00 \\
(-42 \%)\end{array}$ \\
\hline
\end{tabular}

\section{Secondary outcome}

Because of outliers, the Friedman test was used for analyzing the NDI. There was no significant change $\left(X^{2}(5)=10.562, p=0.061\right)$. No significant change in NDI was observed between the two groups (electromechanical $X^{2}(5)=5.234, p=0.388 /$ manual group $X^{2}(5)$ $=5.546, p=0.232)$. The change over time (median) is shown in Table 3 .

Table 3: Median of the Neck Disability Index (NDI) and \% change score over a period of 6 months.

\begin{tabular}{lcccccc}
\hline Manipulation & NDI 1 & NDI 2 & NDI 3 & NDI 6 weeks & NDI 3 month & NDI 6 month \\
\hline All & 10.5 & 6.00 & 7.00 & 7.00 & 6.50 & 6.00 \\
(Change \%) & & $(-43 \%)$ & $(-33 \%)$ & $(-33 \%)$ & $(-38 \%)$ & $(-43 \%)$ \\
Electromechanical Group & 11.00 & 6.00 & 6.85 & 5.50 & 5.50 & 7.00 \\
& & $(-55 \%)$ & $(-38 \%)$ & $(-50 \%)$ & $(-50 \%)$ & $(-36 \%)$ \\
Manual Group & 10.00 & 6.00 & 7.00 & 7.00 & 7.50 & 5.00 \\
& & $(-40 \%)$ & $(-30 \%)$ & $(-30 \%)$ & $(-25 \%)$ & $(-50 \%)$ \\
\hline
\end{tabular}

Table 4: Overview of PGIC outcome, expectation of favourable treatment and additional treatment (chiropractic, physical therapy [PT], and acupuncture), and duration of complaints.

\begin{tabular}{|c|c|c|c|}
\hline & $\begin{array}{c}\text { PGIC } \\
\text { (after the first treatment) }\end{array}$ & $\begin{array}{c}\text { PGIC } \\
\text { (after the second treatment) }\end{array}$ & $\begin{array}{c}\text { PGIC at } 6 \\
\text { weeks }\end{array}$ \\
\hline Participant $1^{\text {(iQ) }}$ & 6 & 6 & 4 \\
\hline Participant $2^{(\mathrm{iQ})}$ & 4 & 5 & 5 \\
\hline Participant $4^{(\mathrm{iQ})}$ & 5 & 6 & 6 \\
\hline Participant $5^{(\mathrm{iQ})}$ & 4 & 4 & 4 \\
\hline Participant $6^{\text {(manual) }}$ & 6 & 6 & 7 \\
\hline Participant $7^{\text {(manual) }}$ & 4 & 4 & 5 \\
\hline Participant $8^{\text {(manual) }}$ & 6 & 6 & 6 \\
\hline Participant 9(manual) & 4 & 4 & 4 \\
\hline Participant $10^{\text {(manual) }}$ & 6 & 6 & 5 \\
\hline
\end{tabular}




\section{PGIC}

After the first treatment, four out of nine patients rated themselves as improved, five patients after the second treatment, three patients after 6 weeks, two patients after 3 months, and three patients after 6 months. All other participants stated that they had no improvement, but the pain did not get worse. In total, there were 10 ratings of improvement in the electromechanical manipulation group and 7 in the manual manipulation group (see Table 4 for a detailed rating).

\section{Additional interventions}

Overall, four participants had additional treatment during the 6 months of follow-up. After 3 months of treatment, two participants visited a physical therapist and one participant received acupuncture once a week. At the 6 months survey, another participant received chiropractic treatment (three times) and one continued to visit a physical therapist, if the neck pain was too severe.

\section{Discussion}

The main goal of our pilot study was to compare short- and long-term effects of two different ways of manipulating the thoracic spine in combination with a standardized exercise program for patients with a main complaint of neck pain. In this study, the main outcome was pain intensity using the VAS. We found a significant reduction in neck pain for all patients, but not between the groups. Additionally, there was a tendency and a clinically relevant decrease in neck disability in accordance with the report of Pereira and

\begin{tabular}{|c|c|c|c|c|}
\hline $\begin{array}{c}\text { PGIC at three } \\
\text { months }\end{array}$ & $\begin{array}{c}\text { PGIC at six } \\
\text { months }\end{array}$ & Expectation & $\begin{array}{l}\text { Additional } \\
\text { treatment }\end{array}$ & $\begin{array}{l}\text { Duration of } \\
\text { complaints }\end{array}$ \\
\hline 5 & 6 & Manual & No & $>90$ days \\
\hline 5 & 2 & Manual & 3x Chiropractic & $>90$ days \\
\hline 5 & 7 & $\mathrm{iQ} \circledast$ & No & 42 days \\
\hline 6 & 4 & Manual & No & $>90$ days \\
\hline 7 & 7 & $\mathrm{iQ} \otimes$ & No & $>90$ days \\
\hline 5 & 4 & $\mathrm{iQ} \otimes$ & No & $>90$ days \\
\hline 5 & 4 & $\mathrm{iQ} \otimes$ & $3 \times \mathrm{PT}$ & $>90$ days \\
\hline 4 & 4 & $\mathrm{i} Q \circledR$ & PT & $>90$ days \\
\hline 5 & 5 & Manual & Acupuncture & $>90$ days \\
\hline
\end{tabular}


colleagues that state a reduction of 5.5 points on the NDI in patients with chronic neck pain is a minimal clinically important difference ${ }^{49}$. In particular, the electromechanical group showed a decrease in their VAS scoring of 5.5 after 6 weeks and after 3 months. Although this did not reach statistical significance, we were able to show a tendency for improvement in this group. However, a wear off in VAS reduction was observed at 6 months. The followup of 6 months could have been too long. Patients may have forgotten the details of the interventions. Four of the patients had additional therapy during the follow-up period. Since our groups were small, this might have influenced the outcomes. One suggestion for further research is to use a paper-based or electronic diary to report all possible relevant incidents and interventions ${ }^{52,53}$. To our knowledge this is the first study that investigated the short- and long-term outcome of electromechanical manipulation. None of the other studies, which were identified during literature review, assessed long-term outcomes of a device with a feedback loop ${ }^{26,27,29}$. Other studies had a follow-up period that lasted only 4 weeks ${ }^{28}$. Huggins and colleagues (2012) postulated the need for more studies evaluating activator adjusting instruments and their long-term outcomes ${ }^{54}$. Patients from previous studies received more treatment than those in our study. Our study had three treatment sessions as recommended by former clinical prediction guidelines ${ }^{55}$. Wood et al. (2001) and Schneider et al. (2011) had eight treatments sessions in 4 weeks ${ }^{26,29,58}$. Shearar et al. (2005) used four treatments over a 2-week period ${ }^{27}$. Even with the fewer treatment sessions, we could reduce pain significantly.

However, in this study, an important difference compared to the other studies is the addition of exercises with the spinal manipulation treatment. The combination of exercise and manipulation is currently the best evidence-based approach for neck pain 6,7 . One important reason for conducting this study relates to the question on cervical spinal manipulation and serious adverse events such as cervical artery dissection. (see Australian Physiotherapy Association guidelines for vertebrobasilar insufficiency) ${ }^{8,56}$. There is a debate in the literature referring to these events, and this serious complication should be considered if a patient is going to be treated with cervical spinal manipulation (see Australian Physiotherapy Association guidelines for vertebrobasilar insufficiency) 8,57-63. In our study, no serious adverse events occurred. This suggests the treatment of patients with neck pain by manual or electromechanical manipulation of the thoracic spine may provide another treatment option. From the findings of our pilot study, we calculated the sample size for each time point of a RCT by using the formula $2 \times\left[(1.96+0.842)^{2} x\right.$ $\mathrm{SD}^{2} \mathrm{j} / 12^{264,65}$. The calculation revealed that a sample size of 20 per treatment arm the first time point would be sufficient to show significant differences in outcomes. However, 
the sample size requirements increased to 24 participants at 6 weeks and 57 participants at 6 months. For a two group pre-test / post-test / follow-up design, a total sample size of 114 participants will be sufficient to reach result with $80 \%$ power at an $\alpha$-level of 0.05 .

\section{Limitation}

One obvious limitation was the small sample size of the study. One recruitment problem was to find patients who had not received previous manual therapy. Recruitment of chronic patients who were not already treated for their pain condition was therefore especially difficult. Furthermore, our exercise program was not tailored to the individual needs of every patient. This could have influenced the outcome because patients might have needed a more individualized exercise program to approach to their problem, although recent literature suggest, that an individualized treatment is not always superior ${ }^{66}$. Nevertheless, we could show that pain decreased during the intervention.

\section{Conclusion}

Neck pain can be influenced by manipulations applied to the thoracic spine in combination with exercise therapy. Additionally, our study suggests that electromechanical manipulations may be able to decrease neck disability. However, caution is advised concerning these results because of the study's small sample size. The findings of this pilot study allowed the power calculation of the actual sample size needed for a larger randomized controlled trial aimed at studying manipulations applied to the thoracic spine in combination with exercise therapy in patients with neck pain.

\section{Supplementary material}

Supplementary File 1: Completed CONSORT checklist.

\section{Data availability}

Dataset 1: Complete set of all data recorded as part of this pilot study. File name - manual vs mechanically_RCT_f1000 10.5256/f1000research.13780.d192478 ${ }^{67}$

\section{Ethics approval}

The study received ethical approval from the Ethics Commission of the Canton of Zurich (2012-0248) and was registered at Current Controlled Trials (ISRCTN88585962).

\section{Competing interests}

No competing interests were disclosed. 


\section{Grant information}

The author(s) declared that no grants were involved in supporting this work.

\section{Acknowledgments}

The Impulse IQ $®$ was provided by Neuromechanical Innovations, Chandler, AZ, USA.

A disclaimer response was written and signed before the start of the study. 


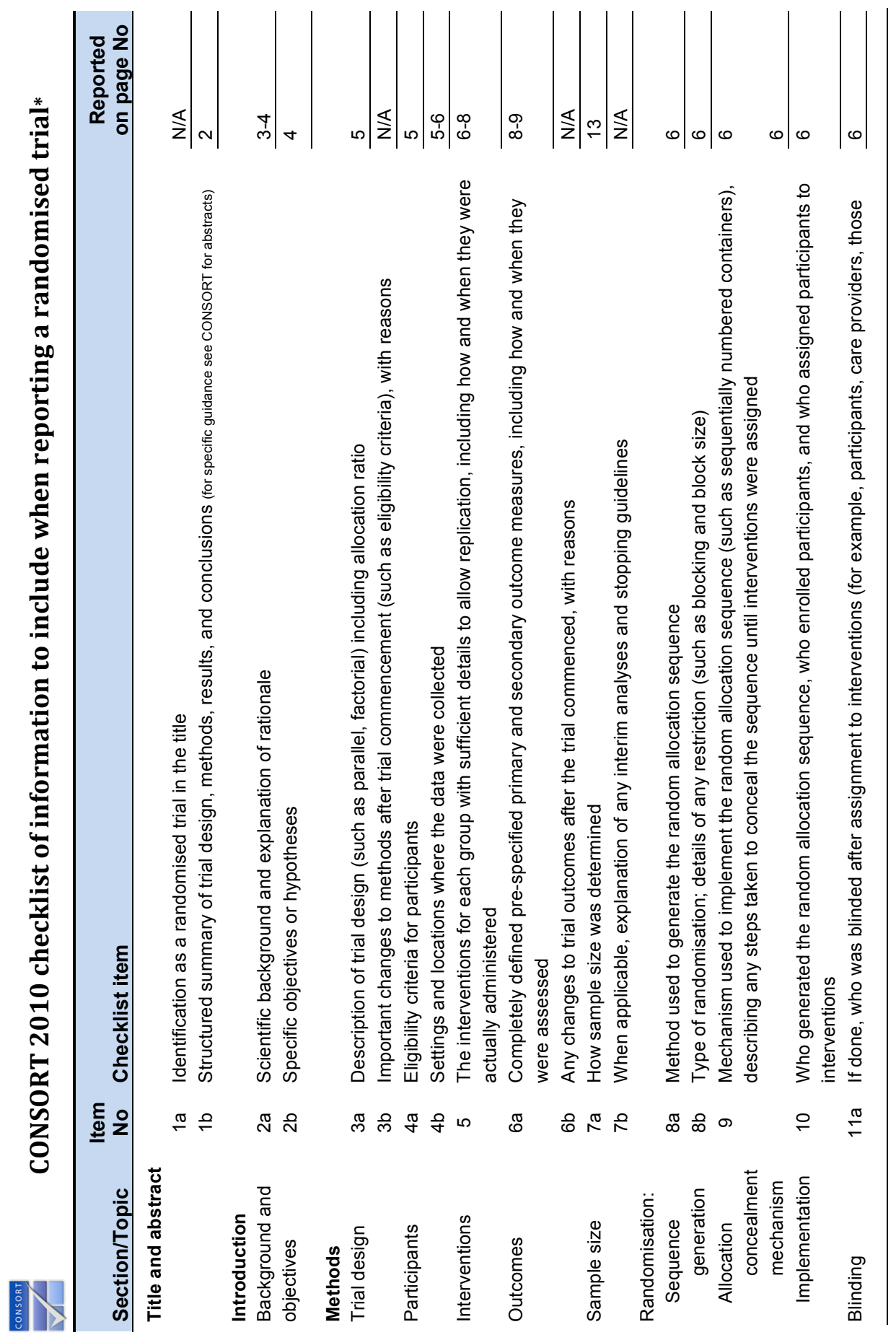



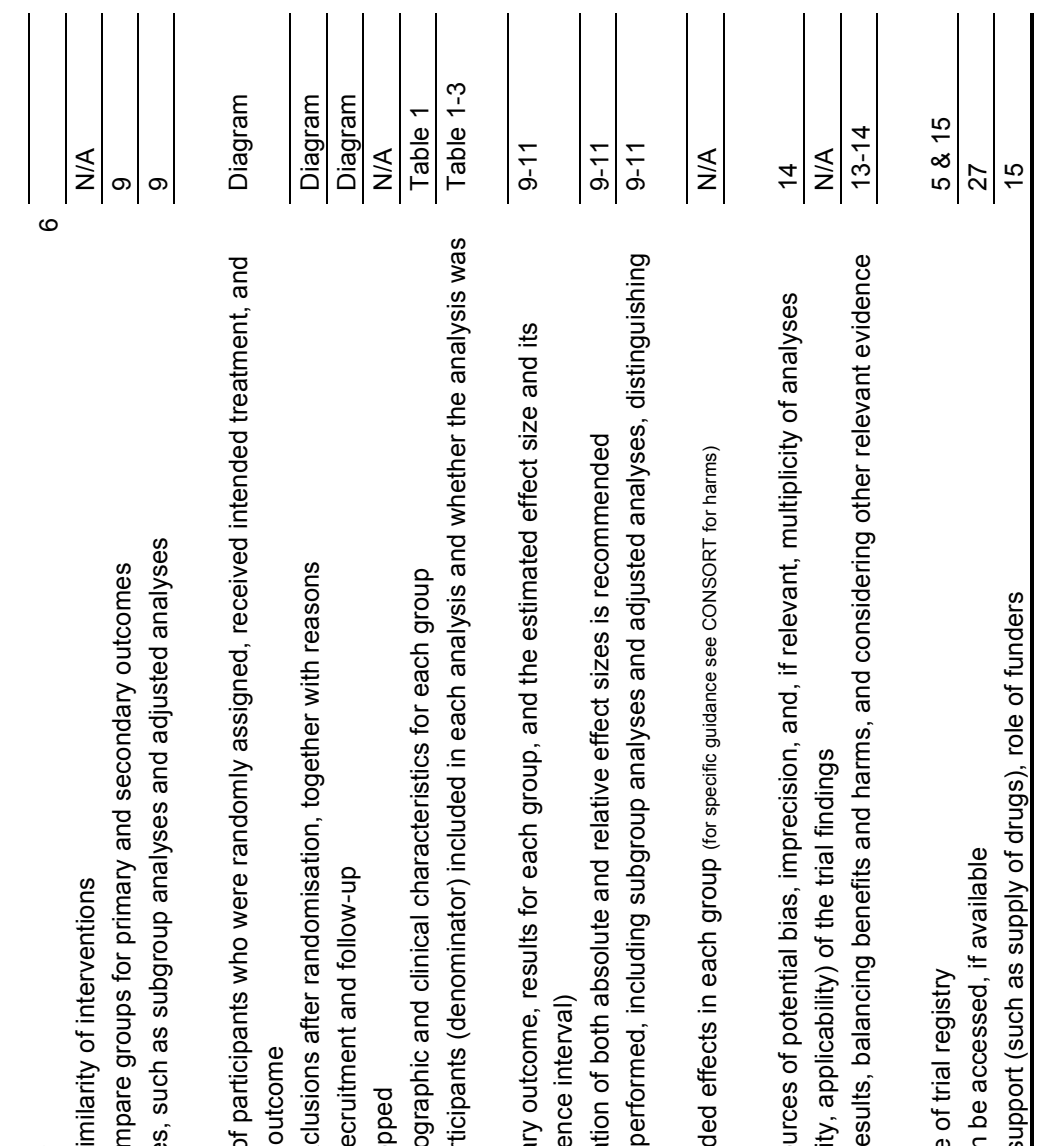

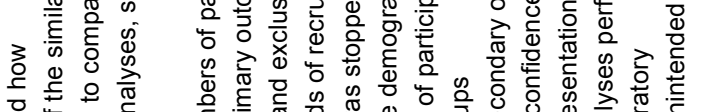

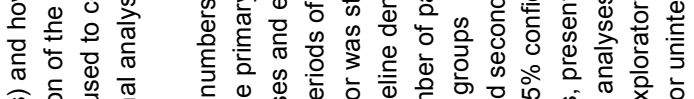

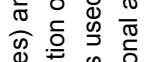

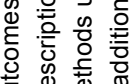

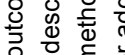

马

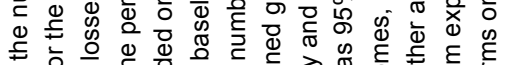

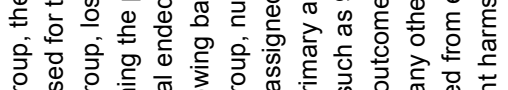

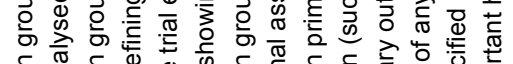

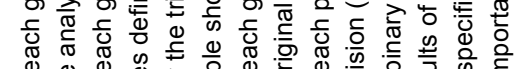

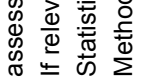

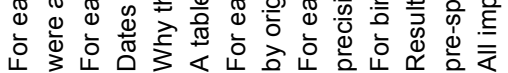

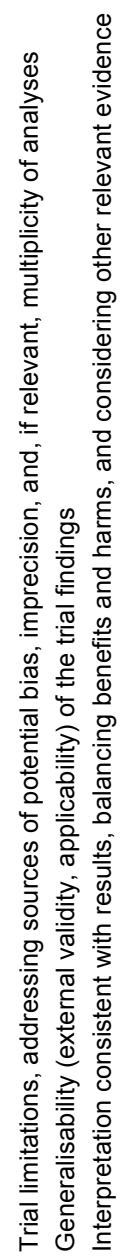

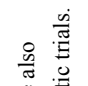

先

है

는

$\pm$

氖

㘴

స

氖

壱

奇

音

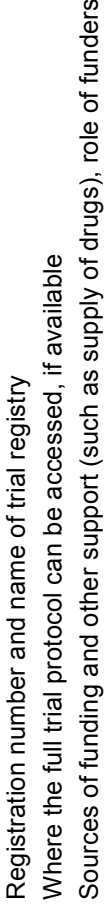

ᄒ․

迎

垔

䓂造

产 券

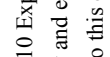

군?

농 焉

Z

语

政

.

帚

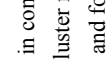

苛 0

跑 苛

量旁

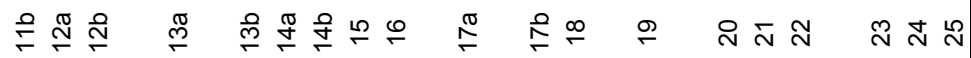

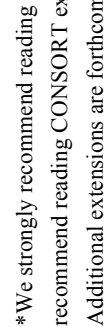

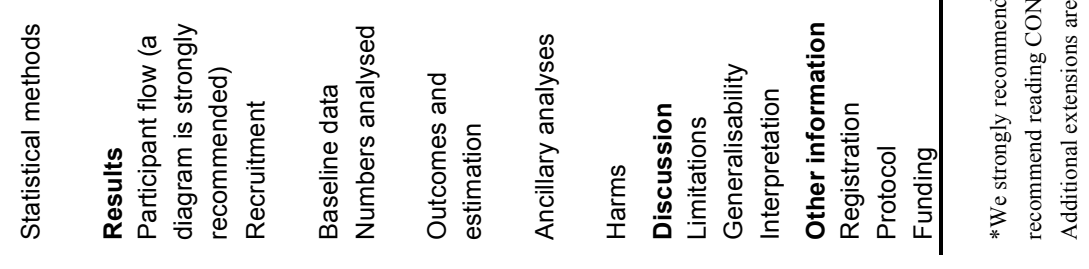





\section{References}

1. Global Burden of Disease Study 2013 Collaborators: Global, regional, and national incidence, prevalence, and years lived with disability for 301 acute and chronic diseases and injuries in 188 countries, 1990-2013: a systematic analysis for the Global Burden of Disease Study 2013. Lancet. 2015; 386(9995): 743-800.

2. Haldeman S, Carroll L, Cassidy JD, et al.: The Bone and Joint Decade 2000-2010 Task Force on Neck Pain and Its Associated Disorders: executive summary. J Manipulative Physiol Ther. 2009; 32(2 Suppl): S7-9.

3. Hurwitz EL, Carragee EJ, van der Velde G, et al.: Treatment of neck pain: noninvasive interventions: results of the Bone and Joint Decade 2000-2010 Task Force on Neck Pain and Its Associated Disorders. J Manipulative Physiol Ther. 2009; 32(2 Suppl): S141-75.

4. Varatharajan S, Ferguson B, Chrobak K, et al.: Are non-invasive interventions effective for the management of headaches associated with neck pain? An update of the Bone and Joint Decade Task Force on Neck Pain and Ist Associated Disorders by the Ontario Protocol for Traffic Injury Management (OPTIMa) Collaboration. Eur Spine J. 2016; 25(7): 1971-99.

5. Gross A, Langevin P, Burnie SJ, et al.: Manipulation and mobilisation for neck pain contrasted against an inactive control or another active treatment. Cochrane Database Syst Rev. 2015; (9): CD004249.

6. Wong JJ, Shearer HM, Mior S, et al.: Are Manual Therapies, Passive Physical Modalities, or Acupuncture Effective for the Management of Patients with Whiplash-Associated Disorders or Neck Pain and Associated Disorders? An Update of the Bone and Joint Decade Task Force on Neck Pain and Its Ass. Elsevier Inc.; 2015.

7. Côté $P$, Wong JJ, Sutton $D$, et al.: Management of neck pain and associated disorders: $A$ clinical practice guideline from the Ontario Protocol for Traffic Injury Management (OPTIMa) Collaboration. Eur Spine J. 2016; 25(7): 2000-22.

8. Haneline MT, Rosner AL: The etiology of cervical artery dissection. J Chiropr Med. 2007; 6(3): 110-20.

9. Mann T, Refshauge KM: Causes of complications from cervical spine manipulation. Aust $\mathrm{J}$ Physiother. 2001; 47(4): 255-66.

10. Biller J, Sacco RL, Albuquerque FC, et al.: Cervical arterial dissections and association with cervical manipulative therapy: A statement for healthcare professionals from the American Heart Association/American Stroke Association. Stroke. 2014; 45(10): 3155-3174.

11. Church EW, Sieg EP, Zalatimo O, et al.: Systematic Review and Meta-analysis of Chiropractic Care and Cervical Artery Dissection: No Evidence for Causation. Cureus. 2016; 8(2): e498.

12. Krauss J, Creighton D, Ely JD, et al.: The immediate effects of upper thoracic translatoric spinal manipulation on cervical pain and range of motion: a randomized clinical trial. J Man Manip Ther. 2008; 16(2): 93-9.

13. Huisman PA, Speksnijder CM, de Wijer A: The effect of thoracic spine manipulation on pain and disability in patients with non-specific neck pain: a systematic review. Disabil Rehabil. 2013; 35(20): 1677-85.

14. Walser RF, Meserve BB, Boucher TR: The effectiveness of thoracic spine manipulation for the management of musculoskeletal conditions: a systematic review and meta-analysis of randomized clinical trials. J Man Manip Ther. 2009; 17(4): 237-46.

15. Cleland JA, Childs JD, McRae M, et al.: Immediate effects of thoracic manipulation in patients with neck pain: a randomized clinical trial. Man Ther. 2005; 10(2): 127-35.

16. Suvarnnato T, Puntumetakul R, Kaber D, et al:: The effects of thoracic manipulation versus mobilization for chronic neck pain: a randomized controlled trial pilot study. J Phys Ther Sci. 2013; 25(7): 865-71.

17. Casanova-Méndez A, Oliva-Pascual-Vaca A, Rodriguez-Blanco C, et al.: Comparative shortterm effects of two thoracic spinal manipulation techniques in subjects with chronic mechanical neck pain: a randomized controlled trial. Man Ther. 2014; 19(4): 331-7. 
18. González-Iglesias J, Fernández-de-las-Peñas C, Cleland JA, et al.: Inclusion of thoracic spine thrust manipulation into an electro-therapy/thermal program for the management of patients with acute mechanical neck pain: a randomized clinical trial. Man Ther. 2009; 14(3): 306-13.

19. Salom-Moreno J, Ortega-Santiago R, Cleland JA, et al.: Immediate changes in neck pain intensity and widespread pressure pain sensitivity in patients with bilateral chronic mechanical neck pain: a randomized controlled trial of thoracic thrust manipulation vs non-thrust mobilization. J Manipulative Physiol Ther. 2014; 37(5): 312-9.

20. Cross KM, Kuenze C, Grindstaff TL, et al.: Thoracic spine thrust manipulation improves pain, range of motion, and self-reported function in patients with mechanical neck pain: a systematic review. J Orthop Sports Phys Ther. 2011;41(9): 633-42.

21. Cleland JA, Glynn P, Whitman JM, et al.: Short-term effects of thrust versus nonthrust mobilization/manipulation directed at the thoracic spine in patients with neck pain: a randomized clinical trial. Phys Ther. 2007; 87(4):431-440.

22. Fernández-de-las-Peñas $C$, Palomeque-del-Cerro L, Rodríguez-Blanco $C$, et al:: Changes in neck pain and active range of motion after a single thoracic spine manipulation in subjects presenting with mechanical neck pain: a case series. J Manipulative Physiol Ther. 2007; 30(4): 312-20.

23. Puntumetakul R, Suvarnnato $T$, Werasirirat $P$, et al:: Acute effects of single and multiple level thoracic manipulations on chronic mechanical neck pain: a randomized controlled trial. Neuropsychiatr Dis Treat. 2015; 11: 137-44.

24. Kawchuk GN, Prasad NG, McLeod RC, et al.: Variability of force magnitude and force duration in manual and instrument-based manipulation techniques. J Manipulative Physiol Ther. 2006; 29(8): 611-8.

25. Colloca CJ, Keller TS, Black P, et al.: Comparison of mechanical force of manually assisted chiropractic adjusting instruments. J Manipulative Physiol Ther. 2005; 28(6): 414-22.

26. Wood TG, Colloca CJ, Matthews R: A pilot randomized clinical trial on the relative effect of instrumental (MFMA) versus manual (HVLA) manipulation in the treatment of cervical spine dysfunction. J Manipulative Physiol Ther. 2001; 24(4): 260-71.

27. Shearar KA, Colloca CJ, White HL: A randomized clinical trial of manual versus mechanical force manipulation in the treatment of sacroiliac joint syndrome. J Manipulative Physiol Ther. 2005; 28(7): 493-501.

28. Herzog W: The biomechanics of spinal manipulation. J Bodyw Mov Ther. 2010;14(3): 280-6.

29. Schneider MJ, Brach J, Irrgang JJ, et al.: Mechanical vs manual manipulation for low back pain: An observational cohort study. J Manipulative Physiol Ther. 2010; 33(3): 193-200.

30. Langenfeld A, Humphreys BK, de Bie RA, et al.: Effect of manual versus mechanically assisted manipulations of the thoracic spine in neck pain patients: study protocol of a randomized controlled trial. Trials. 2015; 16: 233.

31. Guzman J, Haldeman S, Carroll LJ, et al.: Clinical practice implications of the Bone and Joint Decade 2000-2010 Task Force on Neck Pain and Its Associated Disorders: from concepts and findings to recommendations. J Manipulative Physiol Ther. 2009; 32(2 Suppl): S227-43.

32. Krauss JR, Evjenth O, Creighton D: Translatoric Spinal Manipulation for Physical Therapists. 1st edition. A Lakeview Media L.L.C. Publication; 2006.

33. Colloca CJ: Neuromechanical Innovations: Impulse Adjusting System. $1^{\text {st }}$ edition. Chandler, Arizona: Neuromechnical Innovations; 2012.

34. Jull GA, Falla D, Treleaven J, et al.: A therapeutic exercise approach for cervical disorders. In Grieves Mod Man Ther verterbral Column. 3rd edition. Edited by Boyling JD, Jull GA. Edinburgh, London, New York, Oxford, Philadelphia, St. Louis, Sydney, Toronto: Elsevier, Churchill, Livingston; 2004; 451-471.

35. O'Leary S, Jull G, Kim M, et al.: Specificity in retraining craniocervical flexor muscle performance. J Orthop Sports Phys Ther. 2007; 37(1): 3-9.

36. Price DD, McGrath PA, Rafii A, et al.: The validation of visual analogue scales as ratio scale measures for chronic and experimental pain. Pain. 1983; 17(1):45-56.

37. Price DD, Bush FM, Long $S$, et al.: A comparison of pain measurement characteristics of mechanical visual analogue and simple numerical rating scales. Pain. 1994; 56(2): 217-226. 
38. DeLoach LJ, Higgins MS, Caplan AB, et al:: The visual analog scale in the immediate postoperative period: intrasubject variability and correlation with a numeric scale. Anesth Analg. 1998; 86(1): 102-106.

39. Williamson A, Hoggart B: Pain: a review of three commonly used pain rating scales. J Clin Nurs. 2005; 14(7): 798-804.

40. Swanenburg J, Humphreys K, Langenfeld A, et al.: Validity and reliability of a German version of the Neck Disability Index (NDI-G). Man Ther. 2014; 19(1): 52-58.

41. Vernon $\mathrm{H}$ : The Neck Disability Index: state-of-the-art, 1991-2008. J Manipulative Physiol Ther. 2008; 31(7): 491-502.

42. Kim SH, Kim HJ, Lee SI, et al.: Comparing the psychometric properties of the EQ-5D-3L and EQ-5D-5L in cancer patients in Korea. Qual Life Res. 2012; 21(6): 1065-73.

43. Janssen MF, Pickard AS, Golicki D, et al.: Measurement properties of the EQ-5D-5L compared to the EQ-5D-3L across eight patient groups: a multi-country study. Qual Life Res. 2013; 22(7): 1717-27.

44. Hurst $\mathrm{H}$, Bolton $\mathrm{J}$ : Assessing the clinical significance of change scores recorded on subjective outcome measures. J Manipulative Physiol Ther. 2004; 27(1): 26-35.

45. Pool JJ, Ostelo RW, Hoving JL, et al.: Minimal clinically important change of the Neck Disability Index and the Numerical Rating Scale for patients with neck pain. Spine (Phila Pa 1976). 2007; 32(26): 3047-3051.

46. Cleland JA, Childs JD, Whitman JM: Psychometric properties of the Neck Disability Index and Numeric Pain Rating Scale in patients with mechanical neck pain. Arch Phys Med Rehabil. 2008; 89(1): 69-74.

47. Schuller W, Ostelo RW, Janssen R, et al.: The influence of study population and definition of improvement on the smallest detectable change and the minimal important change of the neck disability index. Health Qual Life Outcomes. 2014;12: 53.

48. Young BA, Walker MJ, Strunce JB, et al.: Responsiveness of the Neck Disability Index in patients with mechanical neck disorders. Spine J. 2009; 9(10): 802-808.

49. Pereira M, Cruz EB, Domingues $L$, et al:: Responsiveness and Interpretability of the Portuguese Version of the Neck Disability Index in Patients With Chronic Neck Pain Undergoing Physiotherapy. Spine (Phila Pa 1976). 2015; 1.

50. Swanenburg J, Gruber C, Brunner F, et al.: Patients' and therapists' perception of change following physiotherapy in an orthopedic hospital's outpatient clinic. Physiother Theory Pract. 2015; 31(4): 293-8.

51. Farrar JT, Young JP Jr, LaMoreaux L, et al.: Clinical importance of changes in chronic pain intensity measured on an 11-point numerical pain rating scale. Pain. 2001; 94(2): 149-158.

52. Richardson A: The health diary: an examination of its use as a data collection method. J Adv Nurs. 1994; 19(4): 782-791.

53. Takeuchi A, Mamorita N, Sakai F, et al.: Development of a comprehensive medical recorder on a cellphone. Comput Methods Programs Biomed. 2010; 97(1): 28-38.

54. Huggins T, Boras AL, Gleberzon BJ, et al.: Clinical effectiveness of the activator adjusting instrument in the management of musculoskeletal disorders: a systematic review of the literature. J Can Chiropr Assoc. 2012; 56(1): 49-57.

55. Cleland JA, Childs JD, Fritz JM, et al.: Development of a clinical prediction rule for guiding treatment of a subgroup of patients with neck pain: use of thoracic spine manipulation, exercise, and patient education. Phys Ther. 2007; 87(1): 9-23.

56. Haldeman S, Kohlbeck FJ, McGregor M: Unpredictability of cerebrovascular ischemia associated with cervical spine manipulation therapy: a review of sixty-four cases after cervical spine manipulation. Spine (Phila Pa 1976). 2002;27(1): 49-55.

57. Sweeney A, Doody C: Manual therapy for the cervical spine and reported adverse effects: a survey of Irish manipulative physiotherapists. Man Ther.2010; 15(1): 32-6.

58. Thiel HW, Bolton JE, Docherty S, et al.: Safety of chiropractic manipulation of the cervical spine: a prospective national survey. Spine (Phila Pa 1976). 2007; 32(21): 2375-8; discussion 2379.

59. Miley ML, Wellik KE, Wingerchuk DM, et al.: Does cervical manipulative therapy cause vertebral artery dissection and stroke? Neurologist. 2008; 14(1): 66-73. 
60. Thomas LC, Rivett DA, Attia JR, et al.: Risk factors and clinical features of craniocervical arterial dissection. Man Ther. 2011; 16(4): 351-6.

61. Cassidy JD, Boyle E, Côté P, et al.: Risk of vertebrobasilar stroke and chiropractic care: results of a population-based case-control and casecrossover study. Spine (Phila Pa 1976). 2008; 36 : 92; author reply 92.

62. Marx P, Püschmann H, Haferkamp G, et al.: [Manipulative treatment of the cervical spine and stroke]. Fortschr Neurol Psychiatr. 2009; 77(2): 83-90.

63. Murphy DR: Current understanding of the relationship between cervical manipulation and stroke: what does it mean for the chiropractic profession? Chiropr Osteopat. 2010; 18: 22.

64. Noordzij M, Tripepi G, Dekker FW, et al.: Sample size calculations: basic principles and common pitfalls. Nephrol Dial Transplant. 2010; 25(5): 1388-93.

65. Kelly AM: The minimum clinically significant difference in visual analogue scale pain score does not differ with severity of pain. Emerg Med J. 2001; 18(3):205-7.

66. Svedmark $\AA$, Djupsjöbacka M, Häger $C$, et al.: Is tailored treatment superior to non-tailored treatment for pain and disability in women with non-specific neck pain? A randomized controlled trial. BMC Musculoskelet Disord. 2016; 17(1): 408.

67. Langenfeld A, Humphreys BK, de Bie RA, et al.: Dataset 1 in: Comparing manual and mechanically assisted manipulations of the thoracic spine in neck pain patients: A pilot study. F1000Research. 2018. 


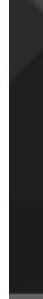




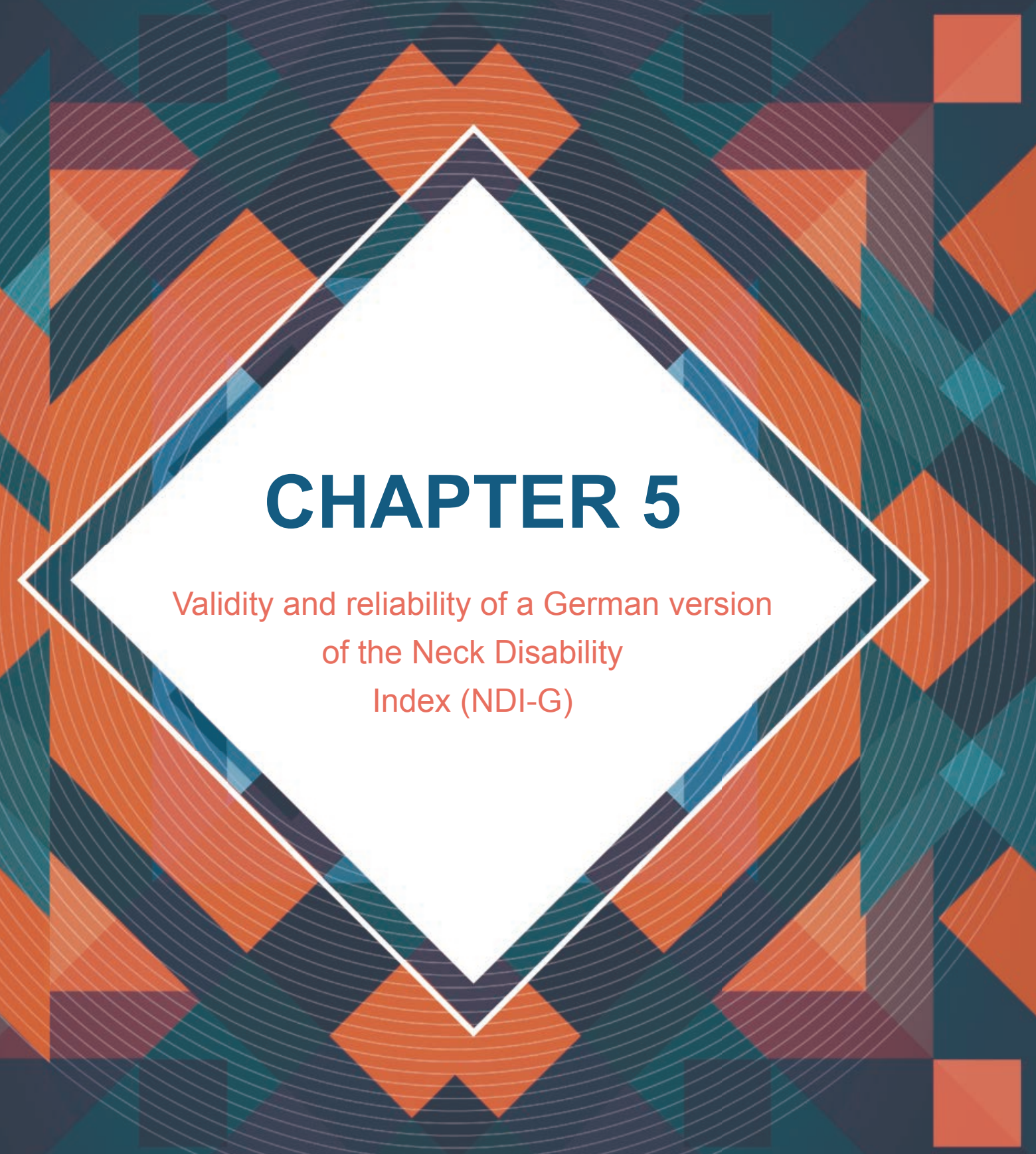

Jaap Swanenburg, Kim Humphreys, Anke Langenfeld, Florian Brunner and Brigitte Wirth

Published: Manual Therapy 19 (2014) 52-58 


\section{Abstract}

The Neck Disability Index (NDI) is a widely used questionnaire in the assessment of disability of neck patients. The aim of this study was to translate the NDI according to established guidelines into German (NDI-G) and to test the psychometric properties. Patients with acute (ACU) and chronic neck pain (CHR) and a healthy control group (HCG) completed the NDI-G twice with a mean test-retest interval of 3 days. The total score of NDI-G showed high reliability (Intraclass correlation coefficient $\left(\mathrm{ICC}_{2,1}\right)=0.92$ ) and a high Cronbach's alpha $(\alpha=0.96)$. The minimal detectable change was 7 points. The BlandAltman plot revealed a small positive systematic error of 1.02 points. The Kruskal-Wallis test showed significant differences in the NDI-G total score among the three groups $\left(X^{2}\right.$. 29.77, $p<0.001$ ). Mann-Whitney $U$ tests showed significant differences in the total score between ACU and HCG ( $p<0.001)$, and CHR and HCG $(p<0.001)$. The factor analysis of NDI-G yielded 2 factors that together explained $67 \%$ of the variance. Spearman's phi coefficients showed no correlation between the NDI-G total score and the visual analogue scale (VAS) in the ACU group (phi $=0.23, p=0.40$ ), and a moderate correlation in the CHR group ( $p h i=0.55, p=0.03$ ). The item analysis of the NDI-G revealed moderate to good reliability for all items. Only the item 'work' could differentiate between the ACU and CHR group. The NDI-G emerged from this study as a valid and reliable assessment. Its psychometric properties are comparable with the original version. Thus, the NDI-G is recommended for research and clinical settings in neck pain in German speaking countries. 


\section{Background}

Neck disorders are a common problem in the today's society. Over $25 \%$ of the population will experience neck pain at some time in their lives ${ }^{1}$. After low back pain, neck pain is the second largest cause of time off work ${ }^{2}$. An often used assessment in this field is the Neck Disability Index (NDI), which is a condition-specific instrument for self-report of disability associated with neck pain ${ }^{3,4}$ It consists of 10 items: pain intensity, personal care, lifting, reading, headaches, concentration, work, driving, sleeping, and recreation ${ }^{3}$. The original NDI has been extensively tested ${ }^{5}$ and has also shown to be a valid and reliable instrument to measure disability related to neck pain in different languages ${ }^{3,4,6-17}$. Although a variety of German NDI versions are used in clinics, none of these versions were validated or tested for reliability. However, a thorough translation process of an assessment consists of producing a version of linguistic and conceptual equivalence to the original and of investigating its validity and reliability ${ }^{18,19}$. Thus, the first aim of this study was to translate the NDI according to a standardized procedure into the German language (NDI-G). The second aim was to test the NDI-G for reliability and validity in patients with acute and chronic neck pain. 


\section{Methods}

\section{Translation process}

After the project was authorized by the author of the original NDI-version (Howard Vernon), the NDI was cross-culturally adapted in five steps according to the guidelines by Beaton 20. In a first step, two native German speakers (a professional translator and a student of human movement sciences) independently translated and culturally adapted the original version. In a second step, a consensus version was produced by synthesizing both translations and discussing disagreements. Third, the consensus version was backwards translated by two professional bilingual translators (both native English-speaking persons). Fourth, a committee of experts involving the investigators and translators produced a prefinal version based on the consensus version and its backwards translations. The whole process was recorded. Fifth, the prefinal version was tested in a group of three patients and six therapists who were asked to critically comment on comprehensibility, wording, and layout. Lastly, the prefinal version of the NDI-G was sent to the author of the original version.

\section{Testing for reliability and validity}

\section{Participants}

Patients with neck pain were recruited from outpatient's clinic of the Balgrist University Hospital Zurich, the physiotherapy department of the University Hospital Zurich and from a private physiotherapy practice. The symptoms were defined as acute if the duration was less than 30 days and as chronic if they lasted for longer than 90 days ${ }^{21}$. Furthermore healthy participants were recruited among the staff of the Balgrist University Hospital and ETH Zurich. Subjects were excluded for arthritis (inflammatory diseases), infections, loco-regional tumor or metastasis, inability to speak and read German fluently and severe psychiatric disorders. The measurements took place at the Physiotherapy Department, Balgrist University Hospital Zurich. All participants gave their informed written consent. The study was approved by the ethics commissions of the Canton of Zürich (KEKZH-Nr: 2011-0303).

\section{Sample size}

The sample size was calculated by the formula of ${ }^{22}$. An ICC value of 0.9 could be expected ${ }^{5,23}$ and ICC values greater than 0.70 wereconsidered to be acceptable ${ }^{24}$. Thus, a sample size of 18 patients was calculated to achieve an agreement of $80 \%$ at a significance level of $0.05^{22}$. 


\section{$N D I-G$}

The NDI-G consists of 10 items referring to various activities (personal care, lifting, driving, work, sleeping, concentration, reading, recreation) and pain (pain intensity, headache) with 6 possible answers per item. Each item is scored from 0 (no pain and no functional limitation) to 5 (worst pain and maximal limitation) points resulting in a maximum possible score of 50 (totally disabled) and a minimal score of 0 (no disability) points ${ }^{3}$. The patients were instructed to choose only one answer, namely the one that most closely suits their condition at the present time.

\section{Study design}

During one visit, demographic characteristics were collected and the NDI-G scale was completed by the chronic neck pain patients (CHR), the acute neck pain patients (ACU), and the healthy control group (HCG). Additionally, the participants were asked to mark their pain on a visual analogue scale (VAS) ${ }^{25}$. After 3-7 days, the patients completed the NDI-G again at home and returned it by mail. If the questionnaire was not returned within 4 days the participant received a reminder telephone call. Subjects who still missed sending the retest back within 7 days were removed from the analysis. As for single missing items, several strategies have been developed ${ }^{5}$. In the present study, one or two missing items were accepted and the averaged score per item (total score divided by 9 or 8 ) was inserted ${ }^{5}$. If three or more items remained unanswered, the administration was regarded as unacceptable and removed from further analyses ${ }^{5}$. An inherent problem of the NDI is that some items, particularly the items 'driving' and 'reading' are not applicable to the life of all patients, which can result in a high number of missing values in these items ${ }^{4}$. If this problem appeared in the present study, an average score per item (total score divided by 9 or 8 ) was inserted ${ }^{4}$. However, for better understanding of these missing values, an open space was provided at the end of NDI-G that allowed for explaining why a question was not answered, as proposed in an earlier study ${ }^{4}$. Additionally, precise instructions were verbally given by the research assistant at the first measurement. The instructions given by the research assistant were the same as those on the questionnaire itself.

\section{Data analysis and statistics}

All analyses apart from discriminative validity were based on the patient data (ACU and (CHR). Descriptive statistics were used to describe the participants' characteristics. Parametric statistical tests ( $\mathrm{ICC}_{2,1}$ and its $95 \%$ confidence interval) were chosen to calculate the relative reliability ${ }^{26}$. ICC results greater than 0.70 were considered to be acceptable ${ }^{27}$. Cronbach's alpha was used to assess the internal consistency of the 
NDI-G. The acceptable range of coefficient alpha values is $0.70-0.95^{19}$. To assess the absolute reliability, the standarderror of measurement (SEM) and the smallest detectable change (SDC) were calculated. The SEM represents the standard deviation of repeated measures in the same patient. The SDC represents the minimal change that a patient must achieve on the scale to ensure that the observed change is a real change and not a change just due to measurement error. The SEM was calculated using the formula SEM $=$ pooled standard deviation of the first and second assessment ${ }^{*} \sqrt{ }(1-I C C){ }^{28}$. The SDC was calculated as $1.96 \times \sqrt{ } 2 \times \mathrm{SEM}^{28}$. Discrepancies between measurements were also assessed by visual interpretation of the amount of agreement of the means of two trials plotted against the difference between the trials (test-retest) (Bland and Altman Plot). The $95 \%$ confidence intervals of these differences represent the smallest detectable difference (SDD), which corresponds to SDC ${ }^{29}$. For construct validity, the ability of the NDI-G to differentiate between ACU, CHR and HCG (discriminative validity) was tested using the Kruskal-Wallis Test and Mann-Whitney $U$ tests as post-hoc tests, and an exploratory factor analysis was conducted. Varimax rotation was applied. Criterion validity was established by correlating the total score of the NDI-G with the VAS. Spearman's coefficient values were interpreted as excellent (>0.9), good (0.7-0.9), moderate (0.5-0.69), fair (0.2-0.5), or minimal to absent $(0.0 \mathrm{e} 0.2)^{30}$. The content validity was assessed by floor and ceiling effects. They were considered to be present if more than $15 \%$ of the respondents achieved the lowest or highest possible total score respectively ${ }^{5}$. In addition to these analyses with the NDI-G total score, absolute and relative reliability as well as discriminative validity were determined for all NDI-G items separately. All analyses were conducted using the IBM-SPSS 20 statistical software (SPSS, Inc., Chicago, IL). The significance level alpha was set at 0.05 and at $0.05 / 3=0.017$ for the post hoc tests. 


\section{Results}

\section{Translation process}

The major differences between NDI-G and the provided German version were found in the items 'personal care', 'lifting' and 'recreation'. Particularly the item 'personal care' was considerably improved for linguistic correctness. In the remaining items only minor modifications were made. The major problem in the translation process was the translation of the adjectives related to pain ('mild', 'moderate', 'severe'). According to the linguist's suggestion,it was decided to translate these words consistently with 'leicht', 'mässig' and 'stark' throughout the whole questionnaire. The replacement of "pain" with "neck pain" in the items pain intensity, personal care and lifting as conducted in other translations ${ }^{4}$ was discussed, but rejected in order to stay as close as possible to the original version. The translated instrument was pretested on three women (mean age.30 \pm 11 years) with acute neck complaints. The general impression of the participants was that the questionnaire and the instructions were easy to understand and that the items were relevant to their situation. Thus, no changes were made to NDI-G after this pretest. NDI-G is shown in Fig. 1.

\section{Testing for reliability and validity}

A total of 51 participants were recruited, 49 of whom completed both measurements there were two drop outs since they missed sending the retest back in time) (Table 1). In two retest questionnaires, three items were missing in total. These questionnaires were complemented by the averaged score per item. Ten participants were not able to drive; two of those were additionally not able to read because of an eye disorder and illiteracy. Both were assisted by the research assistant in the first test and their partners in the retest. These questionnaires were complemented by the averaged score per item. With a value of $\mathrm{ICC}_{2,1}=0.92$, NDI-G showed high reliability. Cronbach's alpha was 0.96 , indicating high correlation among the items in the scale. The SEM was 2.22 and the SDC was 6.16 (Table 2). The Bland-Altman plot (Fig. 2) indicated that all points apart from one lay within the $95 \%$ limits of agreement for test-retest and visual inspection showed no tendency towards heteroscedasticity. A small positive systematic error of 1.02 points was observed. The Kruskal-Wallis test showed significant differences in the NDI-G total score among the three groups $\left(x^{2} .29 .77, p<0.001\right)$ (Table 3$)$. The post-hoc Mann-Whitney $U$ tests showed significant differences in the total score between ACU and HCG $(p<0.001)$ as well as between CHR and HCG ( $p<0.001)$, but not between ACU and CHR $(p=0.02)$. The exploratory factor analysis yielded two factors: Factor 1 , with an eigenvalue of 5.616, 
explained $56 \%$ of the variance; the addition of Factor 2, with an eigenvalue of 1.059 , explained $67 \%$ of the variance. The varimax-rotated factor matrix is presented in Table 4 .

Spearman's phi coefficient values showed no correlation between the NDI-G total score and the VAS in the ACU group ( $p h i=0.23, p=0.40$ ), and a moderate correlation in the CHR group ( $p h i=0.55, p=0.03$ ). There were no floor or ceiling effects. Only one patient of the ACU group scored the lowest possible total score of 0 points. The single item analysis showed ICC ${ }_{2,1}$ values $>0.7$ for all items apart from the item 'reading' $\left(I C C_{2,1}=0.67\right)$ (Table 2). ACU scored significantly different to HCG in all items. The differences between CHR and HCG were significant in all items apart from personal care and work. Only the item 'work' could differentiate between the ACU and CHR group (Table 3). 


\section{NECK DISABILITY INDEX}

Dieser Fragebogen hilft ihrer Ärztin oder ihrem Arzt festzustellen, inwieweit Ihre Nackenschmerzen Ihren Alltag beeinflussen. Bitte wählen Sie aus jedem Abschnitt eine einzige Aussage aus. Wir sind uns bewusst, dass mehrere Aussagen pro Abschnitt auf Sie zutreffen können, doch bitten wir Sie, nur diejenige Aussage zu wählen, welche Ihre Situation am besten beschreibt.

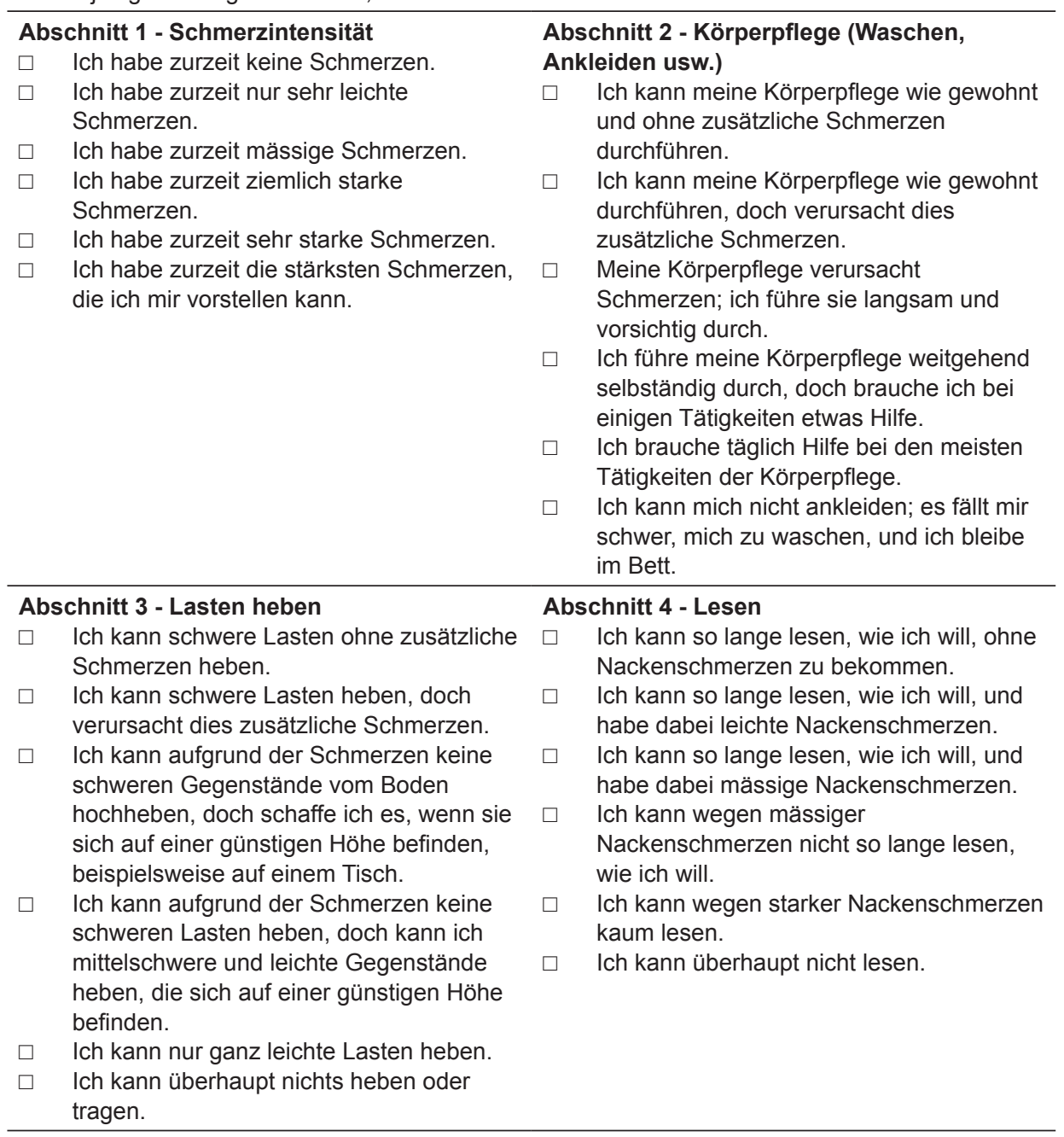




\begin{tabular}{|c|c|}
\hline Abschnit & Absch \\
\hline $\begin{array}{l}\square \quad \text { Ich habe keine Kopfschmerzen. } \\
\square \quad \text { Ich habe selten auftretende, leichte } \\
\text { Kopfschmerzen. } \\
\text { Ich habe selten auftretende, mässige } \\
\text { Kopfschmerzen. } \\
\text { Ich habe häufig auftretende, mässige } \\
\text { Kopfschmerzen. } \\
\text { Ich habe häufig auftretende, starke } \\
\text { Kopfschmerzen. } \\
\text { Ich habe fast immer Kopfschmerzen. }\end{array}$ & $\begin{array}{ll}\square & \text { Ich kann mich problemlos voll } \\
\text { konzentrieren, wann immer ich will. } \\
\square \quad \text { Ich kann mich mit leichten Schwierigkeiten } \\
\text { voll konzentrieren, wann immer ich will. } \\
\square \quad \text { Es fällt mir ziemlich schwer, mich zu } \\
\text { konzentrieren. } \\
\square \quad \text { Es fällt mir sehr schwer, mich zu } \\
\text { konzentrieren. } \\
\square \quad \text { Es bereitet mir grösste Mühe, mich zu } \\
\text { konzentrieren. } \\
\square \quad \text { Ich kann mich überhaupt nicht } \\
\text { konzentrieren. }\end{array}$ \\
\hline $\begin{array}{l}\text { Abschnitt } 7 \text { - Arbeit } \\
\square \quad \text { Ich kann so viel arbeiten, wie ich will. } \\
\square \quad \text { Ich kann meine gewohnte Arbeit erledigen, } \\
\text { jedoch nicht mehr. } \\
\square \quad \text { Ich kann meine gewohnte Arbeit } \\
\quad \text { grösstenteils erledigen, jedoch nicht mehr. } \\
\square \quad \text { Ich kann meine gewohnte Arbeit nicht } \\
\quad \text { erledigen. } \\
\square \quad \text { Ich kann kaum arbeiten. } \\
\square \quad \text { Ich kann überhaupt nicht arbeiten. }\end{array}$ & $\begin{array}{l}\text { Abschnitt } 8 \text { - Autofahren } \\
\square \quad \text { Ich kann ohne Nackenschmerzen Auto } \\
\text { fahren. } \\
\square \quad \text { Ich kann so lange Auto fahren, wie ich will, } \\
\text { und habe dabei leichte Nackenschmerzen. } \\
\square \quad \text { Ich kann so lange Auto fahren, wie } \\
\text { ich will, und habe dabei mässige } \\
\text { Nackenschmerzen. } \\
\quad \text { Ich kann wegen mässiger } \\
\text { Nackenschmerzen nicht so lange Auto } \\
\text { fahren, wie ich will. } \\
\quad \text { Ich kann wegen starker Nackenschmerzen } \\
\text { kaum Auto fahren. } \\
\square \quad \text { Ich kann überhaupt nicht Auto fahren. }\end{array}$ \\
\hline $\begin{array}{l}\text { Abschnitt } 9 \text { - Schlafen } \\
\square \quad \text { Ich kann problemlos schlafen. } \\
\square \quad \text { Mein Schlaf ist sehr leicht gestört (ich } \\
\text { liege weniger als } 1 \text { Stunde wach). } \\
\square \quad \text { Mein Schlaf ist leicht gestört (ich liege 1-2 } \\
\text { Stunden wach). } \\
\square \quad \text { Mein Schlaf ist mässig gestört (ich liege } \\
2-3 \text { Stunden wach). } \\
\quad \text { Mein Schlaf ist stark gestört (ich liege 3-5 } \\
\text { Stunden wach). } \\
\quad \text { Mein Schlaf ist völlig gestört (ich liege 5-7 } \\
\text { Stunden wach). }\end{array}$ & 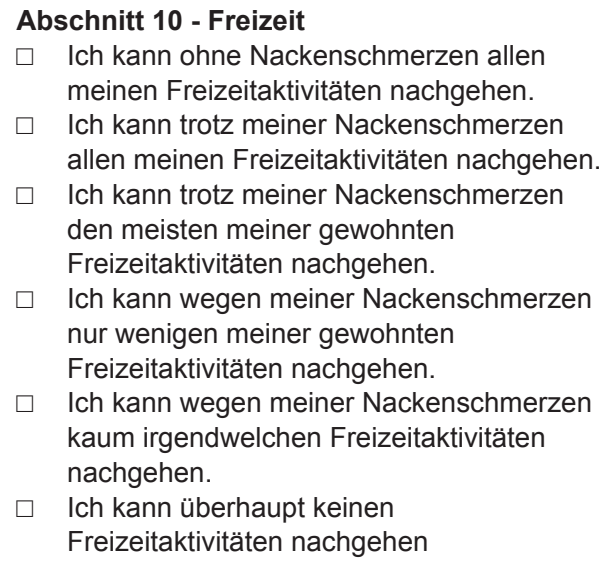 \\
\hline
\end{tabular}

Ich kann Frage nicht beantworten weil... Ich kann Frage _ n nicht beantworten weil... 


\begin{tabular}{lccc}
\hline & $\begin{array}{c}\text { Acute } \\
\text { neck pain } \\
\text { group } \\
(\mathrm{n}=16)\end{array}$ & $\begin{array}{c}\text { Chronic } \\
\text { neck pain } \\
\text { group } \\
(\mathrm{n}=16)\end{array}$ & $\begin{array}{c}\text { Healthy } \\
\text { control } \\
\text { group } \\
(\mathrm{n}=17)\end{array}$ \\
\hline Female & 14 & 11 & 11 \\
Male & 2 & 5 & 6 \\
Age; years (SD) & $34(10)$ & $39(13)$ & $43(20)$ \\
Range & $23 / 59$ & $20 / 61$ & $20 / 81$ \\
Weight; kg (SD) & $64(20)$ & $66(16)$ & $65(14)$ \\
Height; cm (SD) & $168(8)$ & $170(12)$ & $169(8)$ \\
VAS; cm (SD) & $4.1(2.2)$ & $3.0(2.2)$ & $0.1(0.1)$ \\
NDI (SD) & & & \\
first measurement & $19.6(7.8)$ & $12.6(7.9)$ & $1.8(2.4)$ \\
second measurement & $17.3(6.6)$ & $12.8(7.4)$ & $1.6(2.6)$ \\
Trauma (yes/no) & $16 / 0$ & $8 / 8$ & - \\
Onset of the problem, weeks (SD) & $2.1(1.1)$ & $199.3(357.5)$ & - \\
\hline
\end{tabular}

Table 2 Test-Retest Reliability and Agreement parameters of the NDI-G (all items) in all neck patients $(n=32)$

\begin{tabular}{lcccccc}
\hline & $\begin{array}{c}\text { 1st measurement } \\
\text { mean (SD) }\end{array}$ & $\begin{array}{c}\text { 2nd measurement } \\
\text { mean (SD) }\end{array}$ & $\begin{array}{c}\text { ICC } \\
(95 \% \mathrm{Cl})\end{array}$ & $\begin{array}{c}\text { Cronbach's } \\
\text { alpha }\end{array}$ & SDC & SEM \\
\hline NDI-G & 16.09 & 15.07 & 0.92 & 0.96 & 6.16 & 2.22 \\
Total score & $(8.49)$ & $(7.24)$ & $(0.84 / 0.96)$ & & & \\
Item 1 & & & & & & \\
Pain intensity & 1.91 & 1.63 & 0.74 & na & 1.24 & 0.45 \\
Item 2 & $(0.93)$ & $(0.83)$ & $0.53 / 0.87$ & & & \\
Personal care & 0.72 & 0.69 & 0.77 & na & 1.16 & 0.42 \\
Item 3 & $(0.92)$ & $(0.82)$ & $0.58 / 0.88$ & & & \\
Lifting & 1.28 & 1.09 & 0.78 & na & 1.24 & 0.45 \\
Item 4 & $(1.05)$ & $(0.86)$ & $0.59 / 0.88$ & & & \\
Reading & 2.03 & 1.86 & 0.67 & na & 1.91 & 0.69 \\
Item 5 & $(1.17)$ & $(1.23)$ & $0.42 / 0.82$ & & & \\
Headaches & 2.31 & 2.09 & 0.76 & na & 1.90 & 0.68 \\
Item 6 & $(1.49)$ & $(1.30)$ & $0.56 / 0.87$ & & & \\
Concentration & 1.16 & 1.16 & 0.75 & na & 1.22 & 0.44 \\
Item 7 & $(0.92)$ & $(0.85)$ & $0.55 / 0.87$ & & & \\
Work & 1.44 & 1.38 & 0.91 & na & 0.99 & 0.36 \\
Item 8 & $(1.24)$ & $(1.13)$ & $0.82 / 0.96$ & & & \\
Driving & 1.75 & 1.74 & 0.79 & na & 1.23 & 0.44 \\
Item 9 & $(1.05)$ & $(0.88)$ & $0.62 / 0.89$ & & & \\
Sleeping & 1.63 & 1.53 & 0.92 & na & 1.05 & 0.38 \\
Item 10 & $(1.41)$ & $(1.27)$ & $0.85 / 0.96$ & & & \\
Recreation & 1.88 & 1.91 & 0.77 & na & 1.67 & 0.60 \\
\hline & $(1.29)$ & $(1.23)$ & $0.57 / 0.88$ & & & \\
\hline
\end{tabular}


Table 3 Discriminative validity of the NDI-G for ACU, CHR, and HCG.

\begin{tabular}{|c|c|c|c|c|}
\hline & \multirow[t]{2}{*}{$\begin{array}{c}\text { Kruskal-Wallis } \\
x^{2}(p)\end{array}$} & \multicolumn{3}{|c|}{$\begin{array}{c}\text { Post-hoc test } \\
\text { Mann-Whitney U }\end{array}$} \\
\hline & & $\begin{array}{c}\mathrm{ACU} / \mathrm{CHR} \\
\mathrm{p}\end{array}$ & $\begin{array}{c}\text { ACU/HCG } \\
p\end{array}$ & $\begin{array}{c}\mathrm{CHR} / \mathrm{HCG} \\
\mathrm{p}\end{array}$ \\
\hline $\begin{array}{l}\text { NDI-G } \\
\text { Total score }\end{array}$ & $\begin{array}{c}29.77 \\
(p<0.001)^{a}\end{array}$ & 0.021 & $<0.001^{b}$ & $<0.001^{b}$ \\
\hline $\begin{array}{l}\text { Item } 1 \\
\text { Pain intensity }\end{array}$ & $\begin{array}{c}30.87 \\
(p<0.001)^{a}\end{array}$ & 0.196 & $<0.001^{b}$ & $<0.001^{b}$ \\
\hline $\begin{array}{l}\text { Item } 2 \\
\text { Personal care }\end{array}$ & $\begin{array}{c}11.12 \\
(p=0.004)^{a}\end{array}$ & 0.323 & $0.014^{b}$ & 0.068 \\
\hline $\begin{array}{l}\text { Item } 3 \\
\text { Lifting }\end{array}$ & $\begin{array}{c}23.55 \\
(p<0.001)^{a}\end{array}$ & 0.080 & $<0.001^{b}$ & $0.001^{b}$ \\
\hline $\begin{array}{l}\text { Item } 4 \\
\text { Reading }\end{array}$ & $\begin{array}{c}24.34 \\
(p<0.001)^{a}\end{array}$ & 0.029 & $<0.001^{b}$ & $0.001^{b}$ \\
\hline $\begin{array}{l}\text { Item } 5 \\
\text { Headaches }\end{array}$ & $\begin{array}{c}11.36 \\
(p=0.003)^{a}\end{array}$ & 0.926 & $0.005^{b}$ & $0.003^{b}$ \\
\hline $\begin{array}{l}\text { Item } 6 \\
\text { Concentration }\end{array}$ & $\begin{array}{c}21.57 \\
(p<0.001)^{a}\end{array}$ & 0.056 & $<0.001^{b}$ & $0.003^{b}$ \\
\hline $\begin{array}{l}\text { Item } 7 \\
\text { Work }\end{array}$ & $\begin{array}{c}30.82 \\
(p<0.001)^{a}\end{array}$ & $<0.001^{b}$ & $<0.001^{b}$ & 0.068 \\
\hline $\begin{array}{l}\text { Item } 8 \\
\text { Driving }\end{array}$ & $\begin{array}{c}24.20 \\
(p<0.001)^{a}\end{array}$ & 0.224 & $<0.001^{b}$ & $<0.001^{b}$ \\
\hline $\begin{array}{l}\text { Item } 9 \\
\text { Sleeping }\end{array}$ & $\begin{array}{c}17.45 \\
(p<0.001)^{a}\end{array}$ & 0.073 & $<0.001^{b}$ & $0.017^{b}$ \\
\hline $\begin{array}{l}\text { Item } 10 \\
\text { Recreation }\end{array}$ & $\begin{array}{c}23.98 \\
(p<0.001)^{a}\end{array}$ & 0.138 & $<0.001^{b}$ & $<0.001^{b}$ \\
\hline
\end{tabular}




\begin{tabular}{|c|c|c|}
\hline & 1 & 2 \\
\hline $\begin{array}{l}\text { Item } 1 \\
\text { Pain intensity }\end{array}$ & $.872^{a}$ & .008 \\
\hline $\begin{array}{l}\text { Item } 2 \\
\text { Personal care }\end{array}$ & $.673^{a}$ & .316 \\
\hline $\begin{array}{l}\text { Item } 3 \\
\text { Lifting }\end{array}$ & $.707^{\mathrm{a}}$ & .400 \\
\hline $\begin{array}{l}\text { Item } 4 \\
\text { Reading }\end{array}$ & $.724^{a}$ & .446 \\
\hline $\begin{array}{l}\text { Item } 5 \\
\text { Headaches }\end{array}$ & .099 & $.738^{a}$ \\
\hline $\begin{array}{l}\text { Item } 6 \\
\text { Concentration }\end{array}$ & .414 & $.684^{\mathrm{a}}$ \\
\hline $\begin{array}{l}\text { Item } 7 \\
\text { Work }\end{array}$ & $.560^{a}$ & .528 \\
\hline $\begin{array}{l}\text { Item } 8 \\
\text { Driving }\end{array}$ & .600 & $.654^{\mathrm{a}}$ \\
\hline $\begin{array}{l}\text { Item } 9 \\
\text { Sleeping }\end{array}$ & .204 & $.820^{a}$ \\
\hline $\begin{array}{l}\text { Item } 10 \\
\text { Recreation }\end{array}$ & $.789^{a}$ & .257 \\
\hline
\end{tabular}

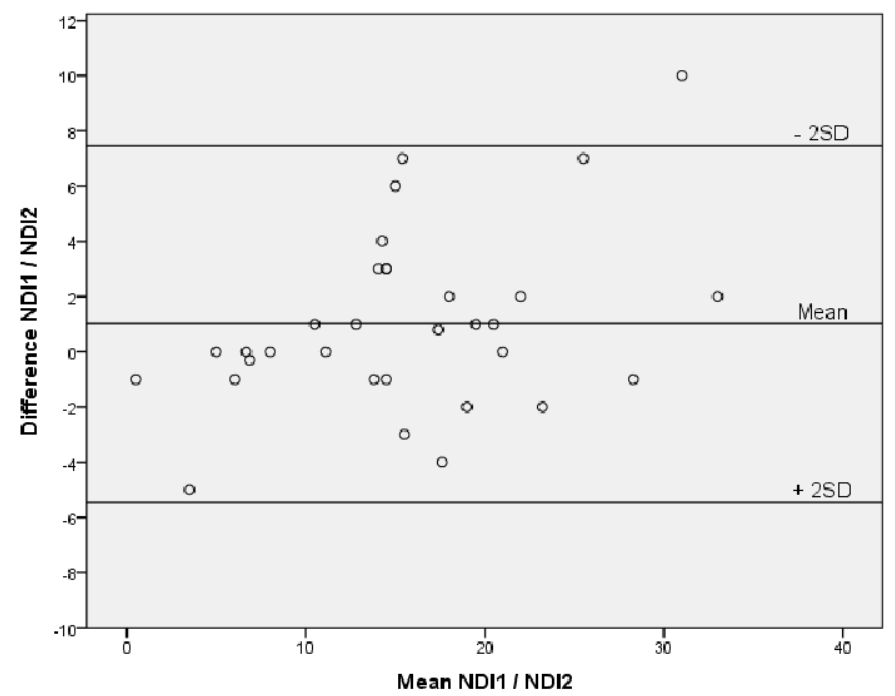

Fig. 2. Mean score of each patient plotted against the difference between test-retest scores of NDI-G. NDI 1. first measurement, NDI 2. second measurement. 


\section{Discussion}

The present study was conducted with the purpose of translating the original NDI according to literature guidelines into German (NDI-G) and to validate the psychometric properties of NDI-G. Other existing non-validated German versions were imprecisely translated into the German language, especially with in terms of the item 'personal care'. In this study, we thus attempted to maximize comprehensibility of the questionnaire. For this reason a linguist was part of the study team. The high test-retest reliability of NDI-G was well in the range of the original paper ${ }^{5,23}$ and of other translations ${ }^{4,6}$. The high Cronbach alpha of 0.96 , however, scored above the results from other studies $(0.74-0.93){ }^{5}$. Although this value is close to the acceptable range of $0.70-0.9518,19$ this might be a slight limitation of NDIG. The SDC of 6.2 points indicates that an individual change of seven points or above after a given intervention would not only be a measurement error, but could be attributed to the intervention. This result is in the range of the SDC scores of other studies (2-16points) $4,31,32,33,34$. For uncomplicated neck pain, a recent systematic review reported the SDC to be around 5 points out of 50 , while it is around 10 out of 50 for cervical radiculopathy ${ }^{23}$. Also the small systematic error of 1 point found in the Bland and Altman plot is in the range of the results of other studies ${ }^{4,6,32,34}$, although most studies found negative systematic errors. However, the systematic error strongly depends on the patient collective as well as on the test-retest interval. In the present study, the error might be caused by the ACU group. In this group, an improvement from 19.6 to 17.3 points was observed from the first to the second measurement, while the results of the chronic patients were stable (12.6 and 12.8 points). The slight improvement in ACU might be due to a spontaneous improvement. Although it was smaller than the SDC, the unstable stage of the ACU group is a further limitation of the present study as it might have influenced other measures. In a further study, either the stability of the stage should be assessed or the test-retest interval should be shortened. The factorial structure of the NDI and its translations has thus far been analyzed in a small number of studies ${ }^{35}$.For the original version ${ }^{35,36}$ and some translations $4,7,16,34$ a one-factor structure was found. However, several translations found a two-factor structure $6,12,17$ explaining $54-56 \%$ of variance. The present study found a two-factor structure that explained $67 \%$ of variance. Similarly to the other studies this structure could be explained as one factor being associated with "pain and functional disability" (items $1,2,3,4,7,10$ ) and a second factor being related to "cognitive functioning" (items 5,6,8,9). In contrast to the previous studies, however, the item pain was associated with function, but the item driving with concentration. However, cultural difference scan influence an assessment's factorial structure ${ }^{35}$. Thus, despite some discrepancies compared to other 
studies that found a two-factor solution, a second factor associated with cognitive function was observed also for NDI-G. The single item analysis of NDI-G showed that only the item "work" could differentiate between ACU and CHR. Although the difference in pain intensity between these groups was only minor (mean 2.1 points for ACU and 1.7 for CHR in item 1) and not significant, work was differently affected by the neck problem in both groups (mean 2.3 points for ACU and 0.6 points for CHR in item 7). This discrepancy might be due to differences in coping strategies or self-efficacy, which might be differently affected dependent on neck pain aetiology (traumatic or non-traumatic). While all of the ACU groups were trauma related, only half of the CHR were due to trauma. However, the reason for this interesting finding needs further investigation. Despite no significant difference, the ACU group suffered to a higher extent from sleeping disturbances (mean 2.1 points) and concentration problems (mean 1.5 points) than the CHR group (1.1 and 0.8 points, respectively). This might mirror some of the cognitive symptoms that can be associated with traumatic neck injuries. However, a further study should also assess the patients working capacity and profession in order to draw conclusions on this issue.

The sample of the present study was small and heterogeneous in terms of aetiology of neck pain which both could have impacted the psychometric properties values. In addition, the test-retest interval was short in order to keep the clinical stage of the ACU patients as stable as possible. Some recall effects can thus not completely be ruled out. For optimization of this trade-off, however, a further study should assess the stability of the neck problem. Nevertheless, in summary, the NDI-G showed acceptable psychometric properties that corresponded to those of translations in other languages. The present study did, however, not assess responsiveness, which is necessary for the complete coverage of an assessment's psychometric properties ${ }^{19}$. Future research should therefore assess these instruments' sensitivity to changes over time after rehabilitative interventions. Patient's sick leave duration and their return to work status were not assessed in this study. These variables might be potential confounders to the NDI score. Thus, future studies should assess these parameters. Lastly, it must be borne in mind that this study was conducted in the German speaking part of Switzerland. Nonetheless, since rather the linguistic aspect than the cultural adaptation was the challenge in the translation process and a professional linguistic was part of the study team, NDI-G can nevertheless also be recommended for the use in other German-speaking countries. 


\title{
Conclusion
}

NDI-G is the first German version of the NDI that was translated and validated strictly according to the guidelines in literature. Ist psychometric properties are comparable with the original version and other translations. Thus, the NDI-G can be recommended as a useful tool for researchers and clinicians in German speaking countries. Thus, the NDI-G can be recommended as a useful tool for researchers and clinicians in German speaking countries. Consecutive studies that include clinically stable patients and assess sick leave duration and work status as well as the NDI-G responsiveness are needed.

\section{Competing interests}

The authors declare that they have no competing interests.

\section{Acknowledgements}

We thank the original author of the NDI, Howard Vernon, for his permission to conduct this study and the Swiss Association of Physiotherapy for the financial support of the project. The authors further thank Jacqueline Hefti Widmer, Nino Hunter and Leanne Pobjoy for their translation work and Jonathan Widmer, Dieter Elsner, Ulrike Juelich of the cervical spine group of the University Hospital Zurich and Nadja Meier from Balgrist University Hospital for recruiting the patients. In addition we like to thank the department of Physical Medicine and Rheumatology at Balgrist University Hospital and the Balgrist Foundation for providing organizational help and supporting the physiotherapy research.

\author{
Abbreviations \\ ACU Acute neck pain patients \\ CHR Chronic neck pain patients \\ HCG Healthy control group \\ NDI Neck disability index \\ NDI-G Neck disability index German version \\ ICC Intraclass correlation coefficient
}




\section{References}

1. Peloso P, Gross A, Haines T, Trinh K, Goldsmith CH, Burnie S. Medicinal and injection therapies for mechanical neck disorders. Cochrane Database Syst Rev 2007;(3): CD000319. PhiladelphiaPanel. Philadelphia Panel evidence-based clinical practice guidelines on selected rehabilitation interventions for shoulder pain. Phys Ther 2001;81(10):1719-30.

2. Philadelphia-Panel. Philadelphia Panel evidence-based clinical practice guidelines on selected rehabilitation interventions for shoulder pain. Phys Ther 2001;81(10):1719-30.

3. Vernon $\mathrm{H}$, Mior S. The neck disability index: a study of reliability and validity. J Manipulative Physiol Ther 1991;14(7):409-15.

4. Trouli MN, Vernon HT, Kakavelakis KN, Antonopoulou MD, Paganas AN, Lionis CD. Translation of the neck disability index and validation of the Greek version in a sample of neck pain patients. BMC Musculoskelet Disord 2008;9:106.

5. Vernon H. The neck disability index: state-of-the-art, 1991e2008. J Manipulative Physiol Ther 2008;31(7):491-502.

6. Wlodyka-Demaille S, Poiraudeau S, Catanzariti JF, Rannou F, Fermanian J, Revel M. French translation and validation of 3 functional disability scales for neck pain. Arch Phys Med Rehabil 2002;83(3):376-82.

7. Cook C, Richardson JK, Braga L, Menezes A, Soler X, Kume P, et al. Cross-cultural adaptation and validation of the Brazilian Portuguese version of the neck disability index and neck pain and disability scale. Spine (Phila Pa 1976) 2006;31(14):1621-7

8. Lee H, Nicholson LL, Adams RD, Maher CG, Halaki M, Bae SS. Development and psychometric testing of Korean language versions of 4 neck pain and disability questionnaires. Spine (Phila Pa 1976) 2006;31(16):1841-5.

9. Vos CJ, Verhagen AP, Koes BW. Reliability and responsiveness of the Dutch version of the neck disability index in patients with acute neck pain in general practice. Eur Spine J 2006;15(11):172936.

10. Mousavi SJ, Parnianpour M, Montazeri A, Mehdian H, Karimi A, Abedi M, et al. Translation and validation study of the Iranian versions of the neck disability index and the neck pain and disability scale. Spine (Phila Pa1976) 2007;32(26):E825-31.

11. Aslan E, Karaduman A, Yakut Y, Aras B, Simsek IE, Yagly N. The cultural adaptation, reliability and validity of neck disability index in patients with neck pain: a Turkish version study. Spine (Phila Pa 1976) 2008;33(11):E362-5.

12. Nieto R, Miro J, Huguet A. Disability in subacute whiplash patients: usefulness of the neck disability index. Spine (Phila Pa 1976) 2008;33(18):E630-5.

13. Andrade Ortega JA, Delgado Martinez AD, Almecija Ruiz R. Validation of the Spanish version of the neck disability index. Spine (Phila Pa 1976) 2010;35(4):E114e8.

14. Salo P, Ylinen J, Kautiainen H, Arkela-Kautiainen M, Hakkinen A. Reliability and validity of the finnish version of the neck disability index and the modified neck pain and disability scale. Spine (Phila Pa 1976) 2010;35(5):552-6.

15. Wu S, Ma C, Mai M, Li G. Translation and validation study of Chinese versions of the neck disability index and the neck pain and disability scale. Spine (Phila Pa 1976) 2010;35(16):1575-9.

16. Misterska E, Jankowski R, Glowacki M. Cross-cultural adaptation of the neck disability index and Copenhagen neck functional disability scale for patients with neck pain due to degenerative and discopathic disorders. Psychometric properties of the polish versions. BMC Musculoskelet Disord 2011;12:84.

17. Monticone M, Ferrante S, Vernon H, Rocca B, Dal Farra F, Foti C. Development of the Italian version of the neck disability index: cross-cultural adaptation, factoranalysis, reliability, validity, and sensitivity to change. Spine (Phila Pa 1976) 2012;37(17):E1038-44.

18. Terwee CB, Dekker FW, Wiersinga WM, Prummel MF, Bossuyt PM. On assessing responsiveness of health-related quality of life instruments: guidelines for instrument evaluation. Qual Life Res 2003;12(4):349-62. 
19. Terwee CB, Bot SD, de Boer MR, van der Windt DA, Knol DL, Dekker J, et al. Quality criteria were proposed for measurement properties of health status questionnaires. $\mathrm{J}$ Clin Epidemiol 2007;60(1):34-42.

20. Beaton DE, Bombardier C, Guillemin F, Ferraz MB. Guidelines for the process of cross-cultural adaptation of self-report measures. Spine (Phila Pa 1976) 2000;25(24):3186-91.

21. Gross A, Miller J, D'Sylva J, Burnie SJ, Goldsmith $\mathrm{CH}$, Graham N, et al. Manipulation or mobilisation for neck pain: a Cochrane Review. Man Ther 2010;15(4):315-33.

22. Walter SD, Eliasziw M, Donner A. Sample size and optimal designs for reliability studies. Stat Med 1998;17(1):101-10.

23. MacDermid JC, Walton DM, Avery S, Blanchard A, Etruw E, McAlpine C, et al. Measurement properties of the neck disability index: a systematic review. J Orthop Sports Phys Ther 2009;39(5):400-17

24. Briggs KK, Lysholm J, Tegner Y, RodkeyWG, Kocher MS, Steadman JR. The reliability,validity, and responsiveness of the Lysholm score and Tegner activity scale for anterior cruciate ligament injuries of the knee: 25 years later. Am J Sports Med 2009a;37(5):890-7.

25. Huskisson EC. Measurement of pain. Lancet 1974;2(7889):1127-31.

26. Swanenburg J, de Bruin ED, Favero K, Uebelhart D, Mulder T. The reliability of postural balance measures in single and dual tasking in elderly fallers and nonfallers. BMC Musculoskelet Disord 2008;9.

27. Briggs KK, Steadman JR, Hay CJ, Hines SL. Lysholm score and Tegner activity level in individuals with normal knees. Am J Sports Med 2009b;37(5):898-901.

28. de Vet HCW, Terwee CB, Knol DL, Bouter LM. When to use agreement versus reliability measures. J Clin Epidemiol 2006;59(10):1033-9.

29. Bland JM, Altman DG. Statistical methods for assessing agreement between two methods of clinical measurement. Lancet 1986;1(8476):307-10.

30. Siegel S, Castellan JNJ. Nonparametric statistics for the behavioral sciences. 2nd ed. Boston Massachusetts: McGraw Hill, Inc; 1988.

31. Pool JJ, Ostelo RW, Hoving JL, Bouter LM, de Vet HC. Minimal clinically important change of the neck disability index and the numerical rating scale for patients with neck pain. Spine (Phila Pa 1976) 2007;32(26):3047-51.

32. Jorritsma W, de Vries GE, Geertzen JH, Dijkstra PU, Reneman MF. Neck pain and disability scale and the neck disability index: reproducibility of the Dutch language versions. Eur Spine $J$ 2010;19(10):1695-701.

33. Young IA, Cleland JA, Michener LA, Brown C. Reliability, construct validity, and responsiveness of the neck disability index, patient-specific functional scale, and numeric pain rating scale in patients with cervical radiculopathy. Am J Phys Med Rehabil 2010;89(10):831-9.

34. Uthaikhup S, Paungmali A, Pirunsan U. Validation of Thai versions of the neck disability index and neck pain and disability scale in patients with neck pain. Spine (Phila Pa 1976) 2011;36(21):E1415-21.

35. Pickering PM, Osmotherly PG, Attia JR, McElduff P. An examination of outcome measures for pain and dysfunction in the cervical spine: a factor analysis. Spine (Phila Pa 1976) 2011;36(7):581-8.

36. Hains F, Waalen J, Mior S. Psychometric properties of the neck disability index. J Manipulative Physiol Ther 1998;21(2):75-80. 



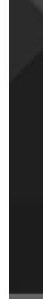




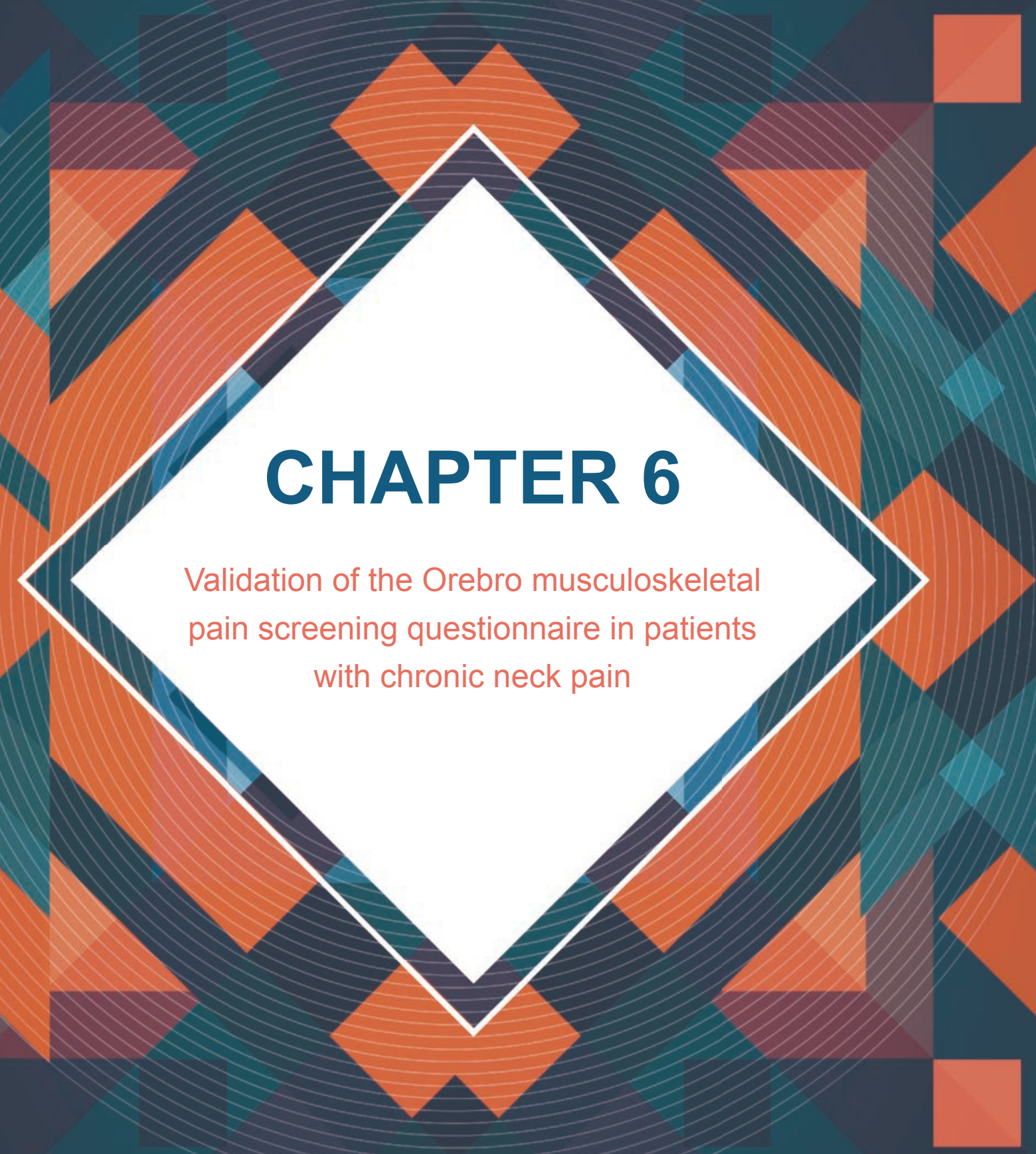

Anke Langenfeld, Carolien Bastiaenen, Florian Brunner and Jaap Swanenburg

Published: BMC Res Notes (2018) 11:161 https://doi.org/10.1186/s13104-018-3269-x 


\begin{abstract}
Objectives: To validate the German version of OMPSQ (OMPSQ-G) for patients with chronic neck pain.

Results: After translating OMPSQ to German, we assessed the discriminant validity between patients and healthy adults. Convergent validity was assessed using Pearson's correlation coefficients between domains of OMPSQ-G and the German version of neck disability index (NDI-G) and visual analogue scale (VAS) of neck pain intensity. Floor and ceiling effects, internal consistency, test-retest and relative reliability were assessed. Fifty patients with chronic neck pain (mean age, 43.6 years; 34 females) and 24 healthy adults (mean age, 50.4 years; 18 females) participated. Mann-Whitney $U$ tests showed significant differences in OMPSQ scores between both groups at the baseline $(z=-4.6 ; p$ $<0.001)$ and second time point $(z=-4.8 ; p<0.001)$. OMPSQ-G scores highly and moderately correlated with NDI-G $(\rho=0.70)$ and VAS $(\rho=0.41)$ scores, respectively. There were no floor or ceiling effects. Cronbach's alpha was 0.94. OMPSQ-G showed high reliability (intraclass correlation 2.1: 0.93; standard error of measurement, 6.9; smallest detectable change, 20 points). The Bland-Altman plot indicated no systematic error. OMPSQ-G showed good validity and reliability in patients with neck pain.
\end{abstract}

Trial registration NCT02540343

Keywords: Validation, OMPSQ, Chronic, Neck pain 


\section{Introduction}

Neck pain is a common complaint that affects $70 \%$ of individuals at least once in their lifetime [1]. Only low back pain (LBP) causes more time off work than neck pain ${ }^{2}$. A frequently used assessment of LBP is the Orebro musculoskeletal pain screening questionnaire (OMPSQ), developed by Linton and Hallden ${ }^{3}$ OMPSQ can be used to identify patients with spinal pain ${ }^{4}$. OMPSQ has been translated into French, Turkish, Spanish, Chinese, Brazilian-Portuguese, Persian ${ }^{5-10}$, including a short form of the questionnaire ${ }^{11}$. The short-form OMPSQ has been translated into German ${ }^{12}$. The original (long-form) version has not previously been translated into German and tested for its psychometric properties. To date, OMPSQ has been mainly used in patients with LBP, and few authors have reported using OMPSQ in patients with neck pain ${ }^{13,14}$. They concluded that OMPSQ could be used as tool for predicting functional outcomes at 8 weeks after the initial manual therapy assessment in patients with LBP, whereas the ability for predicting outcomes of patients with neck pain is uncertain. Gabel et al. ${ }^{14}$ used the OMPSQ to investigate patients with whiplash-associated disorder. So far the original German version of OMPSQ has not previously been validated in patients with chronic neck pain. This study aimed to evaluate OMPSQ-G in German-speaking patients with chronic neck pain. In addition, discriminant and construct validity and reliability were evaluated. 


\section{Methods}

\section{Study design}

This is a translation and validation study. At the beginning the original OMPSQ was translated and culturally adapted into German and afterwards tested for ist validity and reliability in patients with chronic neck pain.

\section{Questionnaire translation process}

This project was authorised by the author of the original OMPSQ. Language translation was based on the original OMPSQ ${ }^{3}$. The cross-cultural adaptation and translation followed the guidelines for the process of cross-cultural adaption of self-report measures by Beaton et al. ${ }^{15}$. Two independent native German speakers translated and culturally adapted the original version. After a consensus meeting, two additional translators back-translated the German version of OMPSQ into English. The pre-final German version of OMPSQ (OMPSQ-G) was pre-tested in five healthy German-speaking volunteers, revealing no difficulties in understanding the questionnaire. Finally, the expert committee concluded that no further adaptations to OMPSQ-G were required.

\section{Study sample}

From November 2014 until October 2016, 50 patients with chronic neck pain were recruited from the department of chiropractic medicine at Balgrist University Hospital. All patients had chronic neck pain for at least 90 days before enrolling for the study 16 and were able to speak, read and write German. Patients were excluded for 'red flags' such as acute trauma, severe pain, signs of spinal cord compression and acute inflammatory arthritis. Furthermore, a group of 26 healthy adults without neck pain were recruited from a local clinic. As recommended by the ethics committee, these subjects should not have any medical knowledge or background.

\section{Study procedure}

During a baseline visit, demographic characteristics were collected, and all participants were asked to independently complete three questionnaires [OMPSQ, NDI and visual analogue scale (VAS)]. After 3-7 days, all participants were asked to independently complete all questionnaires a second time at home and to send them back in a prepaid envelope. Therefore, it can be assumed that the conditions were similar when the participants filled out both the questionnaires. If the questionnaires were not returned by day 4 , the participant received a reminder telephone call. Participants who did not 
return the questionnaires by day 7 were excluded from the study. The mean imputation was conducted for values missing from OMPSQ-G 17. If more than three items of the questionnaire were unanswered, the questionnaire was excluded from further analyses ${ }^{18}$.

\section{Outcome measures}

Ompsq

OMPSQ is a self-administered pain screening questionnaire that was developed to identify patients with acute or subacute musculoskeletal pain who are at risk of delayed recovery 3, 17. A higher score indicates a higher disability. The maximum score is 210 points; a score of $<105$ points indicates a low disability, that between 105 and 130 points indicates a moderate disability and that $>130$ points indicates a high disability 17 .

\section{Ndi}

NDI is a questionnaire used for assessing self-rated disability in patients with neck pain of mechanical origin ${ }^{18}$. It has been translated into a reliable German version (NDI-G) ${ }^{19}$. Scoring 0 points being the best possible score and 50 being the worst ${ }^{20}$.

Vas

VAS is an reliable outcome measure used to assess pain intensity ${ }^{21}$. The left side of the $100 \mathrm{~mm}$ long line indicates "no pain," and the end of the line on the right is "extreme pain" 22.

\section{Statistical analysis}

Descriptive statistics were used to describe participant characteristics. Consistency of the patients' pain was tested using paired t-test of VAS scores.

\section{Validity}

To assess discriminant validity, the ability of OMPSQ-G to differentiate between healthy adults and patients with chronic neck pain was tested using Mann-Whitney $U$ test. All other tests were conducted in the chronic neck pain sample. Criterion validity was established by correlating the total score of OMPSQ-G with those of VAS and NDI-G. Spearman's coefficient values were interpreted as excellent $(>0.9)$, good $(0.7-0.9)$, moderate (0.5$0.69)$, fair (0.2-0.5) or minimal-to-absent (0.0-0.2) 23. A factor analysis with maximum likelihood extraction and varimax rotation with Kaiser normalisation was performed to assess the internal structure of the translated questionnaire. Items with loadings $>0.4$ were automatically included within the matrix and items with a loading $<0.4$ were inspected for 
clinical relevance ${ }^{24}$. Floor and ceiling effects of OMPSQ-G in participants were used to assess content validity. Additionally, we conducted subgroup analysis for correlations of OMPSQ-G, NDI-G and VAS in healthy participants and chronic neck pain patients.

\section{Reliability}

Intraclass correlation coefficients (ICCs) and their associated 95\% confidence intervals (Cls) were selected to calculate the test-retest reliability of OMPSQ-G in patients with chronic neck pain ${ }^{25}$. ICC values of $>0.70$ were considered to be acceptable ${ }^{26}$. In addition, internal consistency was measured. Cronbach's $\alpha$ values of $0.7-0.95$ were deemed to be adequate ${ }^{27}$. To assess absolute reliability, the standard error of measurement (SEM) and smallest detectable change (SDC) were calculated ${ }^{28}$. Limits of agreement (LOA) and systematic bias were assessed using Bland-Altman plots ${ }^{29}$. Analyses were performed using SPSS Version 22.0 statistical software (SPSS, Inc. Chicago, IL, USA), and the statistical significance level was set at $5 \%$. 


\section{Results}

\section{Translation process}

The translated OMPSQ-G was pre-tested in 10 patients with complaints of chronic neck pain. The general impression of these patients was that OMPSQ-G was easy to understand. No changes were made to OMPSQG after the pre-test (Additional file 1). Seventy-six participants (50 patients with chronic neck pain and 26 healthy adults) were included in this study. Two healthy adults had more than three missing items and were excluded from the analysis. Thirteen of 1050 total items (1.2\%) were missing values 'not working' at the baseline, and 14 of 1050 items (1.3\%) were missing at the second time point. Furthermore, three different items from three separate patients were missing $(0.2 \%)$. Patients' pain levels were considered consistent because VAS scores did not significantly change $(p=0.92)$. Participant characteristics and results of all questionnaires at the two time points are shown in Table 1.

Table 1. Participant characteristics by study group

\begin{tabular}{lll}
\hline & Patients with chronic neck pain $(\mathrm{n}=50)$ & Healthy adults $(\mathrm{n}=24)$ \\
\hline Female & 34 & 18 \\
Male & 16 & 6 \\
Age; years (SD) & $43.6(14.5)$ & $50.5(14.2)$ \\
Range & $20-80$ & $25-78$ \\
Weight; kg (SD) & $69.9(17.6)$ & $67.7(14.6)$ \\
Height; cm (SD) & $169.9(10.1)$ & $171.5(7.8)$ \\
Comorbidities & 17 & 4 \\
Employment status & & \\
Active & 43 & 20 \\
Unemployed & 1 & 0 \\
Sick Leave & 0 & 0 \\
Pensioner & 3 & 3 \\
Other & 3 & 1 \\
OMPSQ-G & & $44.1(25.2)$ \\
Baseline measurement & $78.6(25.0)$ & $43.4(23.6)$ \\
Second measurement & $81.3(27.8)$ & $1.6(3.2)$ \\
NDI-G (SD) & & $1.9(4.0)$ \\
Baseline measurement & $13.2(5.9)$ & $0.3(0.1)$ \\
Second measurement & $12.5(6.5)$ & \\
VAS (SD) & & \\
Baseline measurement & $3.5(2.3)$ & \\
Second measurement & $3.5(2.4)$ & \\
\hline
\end{tabular}




\section{Validity}

Mann-Whitney $U$ tests showed significant differences in OMPSQ-G scores between the two groups at baseline $(z=-4.6 ; p<0.001)$ and at the second time point $(z=-4.8$; $p<0.001)$. All Spearman's rho $(\rho)$ coefficients that assessed the correlation between questionnaire scores were significant at baseline (OMPSQ-G and NDI-G at baseline, $\rho=$ 0.71; OMPSQ-G and VAS, $\rho=0.41$ ) and at the second time point (OMPSQ-G and NDI-G, $\rho=0.70$; OMPSQ-G and VAS, $\rho=0.58$ ). No floor or ceiling effects were observed. The lowest and highest possible OMPSQ-G scores were only found once. Subgroup analysis revealed the following correlations in healthy participants: OMPSQ-G and NDI-G ( $\rho=$ $0.355, p=0.089,-0.066$ to $0.68495 \% \mathrm{Cl})$, OMPSQ-G and VAS $(\rho=0.061, p=0.778$, -0.322 to $0.45995 \% \mathrm{Cl}$ ), NDI-G and VAS ( $\rho=0.544, p=0.006,128-0.84695 \% \mathrm{Cl}$ ). In chronic neck pain patients the correlations were as follows: OMPSQ-G and NDI-G ( $\rho$ $=0.726, p=0.000,0.572-0.82695 \% \mathrm{Cl})$, OMPSQ-G and VAS $(\rho=0.425, p=0.002$, $0.170-0.64195 \%)$ and NDI-G and VAS $(\rho=0.604, p=0.000,0.406-0.74895 \% \mathrm{Cl})$.

\section{Reliability}

OMPSQ-G showed high test-retest reliability (ICC, 0.93; 95\% Cl, 0.88-0.96). Cronbach's alpha was 0.94, SEM was 6.9 and SDC was 19.3 points. Bland-Altman plot (Fig. 1) indicated that all points besides three were located within the $95 \%$ LoA for test-retest reliability. No systematic error was observed.

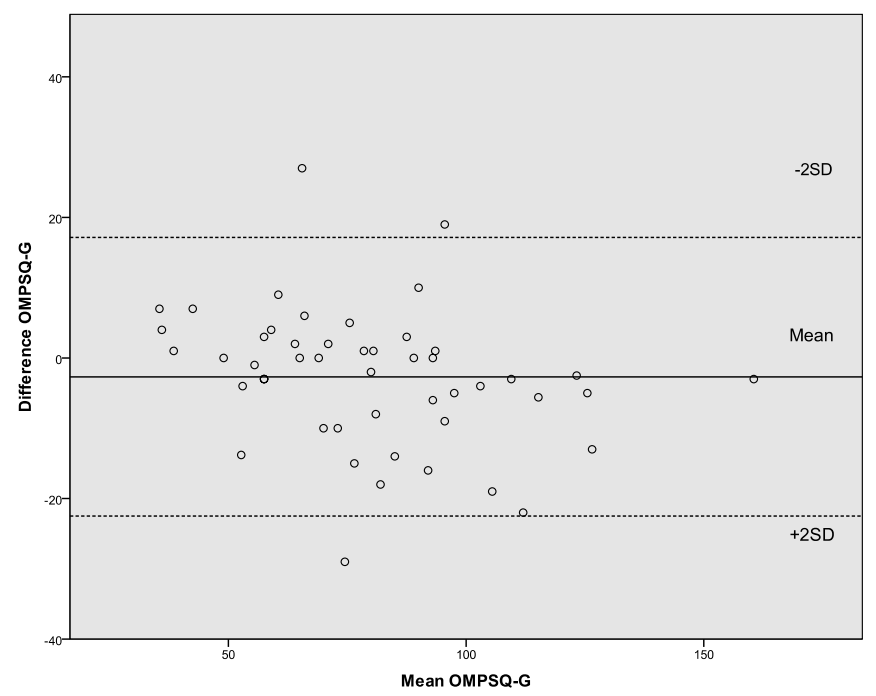

Fig. 1 Bland-Altman plot of OMPSQ-G total scores 


\section{Discussion}

This is the first translation of the long-form OMPSQ into German, which accompanies the earlier translated short-form OMPSQ 8. As there are only a few missing values, patients and healthy participants had no problem to understand the questions, given in the questionnaire.

Mean scores of OMPSQ-G were quite low in this sample of patients with chronic neck pain compared with those of a previous study in patients with acute and subacute neck pain ${ }^{10}$. However, the scores of OMPSQ-G were consistent with those of NDI-G and VAS; NDI-G indicated mild disability ${ }^{20}$, and the VAS score indicated moderate pain ${ }^{30}$. OMPSQ-G, NDI and VAS scores showed large variance.

\section{Comparison with other studies}

This is the first study to show that OMPSQ-G can discriminate between patients with chronic neck pain and healthy adults. Assessment of criterion validity also revealed a good correlation between OMPSQ-G and neck disability scores and a fair correlation with pain scores and comparable with those reported in a previous study ${ }^{8}$. We found no floor or ceiling effects, similar to findings in the Brazilian-Portuguese version of OMPSQ 8. Test-retest reliability (i.e. ICC) of OMPSQ-G was considered acceptable, despite the small sample size, which was considered to be acceptable given that the lower $\mathrm{Cl}$ of ICC was above the minimum accepted level for reliability. The SDC value was smaller than that observed in the Brazilian-Portuguese version of OMPSQ-G in patients with LBP ${ }^{8}$.

\section{Clinical relevance}

In conclusion, given the good validity and reliability of OMPSQ-G demonstrated in this study, the questionnaire can be considered a validated tool for identifying patients with chronic neck pain. The next research step should be to assess the predictive validity of OMPSQ-G.

\section{Limitations}

The OMPSQ-G was not tested in patients with acute neck pain. Although a test-retest interval of 2 weeks is recommended to minimize the effect of recognition, a shorter interval was selected owing to possible varying symptoms in patients with chronic neck pain. Due to the small sample size generalising the results of this study should be performed with caution, and further analysis is recommended for future studies. 


\section{Acknowledgements}

None.

\section{Competing interests}

The authors declare that they have no competing interests.

\section{Availability of data and materials}

The datasets used and/or analysed during the current study are available from the corresponding author on reasonable request.

\section{Consent for publication}

Not applicable.

\section{Ethics approval and consent to participate}

All participants gave their informed written consent. Ethical approval was obtained from the local ethics commissions of the Canton of Zürich Nr: 2013- 0394 and registered by ClinicalTrials.gov identi er: NCT02540343.

\section{Funding}

The study was supported by a grant from physioswiss. 


\section{Additional File 1}

\section{FRAGEBOGEN zu Schulter-Nacken-Rückenschmerzen}

Name:

Adresse:

Telefon:

Bitte lesen und beantworten Sie jede Frage sorgfältig. Überlegen Sie jedoch nicht zu lange, bevor Sie eine Frage beantworten. Es ist wichtig, dass Sie jede Frage beantworten. Es gibt immer eine zutreffende Antwort, die am ehesten auf Ihre Situation zutrifft.

BEISPIELE:

Bitte beantworten Sie nachfolgende Fragen, indem Sie

- $\quad$ eine Antwort einkreisen: Ich mag Orangen.

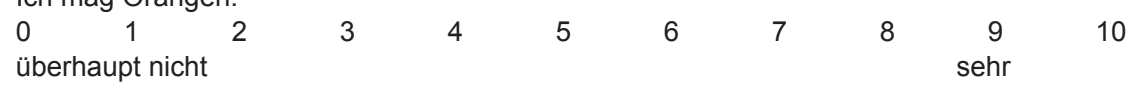

- oder ein Kästchen ankreuzen:

An wie vielen Tagen pro Woche treiben Sie Sport?
$0-1$ Tag $\square$
2-3 Tage $\square$
4-5 Tage $\square$
6-7 Tage $\square$

C Steven J. Linton, Örebro 
1. In welchem Jahr sind Sie geboren?

2. Sind Sie männlich $\square \quad$ weiblich $\square$

3. In welchem Land wurden Sie geboren?

4. In welcher Beschäftigungssituation befinden Sie sich zurzeit?

bezahlte Arbeit $\square \quad$ Studium $\square \quad$ unbezahlte Arbeit zuhause $\square$

arbeitslos $\square$ pensioniert $\square$ andere $\square$ :

5. Wo haben Sie Schmerzen? Es sind mehrere Antworten möglich.

Nacken $\square$ Schulter $\square$ oberer Rücken $\quad \square$ unterer Rücken $\square$ Bein $\square$

6. An wie vielen Tagen konnten Sie, während der letzten 12 Monate, aufgrund von

Schmerzen nicht Ihrer Arbeit nachgehen? Bitte wählen Sie eine Antwort.

0 Tage $\square \quad$ 1-2 Tage $\square \quad$ 3-7 Tage $\square \quad$ 8-14 Tage $\square \quad$ 15-30 Tage $\square$

31-60 Tage $\square$ 61-90 Tage $\square$ 91-180 Tage $\square$ 181-365 Tage $\square \quad>365$ Tage $\square$

7. Wie lange haben Sie dieses Schmerzproblem schon? Kreuzen Sie das entsprechende Kästchen an.
$0-1$ Woche
2-3 Wochen
4-5 Wochen $\square$
6-7 Wochen $\square$
8-9 Wochen $\square$ 10-11 Wochen $\square$
12-23 Wochen $\square$ 24-35 Wochen
36-52 Wochen $\square \quad>52$ Wochen

8. Ist Ihre Arbeit körperlich anstrengend oder monoton? Kreisen Sie die zutreffende Antwort ein.
012
3
4
5
6
7
8
9
10
überhaupt nicht

Ich arbeite nicht.

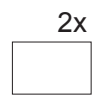

9. Wie stark waren Ihre Schmerzen innerhalb der letzten Woche? Kreisen Sie eine Antwort ein.

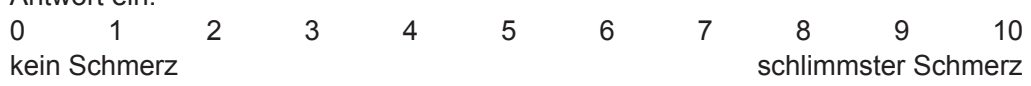

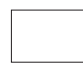

Wie stark, auf einer Skala von 0 bis 10, war Ihr Schmerz während der letzten drei Monate im Durchschnitt? Kreisen Sie eine Antwort ein.

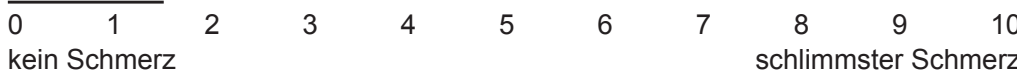

11. Wie oft hatten Sie im Durchschnitt während der letzten drei Monate

Schmerzen? Kreisen Sie eine Antwort ein.

$\begin{array}{llllllllllr}0 & 1 & 2 & 3 & 4 & 5 & 6 & 7 & 8 & 9 & \begin{array}{r}10 \\ \text { nie }\end{array} \\ \text { immer }\end{array}$

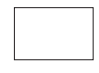

12. Wie weit ist es Ihnen möglich den Schmerz, mit Dingen die Ihnen helfen, zu reduzieren? Kreisen Sie eine Antwort ein.
$\begin{array}{lcc}0 & 1 & 2 \\ \text { Ich kann inn } & \text { überhaupt. }\end{array}$
nicht lindern
$\begin{array}{lllll}6 & 7 & 8 & 9 & 10\end{array}$ Ich kann ihn völlig zum Verschwinden bringen.

$10-x$

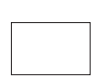

13. Wie angespannt oder unruhig fühlten Sie sich in der letzten Woche? Kreisen Sie eine Antwort ein.

$\begin{array}{lllllllllll}0 & 1 & 2 & 3 & 4 & 5 & 6 & 7 & 8 & 9 & 10\end{array}$ absolut ruhig und entspannt so angespannt und unruhig wie nie zuvor

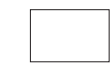

14. Wie niedergeschlagen fühlten Sie sich in der letzten Woche? Kreisen Sie eine Antwort ein.

$\begin{array}{lcccccccccr}0 & 1 \\ \text { überhaupt nicht } & 2 & 3 & 4 & 5 & 6 & 7 & 8 & 9 & \begin{array}{r}10 \\ \text { extrem }\end{array}\end{array}$


23. Ich kann alltägliche Haushaltsarbeiten verrichten.
$0 \quad 1$
2
3
4
5

\section{6}

Das ist mir wegen des

Schmerzes nicht möglich.

24. Ich kann meine Wocheneinkäufe erledigen.
$\begin{array}{lcc}0 & 1 & 2 \\ \text { Das ist mir wegen des }\end{array}$
34
45
Schmerzes nicht möglich.

$\begin{array}{llll}7 & 8 & 9 & 10\end{array}$

Das kann ich, ohne dass der

Schmerz ein Problem darstellt.

$10-x$

25. Ich kann nachts schlafen.

$\begin{array}{llll}0 & 1 & 2 & 3\end{array}$

Das ist mir wegen des

Schmerzes nicht möglich.

6

$\begin{array}{llll}7 & 8 & 9 & 10\end{array}$

Das kann ich, ohne dass der Schmerz ein Problem darstellt.

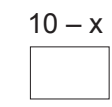

$\begin{array}{llllllll}4 & 5 & 6 & 7 & 8 & 9 & 10\end{array}$

Das kann ich, ohne dass der

$10-x$

Schmerz ein Problem darstellt.

\section{BESTEN DANK FÜR IHRE UNTERSTÜTZUNG!}




\section{References}

1. Cote P, Cassidy JD, Carroll L. The Saskatchewan health and back pain survey: the prevalence of neck pain and related disability in Saskatchewan adults. Spine (Phila Pa 1976). 1998;23:1689_ 98.

2. Hoy D, March L, Woolf A, Blyth F, Brooks P, Smith E, Vos T, Barendregt J, Blore J, Murray C, Burstein R, Buchbinder R. The global burden of neck pain: estimates from the global burden of disease 2010 study. Ann Rheum Dis. 2014;73:1309-15.

3. Linton SJ, Hallden K. Can we screen for problematic back pain? A screening questionnaire for predicting outcome in acute and subacute back pain. Clin J Pain. 1998;14:209-15.

4. Hockings RL, McAuley JH, Maher CG. A systematic review of the predictive ability of the Orebro musculoskeletal pain questionnaire. Spine (Phila Pa 1976). 2008;33:494-500.

5. Nonclercq O, Berquin A. Predicting chronicity in acute back pain: validation of a French translation of the Örebro Musculoskeletal Pain Screening Questionnaire. Ann Phys Rehabil Med. 2012;55:263-78.

6. Öncü J, Ilişer R, Kuran B. Cross-cultural adaptation of the Orebro Musculoskeletal Pain Questionnaire among Turkish workers with low back pain. J Back Musculoskelet Rehabil. 2016;29:135-43.

7. Cuesta-Vargas Al, González-Sánchez M. Spanish version of the screening Örebro Musculoskeletal Pain Questionnaire: a cross-cultural adaptation and validation. Health Qual Life Outcomes. 2014;12:1-7.

8. Fagundes FRC, Costa LOP, Fuhro FF, Manzoni ACT, de Oliveira NTB, Cabral CMN. Örebro Questionnaire: short and long forms of the Brazilian-Portuguese version. Qual Life Res. 2015;24:2777-88.

9. Shafeei A, Mokhtarinia HR, Maleki-Ghahfarokhi A, Piri L. Cross-cultural adaptation, validity, and reliability of the persian version of the Orebro Musculoskeletal Pain Screening Questionnaire. Asian Spine J. 2017;11:520-30.

10. Tsang Chi Chung R, Lau Sau Ying J, Kwong So Fong S, So Ming Loi E, Law Ka Yee R, Wong Fu Yan T, Lee Wai Chi E. Reliability, construct and predictive validity of the Hong Kong Chinese Orebro Musculoskeletal Pain Screening Questionnaire. J Occup Rehabil. 2016;27:584-92.

11. Boersma K, Linton SJ. Screening to identify patients at risk: profiles of psychological risk factors for early intervention. Clin J Pain. 2005;21:38-43-72.

12. Schmidt CO, Kohlmann T, Pfingsten M, Lindena G, Marnitz U, Pfeifer K, Chenot JF. Construct and predictive validity of the German Örebro questionnaire short form for psychosocial risk factor screening of patients with low back pain. Eur Spine J. 2016;25:325-32.

13. Dagfinrud H, Storheim K, Magnussen LH, Ødegaard T, Hoftaniska I, Larsen LG, Ringstad PO, Hatlebrekke F, Grotle M. The predictive validity of the Örebro Musculoskeletal Pain Questionnaire and the clinicians' prognostic assessment following manual therapy treatment of patients with LBP and neck pain. Man Ther. 2013;18:124-9.

14. Gabel CP, Burkett B, Neller A, Yelland M. Can long-term impairment in general practitioner whiplash patients be predicted using screening and patient-reported outcomes? Int J Rehabil Res. 2008;31:79-80.

15. Beaton DE, Bombardier C, Guillemin F, Ferraz MB. Guidelines for the process of cross-cultural adaptation of self-report measures. Spine (Phila Pa 1976). 2000;25:3186-91.

16. Gross A, Miller J, D'Sylva J, Burnie SJ, Goldsmith CH, Graham N, Haines T, Brønfort G, Hoving JL. Manipulation or mobilisation for neck pain: a Cochrane review. Man Ther. 2010;15:315-33.

17. Linton SJ, Boersma K. Early identification of patients at risk of developing a persistent back problem: the predictive validity of the Orebro Musculoskeletal Pain Questionnaire. Clin J Pain. 2003;19:80-6.

18. Vernon H. The neck disability index: state-of-the-art, 1991-2008. J Manipulative Physiol Ther. 2008;31:491-502.

19. Swanenburg J, Humphreys K, Langenfeld A, Brunner F, Wirth B. Validity and reliability of a German version of the neck disability index (NDI-G). Man Ther. 2014;19:52-8. 
20. Vernon H, Mior S. The neck disability index: a study of reliability and validity. J Manipulative Physiol Ther. 1991;14:409-15.

21. Gagliese L, Weizblit N, Ellis W, Chan VWS. The measurement of postoperative pain: a comparison of intensity scales in younger and older surgical patients. Pain. 2005;117:412-20.

22. Williamson A, Hoggart B. Pain: a review of three commonly used pain rating scales. J Clin Nurs. 2005;1994((Spence 2000)):798-804.

23. Siegel S, Castellan NJ. Nonparametric statistics for the behavioral science. 2nd ed. Boston: McGraw Hill Inc; 1988.

24. Dekker C, Bastiaenen CHG, De Vries JE, Laura E, Goossens MEJB, Verbunt JAMCF. Dutch version of the Fear of Pain Questionnaire for adolescents with chronic pain. Disabil Rehabil. 2017. https ://doi.org/10.1080/09638288.2017.

25. Swanenburg J, De Bruin ED, Favero K, Uebelhart D, Mulder T. The reliability of postural balance measures in single and dual tasking in elderly fallers and non-fallers. BMC Musculoskelet Disord. 2008;9:1-10.

26. Briggs KK, Steadman JR, Hay CJ, Hines SL. Lysholm score and Tegner activity level in individuals with normal knees. Am J Sports Med. 2009;37:898-901.

27. Terwee CB, Bot SDM, de Boer MR, van der Windt DA, Knol DL, Dekker J, Bouter LM, de Vet $\mathrm{HCW}$. Quality criteria were proposed for measurement properties of health status questionnaires. J Clin Epidemiol. 2007;60:34-42.

28. Swanenburg J, Koch PP, Meier N, Wirth B. Function and activity in patients with knee arthroplasty: validity and reliability of a German version of the Lysholm score and the Tegner activity scale. Swiss Med Wkly. 2014;144:w13976.

29. Bland J, Altman D. Statistical methods for assessing agreement between two methods of clinical measurement. Lancet. 1986;327:307-10.

30. Collins SL, Moore RA, McQuay HJ. The visual analogue pain intensity scale: what is moderate pain in millimetres? Pain. 1997;72:95-7. 



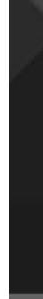




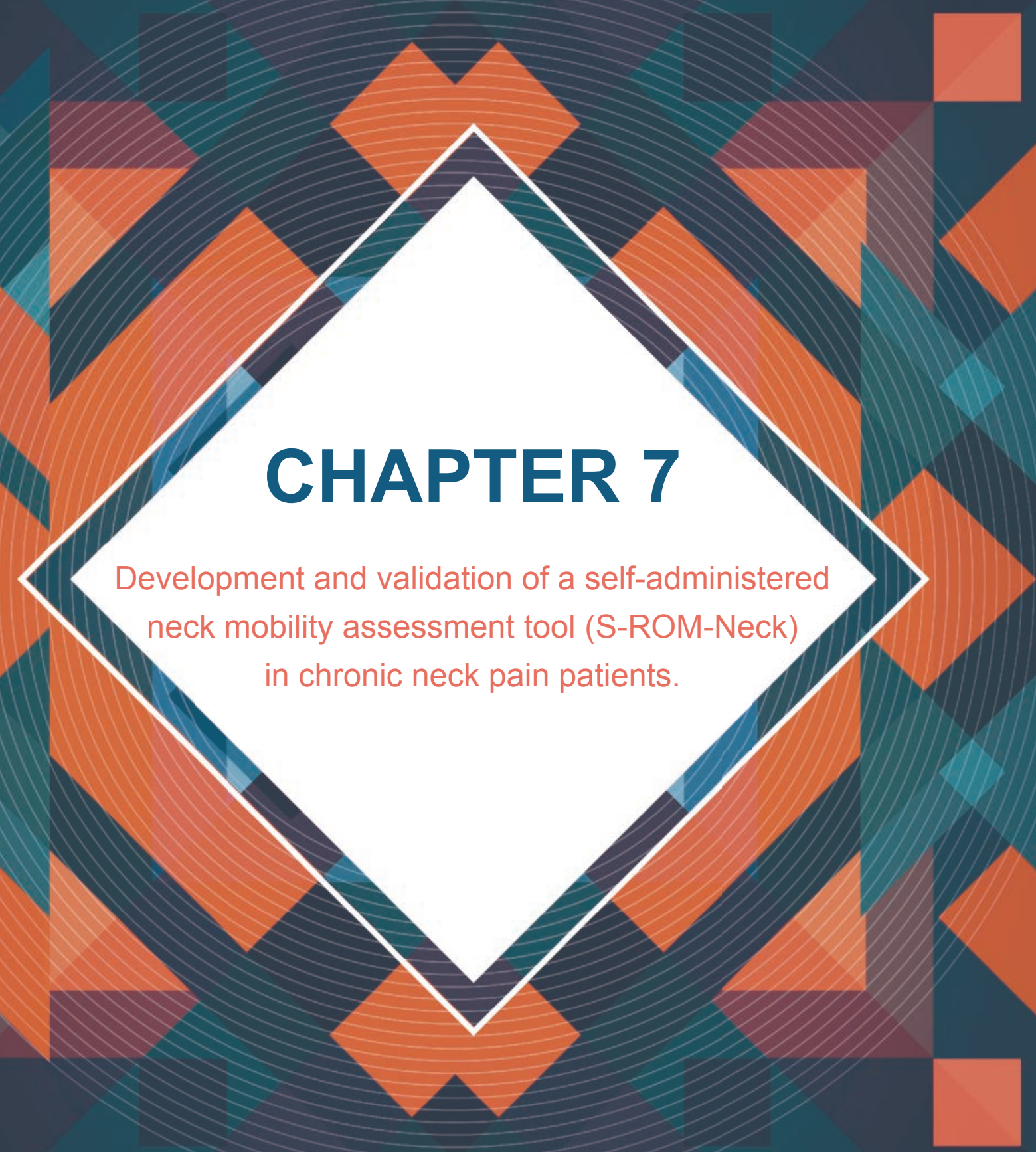

Anke Langenfeld, Caroline Bastiaenen, Judith Sieben and Jaap Swanenburg

Published: Musculoskeletal Science and Practice (2018), https://doi.org/10.1016/j. msksp.2018.04.004 


\begin{abstract}
Background: Cervical spine (CS) range of motion (ROM) is commonly used to assess neck pain. However, this measurement is often limited by the clinician's experience and perception. Therefore, the integration of perceptual feedback of the patient can optimize and personalize treatment.
\end{abstract}

Objective: Develop and validate a questionnaire (S-ROM-Neck) to evaluate ROM of the CS from the patient's perspective.

Design: Validation study.

Methods: The assessment tool was developed and optimized during pretest sessions. Reliability and construct validity of the questionnaire were tested. 50 participants (age>18 years) with neck pain for $>90$ days, able to fluently speak, read, and write in German were included. Exclusion criteria included any condition that limited manual therapy to the CS. Participants completed S-ROM-Neck twice within seven days, along with the visual analogue scale (VAS) for pain intensity and the German version of the Neck Disability Index (NDI-G). The relative reliability, internal consistency, and absolute reliability were analyzed, and Bland-Altman plots were generated. Construct validity was established by correlating the total score of S-ROM-Neck with VAS and NDI-G based on pre-set hypotheses.

Results: S-ROM-Neck demonstrated moderate reliability with an intraclass correlation coefficient of 0.718 (Cronbach's alpha of 0.83 ). There was a medium negative correlation between VAS and S-ROM-Neck [Spearman's rank correlation coefficient $\left(r_{s}\right)=-0.30$, $\mathrm{p}=0.031]$ and the NDI-G and S-ROM-Neck $\left(r_{s}=-0.40, p=0.002\right)$.

Conclusions: These results indicate the reliability and internal consistency of S-ROMNeck. This scale provides patient feedback and perspectives to optimize assessment of neck pain. 


\section{Introduction}

Neck pain is a common cause of disability that is associated with reduced range of motion (ROM) of the cervical spine (CS) ${ }^{1,2}$. CS ROM is a common tool to assess the degree of neck pain and the level of impairment as well as to monitor progress and evaluate the effectiveness of treatment and interventions ${ }^{3,4}$. Typically, CS ROM assessment is conducted and interpreted by a trained clinician. However, patient perception provides an additional understanding of the needs and problems of the patients by translating clinical data into a patient-centered measurement ${ }^{5}$. Furthermore, the patient's point of view can add valuable information to an examination by building a holistic picture of the patient's problems, possible needs, and expectations ${ }^{6-8}$. Self-reported ROM tools have been effectively utilized to evaluate other body parts ${ }^{9-14}$. Furthermore, a previous study employed a similar approach to that used in the present study; however, the prior approach focused on pain intensity induced by head movement ${ }^{15}$. Until now, no study has systematically assessed the ability of patients to rate their own perception of CS mobility. Such a tool would allow the addition of perceptual feedback and patient-specific information on movement restrictions of the CS, thereby improving the understanding of patient limitations, facilitating the selection of therapeutic options by clinicians, and optimizing cooperation between clinicians and patients. This study aimed to develop a self-reported measurement tool to assess ROM of the CS. 


\section{Methods}

\section{Development and pretesting}

The self-reported CS ROM questionnaire (S-ROM-Neck) was developed to evaluate CS ROM because patient assessment in daily practice often lacks assessment of CS mobility from the patient's point of view. Normally, during the first appointment with a patient with neck pain, the clinician assesses CS mobility and the patient is asked to describe pain and movement restrictions. However, to the best of our knowledge, no current questionnaire systematically assesses patient responses. The scale incorporates six questions targeting primary movements of the CS (i.e., flexion, extension, rotation, and lateral flexion). Patients were asked to actively perform each neck movement and then rate the restriction they perceived during the movement. This was done for each of the 6 movement directions. Perceived restriction could have been due to pain, stiffness and or tension. The questions were developed by clinicians and later tested and modified, if needed, during a pretest.

The tool was based upon a visual analogue scale (VAS) with two anchors. The left side contained the words "not at all" to indicate severe ROM restriction and the right side contained the words "as far as I want to" to indicate maximum ROM. Explanatory pictures accompany each question. The total score is calculated by adding the individual scores (minimum score [600]=no restrictions; maximum score [0]=total restriction).

Ten participants who fulfilled the same inclusion and exclusion criteria as the criteria for the main study were recruited for a pretest session to provide feedback on usability components. Based on the pretest feedback, two of the explanatory pictures were changed. These images accompanied the question "Side bending left" and "Side bending right." The person in the pictures was shown from the front. However, the participants reported confusion because the arrow pointed in the opposite direction as the patients were asked to move their heads. Therefore, the images were flipped to indicate the accurate movement (Additional File 1).

\section{Participants and procedures}

The study protocol was approved by the Ethics Committee of the by the ethics commission of the Canton of Zurich (PB_2016-00164) and registered at clinicaltrials.gov (NCT02754934). Eligible patients were asked about their interest in participating in the study. Those who wished to participate in this study received information and signed an informed consent form prior to study participation. Eligibility criteria were age $>18$ years, 
neck pain lasting $>90$ days, and ability to fluently speak, read, and write in German. Participants with any contraindications or limitations to manual therapy to the CS, such as multi-level nerve root pathologies, recent trauma to the CS, spinal cord damage, and active cancer, were excluded from the study ${ }^{16}$.

\section{Measures}

Demographic data of weight, sex, age, height, and duration of complaints were collected at baseline using a form that was completed by each participant. The VAS and the German version of the Neck Disability Index (NDI-G) were administered by a licensed physiotherapist. Participants filled out the forms by themselves. S-ROM-Neck assessment was repeated after 3-7 days. Participants received a prepaid envelope at the initial appointment and were instructed to return the questionnaire upon completion. If the questionnaire was not returned after four days, the participants received a reminder telephone call.

\section{VAS}

VAS is a valid and reliable outcome measure to assess pain intensity ${ }^{17}$. The left side of the $100-\mathrm{mm}$ scale is illustrative of "no pain" and the far right side is "extreme pain" ${ }^{18}$.

\section{NDI-G}

NDI-G is a valid and reliable questionnaire to assess self-rated disability in patients experiencing neck pain ${ }^{19}$. The scores range from 0 to 50 , with a lower score associated with low self-rated disability ${ }^{19,20}$. Hypothesis. There is no gold standard for the measurement of patient perception on the self-reported ROM; hence, the following two hypotheses were created to assess the validity of the tool:

1. There is a negative correlation between S-ROM-Neck and NDI (-0.3 to -0.5$)$

2. There is a negative correlation between S-ROM-Neck and VAS ( -0.3 to -0.5$)$

These hypotheses were based on the assumption that decreases in pain and functional disability would result in an increase in CS mobility.

\section{Data analysis}

Data were stored and analyzed using the IBM SPSS 22 statistical software package (SPSS, Inc., Chicago, IL, USA). Descriptive statistics were used to describe the baseline characteristics of the participants. The reliability of S-ROM-Neck was assessed using an intraclass correlation coefficient (ICC $\left.{ }_{\text {agreement }}\right)$ with 95\% confidence intervals $(\mathrm{Cl})^{21,22}$. 
Cronbach's alpha was used to evaluate internal consistency ${ }^{23}$. The standard error of measurement (SEM) and smallest detectable change (SDC) were used to determine the absolute reliability of S-ROM-Neck ${ }^{21,24}$. Bland-Altman plots were generated to assess agreement of the repeated S-ROM-Neck measures ${ }^{25}$. To establish construct validity, the total score of S-ROM-Neck was correlated with VAS and NDI-G based on pre-set hypotheses ${ }^{26}$. The floor and ceiling effects of S-ROM-Neck were used to assess content validity. 


\section{Results}

A total of 50 participants (mean age, $43.62 \pm 14.94$ years; mean height, $169.94 \pm 10.09$ $\mathrm{cm}$; mean weight, $69.78 \pm 17.57 \mathrm{~kg}$; 35 female participants) with a duration of neck pain of $>90$ days were included in this study. The mean overall S-ROM-Neck score was $42.43 \pm$ $10.70 \mathrm{~mm}$, the mean overall VAS score was $35.7 \pm 22.8 \mathrm{~mm}$, and the mean NDI score was $13.16 \pm 5.92$. Two patients had one missing item, which was not replaced. S-ROM-Neck demonstrated reliability with an ICC value of 0.718 (95\% Cl=0.47-0.88) and Cronbach's alpha of 0.83 . The SEM was $3.1 \mathrm{~mm}$, and the SDC was $8.7 \mathrm{~mm}$. The Bland-Altman plot indicated that all points, except two, were located within $95 \%$ limits of agreement for testretest, and visual inspection showed no tendency toward heteroscedasticity (see Fig. 1). Spearman's rho between VAS and S-ROM-Neck showed a moderate negative correlation $\left(r_{s}=-0.31, p=0.026\right)$, similar to NDI and S-ROM-Neck $\left(r_{s}=-0.42, p=0.002\right)$ (see Figs. 2 and 3). There were no floor or ceiling effects of S-ROM-Neck.

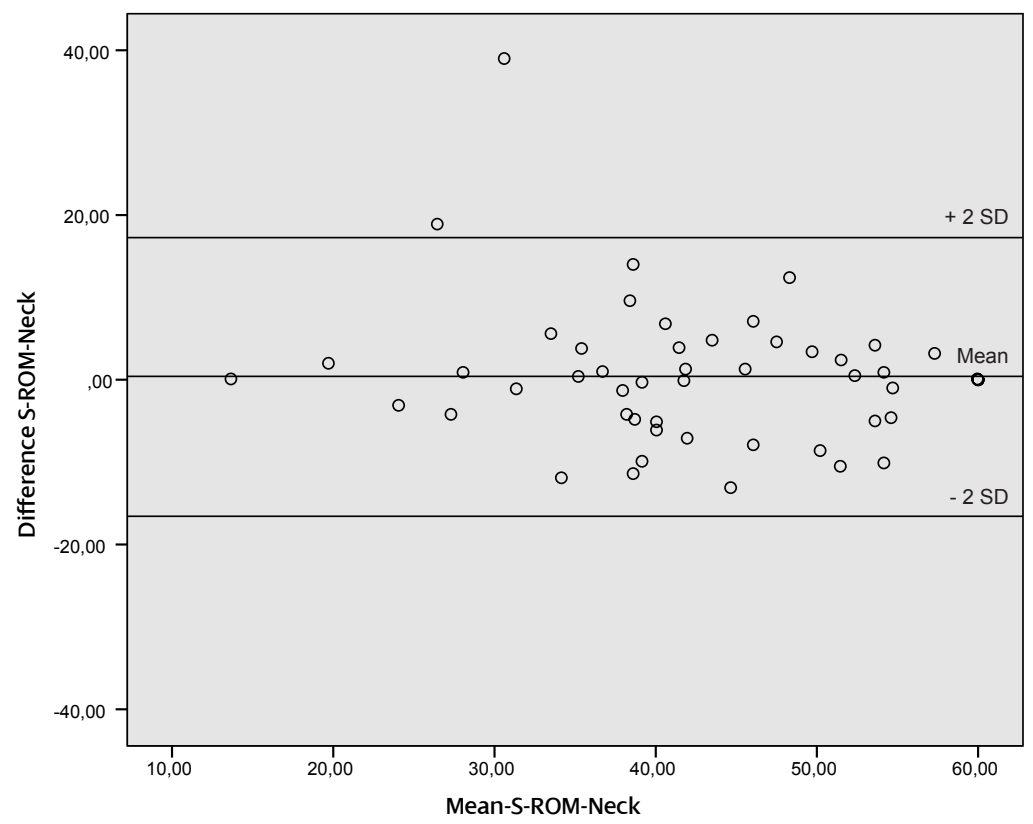

Fig. 1. Bland-Altman plot of S-ROM-Neck. 


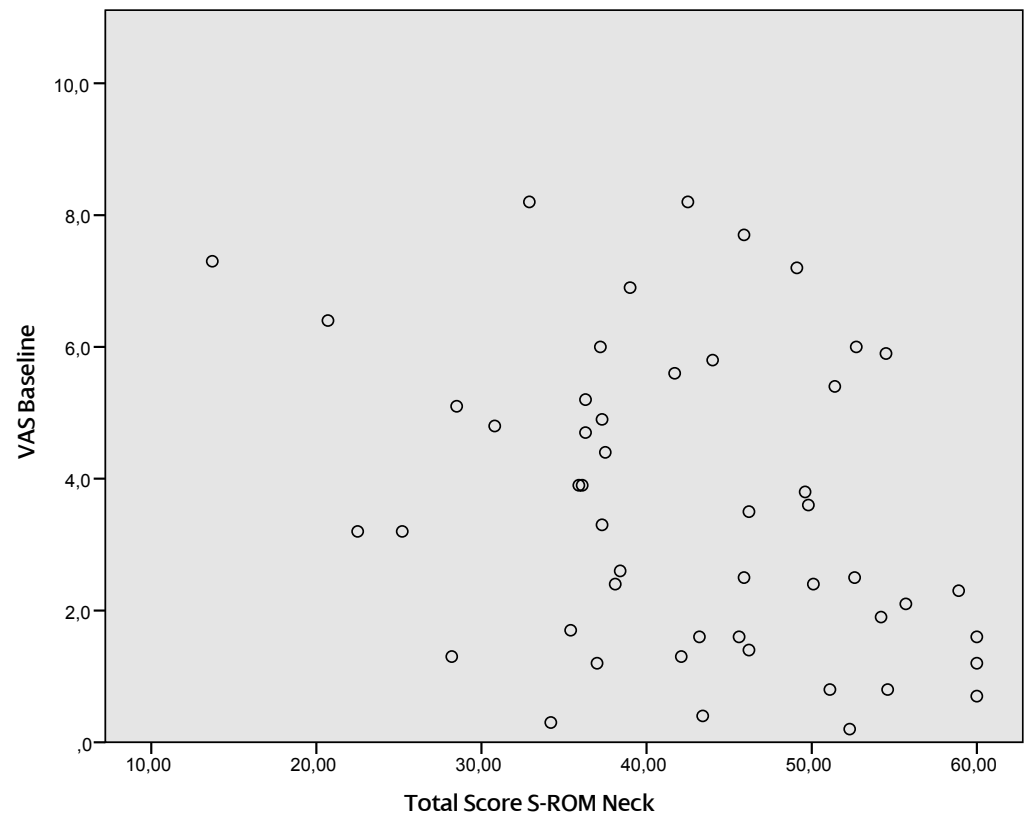

Fig. 2. Scatterplot of VAS vs. total score of S-ROM-Neck

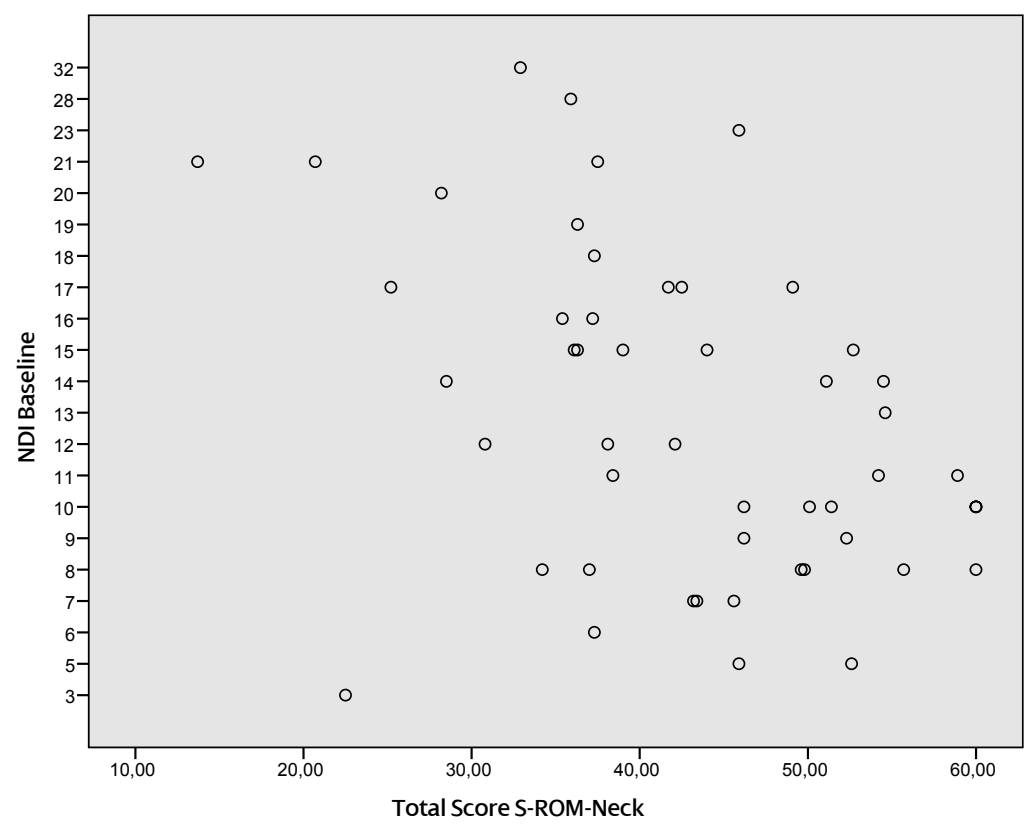

Fig. 3. Scatterplot of baseline NDI-G vs. total score of S-ROM-Neck. 


\section{Discussion}

We aimed to develop a patient-reported assessment tool (S-ROM-Neck) to measure CS ROM from the patient's perspective. This self-assessment adds unique, patient-specific information to support clinical assessment and evaluation. Furthermore, the reliability and construct validity of the assessment tool were evaluated on the basis of the study hypotheses. The Hypothesis that there is a negative correlation between S-ROM-Neck and both external anchors (NDI and VAS) was confirmed. Assessment of the reliability of the novel S-ROM-Neck tool was investigated with an ICC of 0.718 and Cronbach's alpha of $0.83^{23,27}$. A literature review revealed four studies that compared the ratings of ROM of different body parts by the clinicians and patients ${ }^{10,11,12,14}$. But only two of these studies developed and evaluated novel measures for validity and reliability (elbow disorders and mouth-opening) ${ }^{9,13}$. For the total score and subscales, Beirer et al. (2015) calculated the ICC, which ranged from 0.76 to 0.81 , and Cronbach's alpha, which ranged from 0.83 to 0.92. They found a correlation between the Elbow Self-Assessment Score and Oxford Elbow Score that ranged from -0.80 to -0.84 . Saund et al. (2012) reported an ICC of $0.92(95 \% \mathrm{Cl}=0.88-0.95$; Pearson's correlation coefficient $=0.86-0.90)$. The instrument proposed in the present study achieved an ICC of 0.71 . Although this value is lower than that reported by Beirer and Saund, it was sufficient to consider the instrument as moderately reliable ${ }^{9}$. The correlations were medium, indicating that S-ROM-Neck provides additional information that was not assessed by VAS or NDI. This additional information may offer valuable insight into patient-specific care and treatment. The decision to assess construct validity rather than criterion validity was intentional. Criterion validity is used if there is a gold standard to compare the results of a newly developed tool ${ }^{28}$. On the contrary, there is no such gold standard to assess construct validity ${ }^{28}$. Subsequently, the results of the analysis were compared with a pre-set Hypothesis ${ }^{28}$. The construct that we aimed to measure was the patient's perspective on CS ROM. Although there is a reliable standard for CS ROM measurement ${ }^{3,4}$, there is currently no gold standard to measure CS ROM from the patient's perspective.

Self-reported ROM tools have been effectively utilized in shoulder, elbow, jaw, and knee assessment ${ }^{9-14}$, but have used various methods of assessment thus direct comparison is difficult. Interestingly, Lauche et al., 2014 study was most similar to our study, but patients only assessed pain during the movement and pain may not necessarily indicate restriction of movement. Nevertheless, results ie (mean values/600 mm) in the current study were very similar to POM in Lauche's study 2014. This may have been because pain could 
have been one of the causes of the restriction rating in the S-ROM Neck. Since movement restrictions can be caused by other factors than pain, the S-ROM-Neck may provide additional information and future research should investigate this. A difficulty associated with CS mobility is the combination of movements that naturally occur in the spine (e.g., a combination of lateral flexion and rotation) ${ }^{29}$, which may cause difficulty in using a single plane to judge movement of the CS. Intentionally, participants were not instructed on how to conduct the movement, so that they would execute the movement organically to reflect daily movement. Therefore, movements were supported only with pictures rather than with instructions or verbal cues. Participants were not asked to conduct warm-up movements nor were any restrictions placed on how often they executed the movement.

This study had a minimum sample size of 50 patients with chronic neck pain ${ }^{26}$. ICC was moderate, which might be due to the homogenous sample. Therefore, future studies are required for assessing psychometric properties and performing factor analysis in a larger and more heterogeneous group of patients. Nevertheless, the ICC of 0.718 is a positive rating of reliability in a sample of 50 participants ${ }^{27}$. A study focusing on pain intensity induced by head movement used analogue proceedings ${ }^{15}$. Since movement restrictions can also be caused by other factors than pain, it is difficult to compare it with the S-ROMNeck. Moreover having neck pain does not mean that the patient experiences movement restrictions of the cervical spine. Future research should determine differences between those questionnaires. Future studies could combine both questionnaires and evaluate each in a more heterogeneous sample of neck pain patients. Furthermore, because we did not combine the S-ROM-Neck measurements to objective measurements (e.g., ROM), we recommend to do so in future studies in order to assess S-ROM-Neck to acquire additional information. 


\section{Conclusion}

Our findings support the reliability and internal consistency of the S-ROM-Neck instrument. Negative correlations of VAS and NDI with the S-ROM-Neck indicate that a larger CS ROM is associated with less pain and disability. Most importantly, the S-ROM-Neck tool is a useful measure that allows the input of patient-specific information to support a more comprehensive assessment of patients with neck pain.

\section{Funding}

The authors received no specific grant from any funding agency in the public, commercial, or not-for-profit sectors in regard to this report.

\section{Conflicts of interest}

None declared.

\section{Statement of institutional review board approval of the study protocol}

The study was approved by the ethics commission of the Canton of Zurich (PB_201600164) and registered at clinicaltrials.gov (NCT02754934). 


\section{References}

1. Hoy, D., March, L., Woolf, A., Blyth, F., Brooks, P., Smith, E., et al., 2014. The global burden of neck pain: estimates from the global burden of disease 2010 study. Ann.Rheum. Dis. 73, 1309-1315. http://dx.doi.org/10.1136/annrheumdis-2013-204431.

2. Rudolfsson, T., Björklund, M., Djupsjöbacka, M., 2012 Feb. Range of motion in the upper and lower cervical spine in people with chronic neck pain. Man. Ther. 17 (1), 53-59. http://dx.doi. org/10.1016/j.math.2011.08.007. Epub 2011 Sep 25.

3. Fletcher, J.P., Bandy, W.D., 2008. Intrarater reliability of CROM measurement of cervical spine active range of motion in persons with and without neck pain. J. Orthop. Sports Phys. Ther. 38, 640-645. http://dx.doi.org/10.2519/jospt.2008.2680.

4. de Koning, C.H.P., van den Heuvel, S.P., Staal, J.B., Smits-Engelsman, B.C.M., Hendriks, E.J.M., 2008. Clinimetric evaluation of active range of motion measures in patients with nonspecific neck pain: a systematic review. Eur. Spine J. 17, 905-921. http://dx.doi.org/10.1007/ s00586-008-0656-3.

5. Wiklund, I., 2004. Assessment of patient-reported outcomes in clinical trials: the example of health-related quality of life. Fundam. Clin. Pharmacol. 18, 351-363. http://dx.doi.org/10.1111/ j.1472-8206.2004.00234.x

6. Bee, P., McBeth, J., MacFarlane, G.J., Lovell, K., 2016. Managing chronic widespread pain in primary care: a qualitative study of patient perspectives and implications for treatment delivery. BMC Musculoskelet. Disord. 17, 354. http://dx.doi.org/10.1186/ s12891-016-1194-5.

7. Bishop, M.D., Mintken, P.E., Bialosky, J.E., Cleland, J a, 2013. Patient expectations of benefit from interventions for neck pain and resulting influence on outcomes. J. Orthop. Sports Phys. Ther. 43, 457-465. http://dx.doi.org/10.2519/jospt.2013. 4492.

8. Scherer, M., Schaefer, H., Blozik, E., Chenot, J.-F., Himmel, W., 2010. The experience and management of neck pain in general practice: the patients' perspective. Eur. Spine J.19, 963971. http://dx.doi.org/10.1007/s00586-010-1297-x.

9. Beirer, M., Friese, H., Lenich, A., Cr??nlein, M., Sandmann, G.H., Biberthaler, P., et al., 2015. The Elbow Self-Assessment Score (ESAS): development and validation of a new patientreported outcome measurement tool for elbow disorders. Knee Surg. Sport Traumatol. Arthrosc. http://dx.doi.org/10.1007/s00167-015-3647-z.

10. Collins, J.E., Rome, B.N., Daigle, M.E., Lerner, V., Katz, J.N., Losina, E., 2014. A comparison of patient-reported and measured range of motion in a Cohort of total knee replacement Patie. J. Arthroplast 29, 1378-1382. http://dx.doi.org/10.1016/j.arth. 2014.02.023.A.

11. Gioe, T.J., Pomeroy, D., Suthers, K., Singh, J.A., 2009. Can patients help with long-term total knee arthroplasty surveillance? Comparison of the American Knee Society Score self-report and surgeon assessment. Rheumatology 48, 160-164. http://dx.doi.org/ 10.1093/rheumatology/ ken439.

12. Khanna, G., Singh, J.A., Pomeroy, D.L., Gioe, T.J., 2011. Coparison of patient-reported and clinician-assessed outcomes following total knee arthroplasty. J. Bone Jt. Surg. 117, 1-7.

13. Saund, S.S.D., Pearson, D., Dietrich, T., 2012. Reliability and validity of self-assessment of mouth opening: a validation study. BMC Oral Health 12, 1. http://dx.doi.org/10.1186/1472-6831$\underline{12-48}$.

14. Uribe, B., El, Bitar Y., Wolf, B.R., Bollier, M., Kuhn, J.E., Hettrich, C.M., 2016. Agreement between patient self-assessment and physician assessment of shoulder range of motion.J. Shoulder Elb. Surg. http://dx.doi.org/10.1016/j.jse.2016.02.010.

15. Lauche, R., Cramer, H., Langhorst, J., Michalsen, A., Dobos, G.J., 2014. Reliability and validity of the pain on movement questionnaire (POM) in chronic neck pain. Pain Med. (United States) 15, 1850-1856. http://dx.doi.org/10.1111/pme.12534.

16. Rushton, A., Rivett, D., Carlesso, L., Flynn, T., Hing, W., Kerry, R., 2012. International Framework for the Examination of the Cervical Region for Potential Cervical Arterial Dysfunction Prior to Orthopeadic Manual Therapy Intervention. pp. 1-37. http:// www.ifompt.com/site/ifompt/IFOMPT Examination cervical spine doc September 2012 definitive.pdf, Accessed date: 6 February 2015. 
17. Price, D., McGrath, P., Rafii, A., Buckingham, B., 1983. The validation of visual analogue scales as ratio scale measures for chronic and experimental pain. Pain 17, 45-56.

18. Williamson, A., Hoggart, B., 2005. Pain: a review of three commonly used pain rating scales. J. Clin. Nurs. 1994, 798-804.

19. Swanenburg, J., Humphreys, K., Langenfeld, A., Brunner, F., Wirth, B., 2014. Validity and reliability of a German version of the neck disability Index (NDI-G). Man. Ther. 19,52-58. http:// dx.doi.org/10.1016/j.math.2013.07.004.

20. Vernon, H., Mior, S., 1991. The neck disability Index: a study of reliability and validity. J.Manip. Physiol. Ther. 14, 409-415.

21. Darter, B.J., Rodriguez, K.M., Wilken, J.M., 2013. Test-retest reliability and minimum detectable change using the K4b2: oxygen consumption, gait efficiency, and heart rate for healthy adults during submaximal walking. Res. Q. Exerc Sport 84, 223-231.http://dx.doi.org/10.1080/027013 67.2013 .784720

22. Koo, T.K., Li, M.Y., 2016. A guideline of selecting and reporting intraclass correlation coefficients for reliability research. J. Chiropr. Med. 15, 155-163. http://dx.doi.org/ 10.1016/j.jcm.2016.02.012.

23. Bland, J.M., Altman, D.G., 1997. Cronbach's alpha. BMJ 314, 572. http://dx.doi.org/10.1136/ bmj.314.7080.572.

24. Bruton, A., Conway, J.H., Holgate, S.T., 2000. Reliability: what is it, and how is it measured? Physiotherapy 86, 94-99. http://dx.doi.org/10.1016/S0031-9406(05) 61211-4.

25. Bland, J., Altman, D., 1986. Statistical methods for assessing agreement between two methods of clinical measurement. Lancet 327, 307-310. http://dx.doi.org/10.1016/ S0140-6736(86)90837-8

26. de Vet, H.C.W., Terwee, C.B., Mokkink, L.B., Knol, D.L., 2011. Measurements in Medicine. Cambridge University Press.

27. Terwee, C.B., Bot, S.D.M., de Boer, M.R., van der Windt, D a, WM, Knol, D.L., Dekker, J., et al., 2007. Quality criteria were proposed for measurement properties of health status questionnaires. J. Clin. Epidemiol. 60, 34-42. http://dx.doi.org/10.1016/i.jclinepi.2006.03.012.

28. Mokkink, L.B., Terwee, C.B., Patrick, D.L., Alonso, J., Stratford, P.W., Knol, D.L., et al., 2010. The COSMIN study reached international consensus on taxonomy, terminology, and definitions of measurement properties for health-related patient-reported outcomes. J. Clin. Epidemiol. 63, 737-745. http://dx.doi.org/10.1016/j.jclinepi. 2010.02.006.

29. Ishii, T., Mukai, Y., Hosono, N., Sakaura, H., Fujii, R., Nakajima, Y., et al., 2006. Kinematics of the cervical spine in lateral bending: in vivo three-dimensional analysis. Spine 31, 155-160. http:// dx.doi.org/10.1097/01.brs.0000195173.47334.1f. (Phila Pa 1976). 


\section{Selbstbeurteilung Nackenbeweglichkeit (s-Rom-Neck)}

Sehr geehrte Patientin, sehr geehrter Patient!

Wie beeinflussen Nackenschmerzen die Bewegungsfähigkeit Ihrer Halswirbelsäule? Dieser Fragebogen hilft uns, die Ursachen dafür besser zu verstehen.
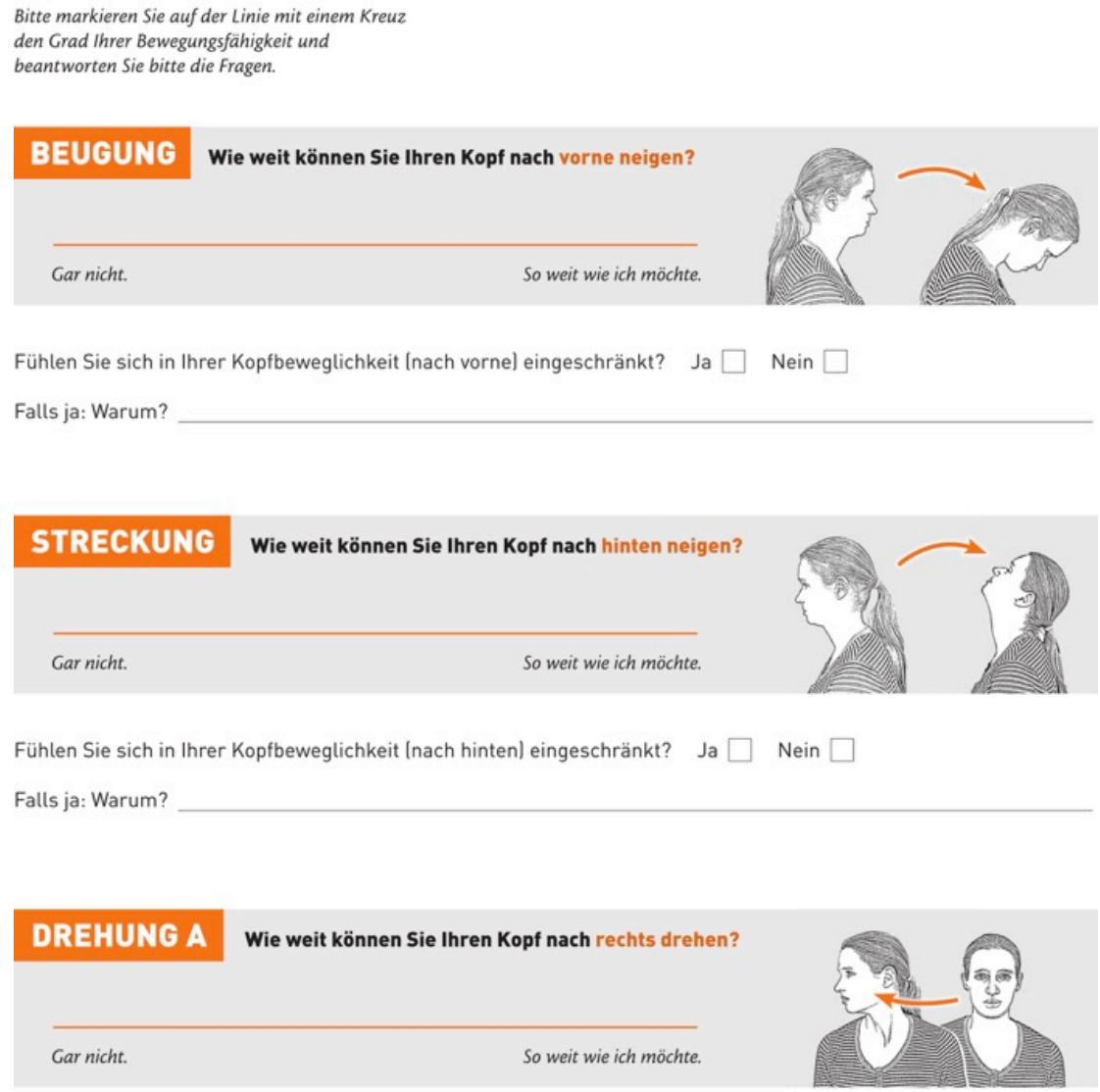

Fühlen Sie sich in Ihrer Kopfbeweglichkeit (Drehbewegung nach rechts) eingeschränkt? Ja $\square$ Nein Falls ja: Warum? 


\section{Selbstbeurteilung Nackenbeweglichkeit (s-RoM-Neck)}

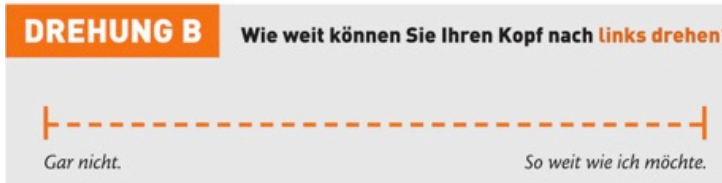

Fühlen Sie sich in Ihrer Kopfbeweglichkeit (Drehbewegung nach links) eingeschränkt? Falls ja: Warum?

Ist die Bewegung auf beide Seiten gleich gut möglich? Falls nicht: Nennen Sie bitte die Seite und die Ursache:

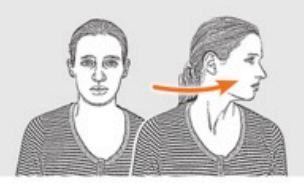

Nein

\section{SEITNEIGUNG A Wie weit können Sie Ihren Kopf nach rechts neigen? \\ Gar nicht. \\ So weit wie ich möchte. \\ Fühlen Sie sich in Ihrer Kopfbeweglichkeit (Neigung nach rechts) eingeschränkt? Ja $\square$ Nein $\square$ \\ Falls ja: Warum?}

\section{SEITNEICUNG B Wie weit können Sie Ihren Kopf nach links neigen?}

$$
\text { Gar nicht. }
$$

So weit wie ich möchte.

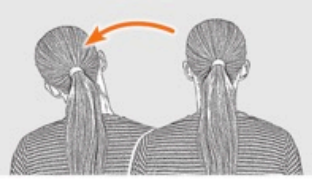

Fühlen Sie sich in Ihrer Kopfbeweglichkeit (Neigung nach links) eingeschränkt? Ja

Nein

Falls ja: Warum?

Ist die Bewegung auf beide Seiten gleich gut möglich? Falls nicht: Nennen Sie bitte die Ursache: 


\section{Self-assessment Neck mobility (s-rom Neck)}

\section{Dear patient,}

How does neck pain affect the mobility of your cervical spine?

The following questionnaire helps us to better understand the causes.

Please mark the degree of mobility by placing a cross somewhere on the line below.

\section{BENDING How far can you bend your head forward?}

Notatall

As faras I want

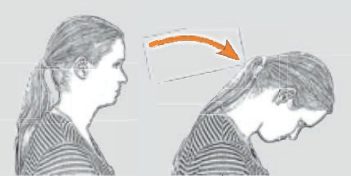

Do you feel the (forward) movement of your head is restricted? Yes $\square$ No $\square$

If the answer is Yes: Why?

\section{EXTENSION How far can you bend your head backward? \\ Notatall \\ As faras I want}

Do you feel the (backward) movement of your head is restricted? Yes $\square$ No $\square$

If the answer is Yes: Why?

\section{TURNING A How far can you turn your head to the right? \\ Notatall \\ As faras I want}

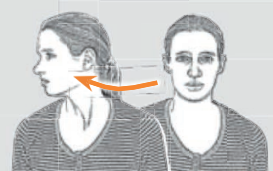

Do you feel the movement of your head (to the right) is restricted? Yes

If the answer is Yes: Why? 


\section{Self-assessment Neck mobility (s-Rom Neck)}

\section{TURNING B How far can you turn your head to the left? \\ Notatall \\ Asfaras/want}

Do you feel themovement of your head (to the left) is restricted? Yes

If the answer is Yes: Why?

Can you move your head equally well in both directions? If you cannot, please give the side and the cause:

\section{LATERAL TILT A How far can you tilt your head to the right?}

Notatall

Asfaras/want

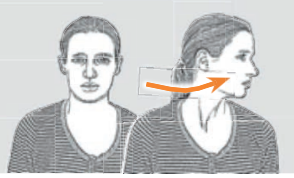

Doyou feel themovement of yourhead (righttilt) is restricted? Yes

No

If the answer is Yes: Why?

\section{LATERAL TILTB How far can you tilt your head to the left?}

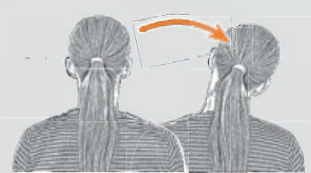

Do you feel the movement of yourhead (left tilt) is restricted? Yes No

If the answer is Yes: Why?

Can you tilt your head equally well in both directions? If you cannot, please give the cause: 


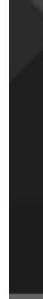




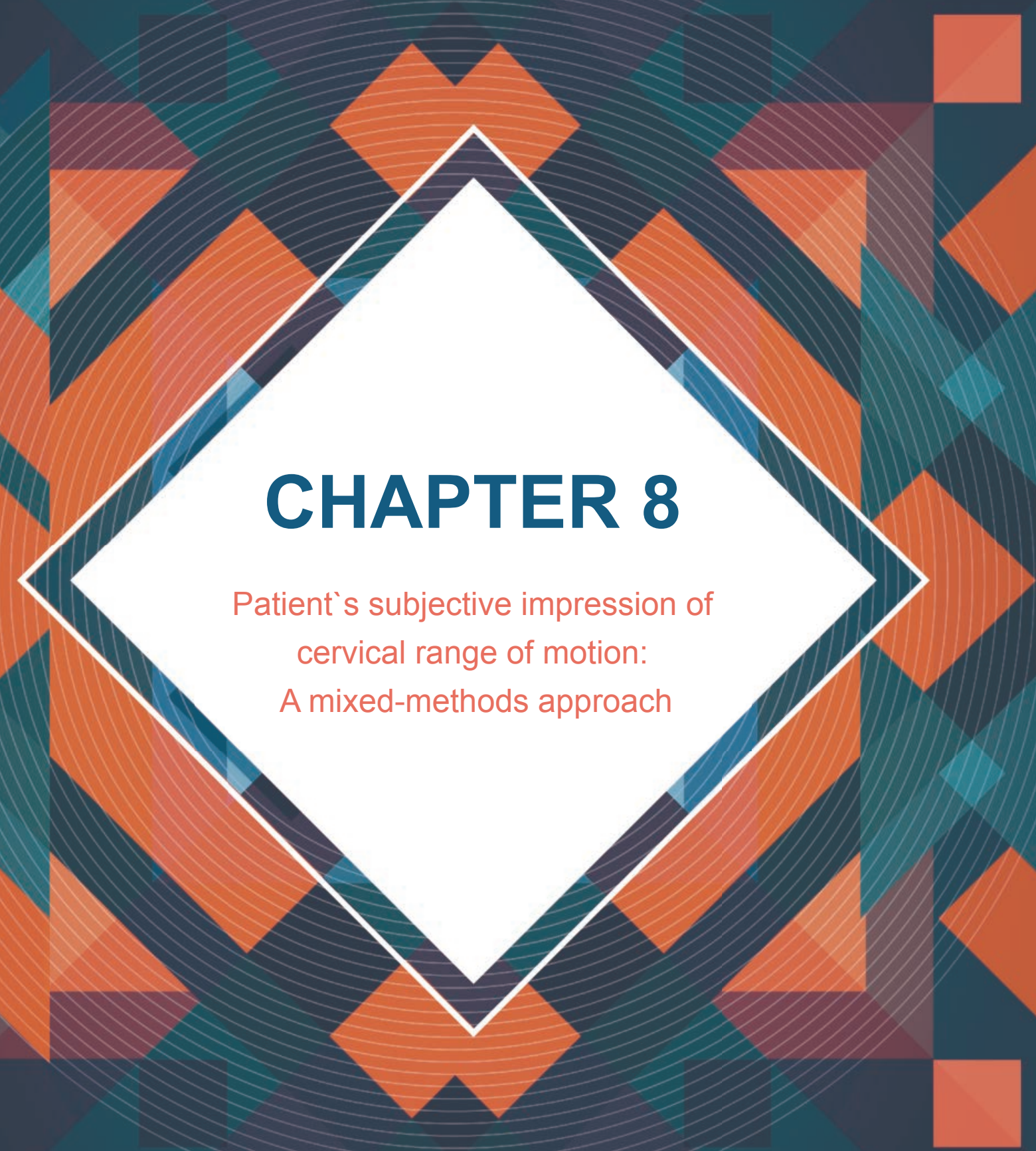

Anke Langenfeld, Carolien Bastiaenen, Judith Sieben, B. Kim Humphreys and Jaap Swanenburg

Published: SPINE An International Journal for the study of the spine,

DOI: 10.1097/BRS.0000000000002627

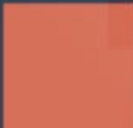




\section{Abstract}

Study Design: Mixed-method.

Objective: To evaluate the association between objective and subjective cervical range of motion (ROM) among patients with neck pain, and to assess the awareness of impairments.

Summary of Background Data: Cervical ROM is frequently used to evaluate neck pain, but it is also important to know what a patient expects from treatment, because this can profoundly affect treatment outcomes and patient satisfaction.

Methods: We used a cervical ROM instrument, the Neck Disability Index (NDI), and a self-administered ROM questionnaire for the neck (S-ROM-Neck). Ten patients took part in semi-structured interviews. Correlations were analyzed using Spearman rank order correlations $\left(r_{s}\right)$. Differences between patient and assessor were evaluated by the MannWhitney U test. Qualitative data were analyzed by content analysis.

Results: Thirty participants (mean age 43.80 years; 21 females) were included. The correlation $\left(r_{s}\right)$ for the S-ROM-Neck between patient and assessor was 0.679 (95\% confidence interval $[95 \% \mathrm{Cl}] 0.404-0.884 \mathrm{p}=0.000)$. The correlation between the NDI and S-ROM-Neck was $0.178(95 \% \mathrm{Cl}-0.233$ to $-0.533 ; \mathrm{p}=346)$ for the assessor and -0.116 $(95 \% \mathrm{Cl}-0.475$ to $-0.219, \mathrm{p}=0.541)$ for the patient $(\mathrm{U}=448, z=-0.030, p=0.976)$. Qualitative analysis revealed that patients had general restrictions in daily life and with specific movements, but that they adjusted their behavior to avoid impairment.

Conclusion: There was a significant correlation between patient and therapist ratings of cervical spine mobility. Although patients experience restriction while moving and are impaired in specific activities, they adjust their lifestyle to accommodate their limitations.

Key words: Neck pain, cervical range of motion, patient's perspective, impairments, mixedmethod, awareness, quantitative, qualitative, interview 


\section{INTRODUCTION}

Range of motion (ROM) is used to assess joint movement for treatment, symptom monitoring, and treatment evaluation. ${ }^{1,2}$ Cervical ROM (CROM) is specifically assessed for neck problems, ${ }^{3-7}$ and includes flexion, extension, lateral flexion (left/right), and rotation (left/right). ${ }^{7}$

Although measurements can be taken by various methods (e.g., tape measure or inclinometer), ${ }^{8-15}$ it is equally important to know a patient's expectations of treatment, ${ }^{16,17}$ because these can affect outcomes and satisfaction. ${ }^{16}$ Expectations are unique to an individual, and may be influenced by a multitude of factors. ${ }^{16,18}$ To date, there has only been limited research on the patient's perspective, including why they consult doctors and what they think about the different therapies for neck pain. ${ }^{17}$ This must be rectified if we are to direct therapy to meet patient needs and expectations, and, ultimately, improve outcomes. ${ }^{19,20}$ Therefore, we studied the association between objective CROM restriction and the subjective perspectives of patients and therapists. We also evaluated patient awareness of impaired neck movement and how it limited their activities of daily living (ADLs). We hypothesized that differences would exist in the subjective and objective measures of CROM, and that restricted CROM would not be important to patients until it interfered with their ADLs. 


\section{MATERIALS AND METHODS}

\section{Patients}

We recruited 30 patients with neck pain from physiotherapy practices in Zurich. All patients were referred by a general practitioner or chiropractor. We included patients if they provided informed consent, were older than 18 years, had neck pain (any duration), and could read, speak, and write German. We excluded patients with radiculopathy and disk herniation of the cervical spine, stenosis of the cervical spinal, acute whiplash disorder, prior cervical spine surgery, or an implanted pacemaker or defibrillator.

\section{Study Design}

A mixed-methods approach was used with an explanatory-sequential design. ${ }^{21}$ Age, gender, weight, height, diagnosis, comorbidities, medication, duration, and dexterity data were collected. We then performed assessments with the CROM instrument, the Neck Disability Index (NDI), and the Self-administered Range of Motion Questionnaire for the Neck (S-ROM-Neck). Patients were also selected at random for the qualitative study. Mixed-methods research uses a combination of quantitative and qualitative data in response to a research question. This combination of research methods uses the strength from both data sets to understand research problems. The explanatory-sequential design uses the qualitative approach to explain and investigate the data from the quantitative approach more in depth. ${ }^{22}$ 


\section{Assessments}

\section{The CROM instrument}

We used a goniometer with established validity and reliability to measure active CROM. ${ }^{12,23-}$ ${ }^{26}$ The researcher demonstrated the required movements before each measurement. The subject was asked to undress the upper body, sit erect in a straight-back chair, place the sacrum against the back of the chair but the thoracic spine away from it, and leave their arms hanging at their sides and feet flat on the floor. ${ }^{27,28}$ Measurements were taken once in each position, with participants returning to the neutral position for a rest of 5-10 s between movements.

\section{The NDI}

The NDI is a self-rated disability questionnaire for assessing neck pain. ${ }^{29,30}$ It consists of ten items, such as working and driving, with each item scoring up to five points (total score $=50$ ). The lower the score, the less the self-rated disability. ${ }^{30}$ The validity and reliability of a German version have been confirmed. ${ }^{31}$

\section{The S-ROM-Neck questionnaire}

The S-ROM-Neck questionnaire was only recently developed, and although its validity and reliability have been assessed, further study is needed (Langenfeld, 2017). It is a self-administered questionnaire that uses visual analog scales (VAS) to measure pain-free active CROM for all neck movements. The patient is asked to place a mark on a $100 \mathrm{~mm}$ line (0 mm indicates "no movement possible" and $100 \mathrm{~mm}$ indicates "as far as possible"). The result, in millimeters, reflects the patient's ability to move. The reason for restricted movement is also recorded. Rotation and lateral flexion are compared bilaterally. The total score is the sum of the individual scores ( $\mathrm{min}$. score $(600)=$ no restrictions and max. score $(0)=$ total restriction). The patient (S-ROM-Neck-P) and the assessor (S-ROM-Neck-A) both filled out the questionnaire. This was done separately but at the same time. The assessor observed the movement done by the patient and rated it on the S-ROM-Neck as did the patient. We compared the S-ROM-Neck results for the patient (S-ROM-Neck-P) and the assessor (S-ROM-Neck-A).

\section{Interviews}

We conducted semi-structured interviews, ${ }^{32}$ starting with general questions to get an overview of the patient's complaint (e.g., the reason for attendance, the main complaint, and whether the complaint prevented ADLs). The patient and interviewer both completed 
S-ROM-Neck questionnaires during the interview, with the interviewer asking whether a movement caused restriction at each point; if it did, the interviewer asked why, and whether it interfered with ADLs. The interview was recorded and afterwards transcribed.

\section{Data Analysis}

In the study we combined two ways of data collection, quantitative and qualitative. To have a good explanatory power of the quantitative data 24 patients were needed. A sample of 24 is adequate for a cross-sectional study to provide statistical significant outcome. ${ }^{33} \mathrm{We}$ planned to use nonparametric tests in the analyzes, therefore we added $15 \%$ to the sample size and another two because for potential dropouts. The total number of participants is 30. For the qualitative part, which is used to understand and interpret the quantitative data, 10 interviews with participants were conducted..$^{22}$

\section{Quantitative analyses}

The Shapiro-Wilk test was used to assess the normality of the CROM, S-ROM-Neck, and NDI data. To identify correlations between the CROM, NDI, and both S-ROM-Neck scores (assessor and participant), we calculated Spearman rank order correlations $\left(r_{s}\right)$. Coefficients of 1 and -1 indicated perfect positive and negative correlations, respectively. ${ }^{34}$ The Mann-Whitney $U$ test was used to assess differences in the S-ROM-Neck-P and S-ROM-Neck-A. ${ }^{35}$ Significance was set at $p<0.05$. Average scores were calculated for every item of the NDI when evaluating what ADLs were restricted.

\section{Qualitative analyses (interviews)}

Qualitative assessment was done by content analysis, using transcribed interview data. ${ }^{36-}$ ${ }^{40}$ We used content structuring to extract specific interview data, based on pre-determined criteria. ${ }^{39}$ The aim was to extract examples for a category framework ${ }^{41}$ that could be used to analyze the interviews by establishing coding rules. ${ }^{41}$ The interviews were analyzed by two researchers and their findings were compared and discussed. 


\section{RESULTS}

\section{Quantitative Analysis}

We enrolled 30 participants (21 female, 9 male), of whom 27 had chronic neck pain and 3had acute problems (Table 1). The CROM, S-ROM-Neck, and NDI data were not normally distributed, and all data had a monotonic relationship. Correlations were calculated for the CROM measurements and the S-ROM-Neck-P and the S-ROM-Neck-A (Table 2 and Figure 1). There was good correlation between the S-ROM-Neck-P and the S-ROM-Neck-A $\left(r_{s} 0.679,95 \%\right.$ confidence interval $\left.[95 \% \mathrm{Cl}] 0.404-0.884 ; p=0.000\right)$. The NDI scores correlated with both the S-ROM-Neck-P total score $\left(r_{s}-0.116,95 \% \mathrm{Cl}\right.$ -0.475 to $0.219 ; p=0.541)$ and S-ROM-Neck-A total score $\left(r_{s} 0.178,95 \% \mathrm{Cl}-0.233\right.$ to $0.533 ; p=0.346)$. Visual inspection revealed similar score distributions, but no statistically significantly difference in the median total score for S-ROM-Neck-P (473.50) and S-ROMNeck-A $(458.00)(U=448, z=-0.030 ; p=0.976)$. Single item analysis of the NDI revealed high scores for headaches, recreation, reading, pain intensity, and driving (7 did not drive a car) (Table 3).

Table 1: Baseline characteristics of all participants including range of motion (ROM) measures for all cervical spine movements, S-ROM-Neck and Neck Disability Index (NDI-G) ratings.

\begin{tabular}{lcccc}
\hline Variable & Min & Max & Mean & SD \\
\hline Age (years) & 23 & 77 & 43.80 & 12.42 \\
Weight (kg) & 45 & 131 & 69.28 & 17.20 \\
Height (cm) & 152 & 192 & 170.41 & 08.87 \\
Flexion (degrees) & 10 & 72 & 47.00 & 15.29 \\
Extension (degrees) & 28 & 86 & 58.47 & 15.00 \\
Lateral Flexion right & 14 & 62 & 34.70 & 11.60 \\
(degrees) & & & & \\
Lateral Flexion left & 18 & 60 & 37.73 & 11.29 \\
(degrees) & & & & \\
Rotation right (degrees) & 40 & 90 & 63.90 & 14.66 \\
Rotation left (degrees) & 30 & 90 & 58.90 & 16.84 \\
Total score NDI (points) & 0 & 30 & 11.10 & 06.20 \\
Total score S-ROM- & 92 & 600 & 452.33 & 111.89 \\
Neck patient (mm) & & & & \\
Total score S-ROM- & 256 & 600 & 459.63 & 87.63 \\
Neck Assessor (mm) & & & & \\
\hline
\end{tabular}


Table 2: Correlations of Flexion, Extension, Rotation (both sides), Lateral Flexion (both sides) of the CROM and S-ROM-Neck measures (patient and assessor) including significance and $95 \% \mathrm{Cl}$.

\begin{tabular}{lcccc}
\hline & $\begin{array}{c}\text { CROM / S-ROM-Neck } \\
(\mathrm{pt})\end{array}$ & Sig. & $95 \%$ Cl & CROM / S-ROM (Ass) \\
\hline Flexion & .499 & .005 & $.116-.792$ & .497 \\
Extension & .356 & .054 & $-.007-.651$ & .734 \\
Rotation right & .631 & .000 & $.406-.802$ & .763 \\
Rotation left & .661 & .000 & $.376-.836$ & .716 \\
Lateral flexion right & .382 & .037 & $-.047-.740$ & .582 \\
Lateral flexion left & .371 & .043 & $-.023-.661$ & .488 \\
\hline
\end{tabular}

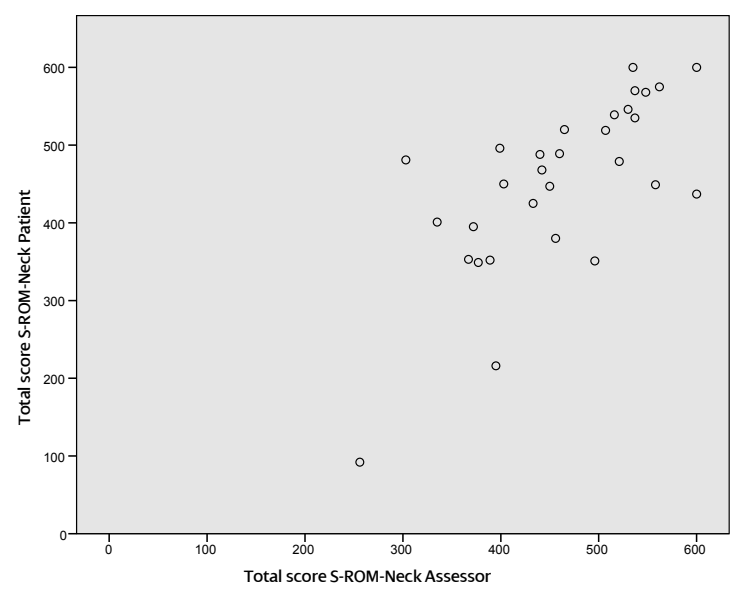

Figur 1: Scatterplot; Correlation of S-ROM-Neck assessor and patient $\left(r_{s}=.679\right.$, sig. $.000,95 \%$ Cl.404-.884)

Table 3. Single item results of the Neck Disability Index (NDI) including minimum points (pt), maximum points, mean (median) and standard deviation (SD).

\begin{tabular}{llcccc}
\hline Item & $\mathrm{N}$ & Minimum & Maximum & Mean (Median) & $\mathrm{SD}$ \\
\hline Pain intensity & 30 & $0 \mathrm{pt}$ & $4 \mathrm{pt}$ & $1.43(2)$ & $.97(.97)$ \\
Personal care & 30 & $0 \mathrm{pt}$ & $2 \mathrm{pt}$ & $.13(0)$ & $.43(.43)$ \\
Lifting & 30 & $0 \mathrm{pt}$ & $4 \mathrm{pt}$ & $.77(0)$ & $1.22(1.22)$ \\
Reading & 30 & $0 \mathrm{pt}$ & $4 \mathrm{pt}$ & $1.47(1)$ & $1.10(1.10)$ \\
Headaches & 30 & $0 \mathrm{pt}$ & $5 \mathrm{pt}$ & $1.90(2)$ & $1.37(1.37)$ \\
Concentration & 30 & $0 \mathrm{pt}$ & $3 \mathrm{pt}$ & $.80(1)$ & $.84(.84)$ \\
Work & 30 & $0 \mathrm{pt}$ & $3 \mathrm{pt}$ & $.83(1)$ & $.79(.79)$ \\
Driving & 30 & $0 \mathrm{pt}$ & $4 \mathrm{pt}$ & $1.34(1)$ & $1.00(1.00)$ \\
Sleeping & 30 & $0 \mathrm{pt}$ & $4 \mathrm{pt}$ & $1.03(1)$ & $1.12(1.12)$ \\
Recreation & 30 & $0 \mathrm{pt}$ & $5 \mathrm{pt}$ & $1.47(2)$ & $1.07(1.07)$ \\
\hline
\end{tabular}




\begin{tabular}{llclc} 
Sig. & $95 \% \mathrm{Cl}$ & $\begin{array}{c}\text { S-ROM-Neck (pt) / S-ROM } \\
(\text { Ass })\end{array}$ & Sig. & $95 \% \mathrm{Cl}$ \\
.005 & $.182-.772$ & .730 & .000 & $.488-.886$ \\
.000 & $.490-.866$ & .462 & .010 & $.121-.705$ \\
.000 & $.555-.859$ & .606 & .000 & $.284-.799$ \\
.000 & $.434-.868$ & .595 & .001 & $.280-.805$ \\
.001 & $.254-.834$ & .276 & .140 & $-.152-.635$ \\
.006 & $.145-.730$ & .387 & .035 & $.021-.685$ \\
\hline
\end{tabular}

Qualitative Analysis

We interviewed six women and four men (Interviewee 1-10); nine had chronic and one had acute neck pain, but all ten were right handed (Table 4).

Table 4: Baseline characteristics of the ten participants taking part in an interview including range of motion (ROM) measures for all cervical spine movements, S-ROM-Neck and Neck Disability Index (NDI-G) ratings

\begin{tabular}{lcccc}
\hline Variable & Min & Max & Mean & SD \\
\hline Age (years) & 33 & 77 & 51.60 & 13.14 \\
Weight (kg) & 51 & 86 & 71.70 & 11.46 \\
Height (cm) & 158 & 185 & 172.60 & 08.20 \\
Flexion (degrees) & 10 & 60 & 41.80 & 16.12 \\
Extension (degrees) & 28 & 80 & 53.60 & 18.32 \\
Lateral Flexion right (degrees) & 14 & 40 & 28.80 & 09.39 \\
Lateral Flexion left (degrees) & 18 & 50 & 34.60 & 12.89 \\
Rotation right (degrees) & 40 & 72 & 53.40 & 11.43 \\
Rotation left (degrees) & 30 & 80 & 53.00 & 21.15 \\
Total score NDI (points) & 5 & 30 & 11.50 & 07.29 \\
Total score S-ROM-Neck patient (mm) & 92 & 570 & 449.40 & 140.50 \\
Total score S-ROM-Neck Assessor (mm) & 256 & 548 & 430.80 & 99.56 \\
\hline
\end{tabular}

\section{Reason for seeing a physical therapist}

All patients reported neck pain as the main complaint, but also had shoulder pain, headaches, dizziness, nausea, visual impairments, and jaw pain: "Yes. Exactly. Because of neck pain and shoulder pain but also seeing impairments. Recently I started to have headaches and sometimes nausea, seldom and lightly, but I have it. And pain in the jaw" 
(Interviewee 1). One patient was diagnosed with neck pain, but the main complaint was restricted movement, plus blocking and pain: "Due to restriction of the movement, blocking and pain as well." (Interviewee 4).

\section{ADL restrictions due to neck pain}

Driving a car, sports participation, work, reading, and sleep were typically affected: "Yes. Moving the left arm during dancing. During singing, I feel a little ... everything is so tight around the neck. And during Yoga classes and such things, I cannot move as usual." (Interviewee 6). Concentration and patience were also affected by the lack of sleep: "Yes, yes, erm, I am less concentrated at work, and due to the lack of sleep I am less patient with others, yes." (Interviewee 5). Others had no impairment but the pain:" I am not really restricted, so...yes, a little, the movement is restricted, but it does not interfere with any of my activities."(Interviewee 3).

\section{General description of the problem}

Pain was most frequently mentioned, together with stiffness, resistance, pressure, pinching or muscle soreness: "Pain and some pressure, so I ... it is pinching me." (Interviewee 6).

\section{Perception on head movement}

Head movement ranged from being no problem at all ("That is no problem, as far as I want to."; interviewee 4) to being completely restricted by pain ("Well, I cannot do it very well. It is painful ... and I cannot go any further."; Interviewee 9). Tightness, stiffness, and blocking were also reported: "Hmm, it feels as if the muscle is too short on the left side." (Interviewee 6).

One patient reported dizziness and nausea on flexion, extension, and rotation: "Now, it is causing pain and dizziness ... and I am feeling a little bit sick." (Interviewee 2). Some patients heard a cracking or popping sound during movement: "It is always related to pain and it is cracking" (Interviewee 10) and "I always feel it if I move, then it pops" (Interviewee 1). Other patients had not done the movement before and said it felt unnatural to execute: "Yes, so I, it feels restricted to me, but I never do it. Moving my head to the front. I would say I bend forward with my whole body, if needed. I never do this movement. It feels unnatural to me." (Interviewee 5) and "Funny, but if you never do it ... this is a movement I never do." (Interviewee 8). 


\section{Subjective impression of movement restriction}

Flexion and extension subjectively felt least restricted in six patients: "I am not restricted to move my head forward, that works fine." (Interviewee 4). However, four felt restricted in flexion: "Yes, ok. But if I go further, then I have to use a lot of force and it starts to be really painful" (Interviewee 10). The most restricted movement was left rotation ("Yes, a little. Because if I would like to turn ... I have to turn completely. So, I have to turn my whole body, I cannot do it like this."; Interviewee 9) followed by right rotation ("Yes, definitely. So, I think, that a person without my problem will be able to move further, for sure."; Interviewee 10) and right lateral flexion ("Yes, I do not think I can go any further"; Interviewee 10).

\section{ADL limitations due to movement restrictions}

ADL limitations were reported for restrictions to flexion, extension, and left and right rotation. Limited flexion impaired the ability to do household chores (e.g., taking things off a shelf), working at a computer, opening a car door, and hobbies (e.g., reading and badminton): "If you take a pan out of the cupboard... if I open a car door." (Interviewee 10). Limited extension also impaired household chores, driving, and hobbies: "More during my spare time. Especially while I dive. When I am looking around I feel it in my neck." (Interviewee 1). Finally, limited neck rotation affected several ADLs. Driving was one of the most common restrictions: "Yes, driving a car. Nowadays I use the mirrors." (Interviewee 9). Participants stated that they rotated the whole body when needing to look to the side in a seat: "Erm, if I sit in front of a computer and a colleague starts talking to me from the side ... I turn my chair to face my colleague." (Interviewee 5) and "it is difficult in a restaurant. If my husband tells me to look at someone, I cannot move my head, I have to turn my chair..." (Interviewee 8). Limited right and left lateral flexion also impaired household chores and work. Some participant stated, that although they had problems with specific movement, they adjusted their behavior so that the restriction did not interfere with activities: “... I am a little bit slower and careful ... to be able to control the movement, so that is does not bother me during my activities." (Interviewee 3 ) and "... but you can definitely live with it." (Interviewee 8). 


\section{DISCUSSION}

We showed medium and strong statistically significant correlations between objective and subjective CROM, and that patients judged CROM as well as assessors. However, although patients did report ADL impairment, they also reported effective coping strategies. Our results for CROM evaluation are comparable with other studies. For one study, our results were similar for flexion but not for extension and rotation. ${ }^{42}$ This was possibly because that study only included women, who typically have greater ROM, ${ }^{43}$ and excluded participants with psychiatric, vestibular, and dizziness complaints. ${ }^{42}$ Patients with neck pain, especially those with acute whiplash disorder, are known to have dizziness and sensorimotor impairments due to disturbed cervical spine receptors, ${ }^{44,45}$ so we excluded this group; but, some patients may have had a traumatic neck injury that caused dizziness or vertigo. We used ROM as an outcome measure because current literature suggests that it is restricted in chronic neck pain and that it decreases with age..$^{42,43,46-48}$ Normal values for CROM have been reported in asymptomatic participants..$^{5}$ In our study, left rotation $\left(20^{\circ}\right)$, right rotation $\left(14^{\circ}\right)$, flexion $\left(12^{\circ}\right)$, and extension $\left(8^{\circ}\right)$ differed most compared with asymptomatic agematched controls.5 Finally, patient and assessor CROM ratings were comparable, and the results were statistically significant in all but two cases. Thus, although subjective and objective assessments overlap, the S-ROM-Neck adds complementary information that might affect treatment decisions. The mean NDI rating indicated that our patients had mild disabilities, but specific problems (e.g., headaches, recreation, reading, pain, and driving difficulties). Although this was confirmed at interviews, patients also reported adjusting their ADLs to limit restriction. Work scored a maximum of 3 , but the interview revealed that different aspects of work were impaired more (e.g., communication and reading); again, patients reported adjusting their behavior. Driving also scored a high NDI rating among drivers, although interviews again revealed that patients made adjustments. Although the average NDI ratings were not very high, during the interview patients stated that they experienced $A D L$ restrictions. This might explain the low correlation between the functional NDI scores and the S-ROM-Neck scores. The NDI is meant to assess pain/functional disability and cognitive functioning, ${ }^{31}$ whereas the S-ROM-Neck assesses potentially unrevealed physiological functioning.

Comparable to other studies, the correlation between patient- and assessor-rated CROM was medium to good between movement directions.49-51 For example, measurements ranged from 0.86 to 0.90 when evaluating mouth opening with a cardboard scale.49 In that study, the higher correlation probably resulted from proper use, with patients instructed to use the scale in front of a mirror, allowing them to make adjustments. $49 \mathrm{In}$ 
our study, patients only completed a form and were asked to execute movements as they interpreted them, without instruction or correction. Moreover, sensorimotor control could have been impaired in our patients. ${ }^{45}$ Using the elbow self-assessment score ${ }^{51}$ patients also used visual inspection and control to judge their movement based on pictures of the desired movement. ${ }^{51}$ However, our results are closer to those published for the Patient's Global Impression of Change and the Clinical Global of Change scales for measuring the perception of change.50 Although they used Likert-type scales ${ }^{52}$ and we used the VAS, both measures rely on the subjective judgment of the user, making it reasonable to compare the correlations. The interviews revealed that patients were aware of ADL restrictions, but that they denied impairment; instead, patients adjusted, raising the question of whether obvious restrictions that do not interfere with ADLs should be treated. It also confirms that it is important to establish treatment goals with patients, which can ensure active involvement and successful outcomes. ${ }^{53}$

Therefore, practitioners should carefully evaluate a patient's needs and goals to ensure focused treatment that does not expose the patient to unnecessary interventions that do not meet his or her goals. ${ }^{54,55}$

\section{Limitations}

Warm-up movements have been recommended before measuring ROM in clinical settings, ${ }^{56}$ but we did not ask for this because we wanted to mimic normal ADL situations where warm-up movements are unlikely. We also included more patients with chronic than acute neck pain, limiting our ability to generalize the results. Furthermore the study sample has a low pain level, therefore future studies should include patients with a higher pain levels due to neck pain.

\section{Conclusion}

There was a significant correlation between patient and therapist CROM ratings. Although patients experienced movement restrictions and ADL impairments, they adjusted their lifestyles to accommodate those limitations. Considering the patient's perspective in this way gives us an important insight into the extent to which pain is a problem. Including patients in goal setting may improve treatment success and help avoid unnecessary examination and treatment. 


\section{References}

1. Rheault W, Albright B, Byers C, Franta M, Skowronek M, Dougherty I. Intertester Reliability of the Cervical Range of Motion Device. JOSPT. 1992;15(3).

2. Macdermid JC, Walton DM, Côté P, Santaguida PL, Gross A, Carlesso L. Use of outcome measures in managing neck pain: an international multidisciplinary survey. Open Orthop J. 2013;7:506-520. doi:10.2174/1874325001307010506.

3. Gajdosik RL, Bohannon RW. Clinical measurement of range of motion. Review of goniometry emphasizing reliability and validity. Phys Ther. 1987;67(12):1867-1872.

4. de Koning CHP, van den Heuvel SP, Staal JB, Smits-Engelsman BCM, Hendriks EJM. Clinimetric evaluation of active range of motion measures in patients with non-specific neck pain: a systematic review. Eur Spine J. 2008;17(7):905-921. doi:10.1007/s00586-008-0656-3.

5. Swinkels R a HM, Swinkels-Meewisse IEJCM. Normal values for cervical range of motion. Spine (Phila Pa 1976). 2014;39(5):362-367.doi:10.1097/BRS.0000000000000158.

6. Snodgrass SJ, Cleland J a., Haskins R, Rivett D a. The clinical utility of cervical range of motion in diagnosis, prognosis, and evaluating the effects of manipulation: A systematic review. Physiother (United Kingdom). 2014;100(4):290-304. doi:10.1016/j.physio.2014.04.007.

7. Prushansky T, Dvir Z. Cervical Motion Testing: Methodology and Clinical Implications. J Manipulative Physiol Ther. 2008;31(7):503-508. doi:10.1016/j.jmpt.2008.08.004.

8. Asha SE, Pryor R. Validation of a method to assess range of motion of the cervical spine using a tape measure. J Manipulative Physiol Ther. 2013;36(8):538-545.doi:10.1016/j.jmpt.2013.07.005.

9. Gelalis ID, Defrate LE, Stafilas KS, Pakos EE, Kang JD, Gilbertson LG. Three dimensional analysis of cervical spine motion: Reliability of a computer assisted magnetic tracking device compared to inclinometer. Eur Spine J. 2009;18(2):276-281.doi:10.1007/s00586-008-0853-0.

10. Sarig-Bahat H, Weiss PL, Laufer Y. Cervical motion assessment using virtual reality. Spine (Phila Pa 1976). 2009;34(10):1018-1024. doi:10.1097/BRS.0b013e31819b3254.

11. Youdas JW, Garrett TR, Suman VJ, Bogard CL, Hallman HO, Carey JR. Normal range of motion of the cervical spine: an initial goniometric study. Phys Ther. 1992;72(11):770-780.

12. Florêncio LL, Pereira P a, Silva ERT, Pegoretti KS, Gonçalves MC, Bevilaqua-Grossi D. Agreement and reliability of two non-invasive methods for assessing cervical range of motion among young adults. Rev Bras Fisioter. 2010;14(2):175-181.

13. Koerhuis CL, Winters JC, Van der Helm FCT, Hof a. L. Neck mobility measurement by means of the "Flock of Birds" electromagnetic tracking system. Clin Biomech. 2003;18(1):14-18. doi:10.1016/S0268-0033(02)00146-8.

14. Kauther MD, Piotrowski M, Hussmann B, Lendemans S, Wedemeyer C. Cervical range of motion and strength in 4,293 young male adults with chronic neck pain. Eur Spine J. 2012;21(8):15221527. doi:10.1007/s00586-012-2369-x.

15. Tousignant-Laflamme Y, Boutin N, Dion AM, Vallée C-A. Reliability and criterion validity of two applications of the $\mathrm{iPhone}^{\mathrm{TM}}$ to measure cervical range of motion in healthy participants. $\mathrm{J}$ Neuroeng Rehabil. 2013;10(1):69. doi:10.1186/1743-0003-10-69.

16. Bishop MD, Mintken PE, Bialosky JE, Cleland J a. Patient expectations of benefit from interventions for neck pain and resulting influence on outcomes. J Orthop Sports Phys Ther. 2013;43(7):457-465. doi:10.2519/jospt.2013.4492.

17. Scherer M, Schaefer H, Blozik E, Chenot J-F, Himmel W. The experience and management of neck pain in general practice: the patients' perspective. Eur Spine J. 2010;19(6):963-971. doi:10.1007/s00586-010-1297-x.

18. Bee P, McBeth J, MacFarlane GJ, Lovell K. Managing chronic widespread pain in primary care: a qualitative study of patient perspectives and implications for treatment delivery. BMC Musculoskelet Disord. 2016;17(1):354. doi:10.1186/s12891-016-1194-5.

19. Odell $A$, Bång $A$, Andréll $P$, et al. Patients expectations and fulfilment of expectations before and after treatment for suspected coronary artery disease assessed with a newly developed questionnaire in combination with established health-related quality of life questionnaires. 2017;4(1):1-12. doi:10.1136/openhrt-2016-000529. 
20. Vaucher C, Maillard MH, Froehlich F, Burnand B, Michetti P, Pittet V. Patients and gastroenterologists' perceptions of treatments for inflammatory bowel diseases: do their perspectives match? Scand J Gastroenterol. 2016;51(9):1056-1061. doi:10.3109/00365521.20 16.1147065.

21. Fetters MD, Curry LA, Creswell JW. Achieving integration in mixed methods designs -Principles and practices. Health Serv Res. 2013;48(6 PART2):2134-2156. doi:10.1111/1475-6773.12117.

22. Creswell JW. A Concise Introduction to Mixed Methods Research. 1st ed. Los Angeles, London, New Delhi, Singapore, Washington DC: SAGE; 2015.

23. Tousignant M, de Bellefeuille L, O'Donoughue S, Grahovac S. Criterion validity of the cervical range of motion (CROM) goniometer for cervical flexion and extension. Spine (Phila Pa 1976). 2000;25(3):324-330. doi:10.1097/00007632-200002010-00011.

24. Audette I, Dumas J-P, Côté JN, De Serres SJ. Validity and between-day reliability of the cervical range of motion (CROM) device. J Orthop Sports Phys Ther. 2010;40(5):318-323. doi:10.2519/ jospt.2010.3180.

25. Fletcher JP, Bandy WD. Intrarater reliability of CROM measurement of cervical spine active range of motion in persons with and without neck pain. J Orthop Sports Phys Ther.2008;38(10):640645. doi:10.2519/jospt.2008.2680.

26. Williams M a., Williamson E, Gates S, Cooke MW. Reproducibility of the cervical range of motion (CROM) device for individuals with sub-acute whiplash associated disorders. Eur Spine J. 2012;21(5):872-878. doi:10.1007/s00586-011-2096-8.

27. Associates PA. Procedure for Measuring Neck Motion with the CROM.; 1988.

28. Strimpakos N, Sakellari V, Gioftsos G, et al. Cervical spine ROM measurements: Optimizing the testing protocol by using a 3D ultrasound-based motion analysis system.Cephalalgia. 2005;25(12):1133-1145. doi:10.1111/j.1468-2982.2005.00970.x.

29. Vernon H, Mior S. The Neck Disability Index: A Study of Reliability and Validity. J Manipulative Physiol Ther. 1991;14(7):409-415.

30. Vernon H. The Neck Disability Index: state-of-the-art, 1991-2008. J Manipulative Physiol Ther. 2008;31(7):491-502. doi:10.1016/j.jmpt.2008.08.006.

31. Swanenburg J, Humphreys K, Langenfeld A, Brunner F, Wirth B. Validity and reliability of a German version of the Neck Disability Index (NDI-G). Man Ther. 2014;19:52-58.doi:10.1016/j. math.2013.07.004.

32. Hopf C. Qualitative Interviews-Ein Überblick. In: Flick U, von Kardoff E, Ines S, eds. Qualitative Forschung; Ein Handbuch. 5th ed. Reinbek bei Hamburg: Rowohlt Taschenbuch Verlag; 2007:349-360.

33. Charan J, Biswas T. How to Calculate Sample Size for Different Study Designs in Medical Research? Indian J Psychol Med. 2013;35(2):121-126. doi:10.4103/0253-7176.116232.

34. Bortz J, Schuster C. Statistik Für Human-Und Sozialwissenschaftler. 7th ed. BerlinHeidelberg: Springer-Verlag; 2010.

35. Norman GR, Streiner DL. Biostatistics - The Bare Essentials. 3rd ed. Shelton: People's Medical Publishing House; 2008.

36. Klassen AC, Creswell J, Plano Clark VL, Smith KC, Meissner HI. Best practices in mixed methods for quality of life research. Qual Life Res. 2012;21(3):377-380.doi:10.1007/s11136-012-0122-x.

37. Kowal S, O'Connell DC. Transkription von Gesprächen. In: Flick U, von Kardoff E, Steinke I, eds. Qualitative Forschung. 5th ed. Reinbek bei Hamburg: Rowohlt Taschenbuch Verlag; 2007:437446.

38. Mayring P. Qualitative Inhaltsanalyse; Grundlagen Und Techniken. 9th ed. Weinheim:Deutscher Studien Verlag; 2007.

39. Mayring P. Einführung in Die Qualitative Sozialforschung. 5th ed. Weinheim und Basel: Beltz Verlag; 2002.

40. Hsieh H-F, Shannon SE. Three approaches to qualitative content analysis. Qual Health Res. 2005;15(9):1277-1288. doi:10.1177/1049732305276687.

41. Mayring P. Qualitative Inhaltsanalyse. In: Flick U, von Kardorff E, Steinke S, eds. Qualitative Forschung; Ein Handbuch. 5th ed. Reinbek bei Hamburg: RowohltTaschenbuch Verlag; 2007:468-475. 
42. Rudolfsson $T$, Björklund $M$, Djupsjöbacka $M$. Range of motion in the upper and lower cervical spine in people with chronic neck pain. Man Ther. 2012;17(1):53-59. doi:10.1016/j.math.2011.08.007.

43. Liu B, Wu B, Van Hoof $\mathrm{T}$, et al. Are the standard parameters of cervical spine alignment and range of motion related to age, sex, and cervical disc degeneration? J Neurosurg Spine. 2015;23(3):274-279. doi:10.3171/2015.1.SPINE14489.

44. Treleaven J. Sensorimotor disturbances in neck disorders affecting postural stability, head and eye movement control-Part 2: Case studies. Man Ther. 2008;13(3):266-275. doi:10.1016/j. math.2007.11.002.

45. Treleaven J. Dizziness, Unsteadiness, Visual Disturbances, and Sensorimotor Control in Traumatic Neck Pain. J Orthop. 2017;(july):492-502. doi:10.2519/jospt.2017.7052.

46. Niederer D, Vogt L, Wilke J, Rickert M, Banzer W. Age-related cutoffs for cervical movement behaviour to distinguish chronic idiopathic neck pain patients from unimpaired subjects. Eur Spine J. 2015;24(3):493-502. doi:10.1007/s00586-014-3715-y.

47. Vogt L, Segieth C, Banzer W, Himmelreich H. Movement behaviour in patients with chronic neck pain. Physiother Res Int. 2007;12(4):206-121. doi:10.1002/pri.377.

48. Machino M, Yukawa $\mathrm{Y}$, Imagama $\mathrm{S}$, et al. Age-Related and degenerative Changes in the Osseous Anatomy, Alignment, and Range of Motion of the cervical Spine: A Comparative Study of Radiographic Data From 1016 Patients With Cervical Spondylotic Myelopathy and 1230 Asymptomatic Subjects. Spine (Phila Pa 1976). 2016;41(6):476-482.doi:10.1097/ BRS.0000000000001237.

49. Saund SSD, Pearson D, Dietrich T. Reliability and validity of self-assessment of mouth opening: a validation study. BMC Oral Health. 2012;12:1. doi:10.1186/1472-6831-12-48.

50. Swanenburg J, Gruber C, Brunner F, Wirth B. Patients' and therapists' perception of change following physiotherapy in an orthopedic hospital's outpatient clinic. Physiother Theory Pract. 2014;3985(January 2016):1-6. doi:10.3109/09593985.2014.994152.

51. Beirer M, Friese H, Lenich A, et al. The Elbow Self-Assessment Score (ESAS): development and validation of a new patient-reported outcome measurement tool for elbow disorders. Knee Surgery, Sport Traumatol Arthrosc. 2015.doi:10.1007/s00167-015-3647-z.

52. Geisser ME, Clauw DJ, Strand V, Gendreau RM, Palmer R, Williams DA. Contributions of change in clinical status parameters to Patient Global Impression of Change (PGIC) scores among persons with fibromyalgia treated with milnacipran. Pain. 2010;149(2):373-378. doi:10.1016/j. pain.2010.02.043.

53. Schliehe F. Rehabilitationsziele von Rehabilitanden. Rehabilitation. 2013;52(2):74 doi:10.1055/s-0033-1341483.

54. Calner T, Isaksson G, Michaelson P. "I know what I want but I'm not sure how to get it" -Expectations of physiotherapy treatment of persons with persistent pain. Man Ther.2016;25(3):e142-e143. doi:10.1016/j.math.2016.05.274.

55. Hadi MA, Alldred DP, Briggs M, Marczewski K, Closs SJ. "Treated as a number, not treated as a person": a qualitative exploration of the perceived barriers to effective pain management of patients with chronic pain. BMJ Open. 2017;7(6):e016454.doi:10.1136/bmjopen-2017-016454.

56. Strimpakos $\mathrm{N}$. The assessment of the cervical spine. Part 1: Range of motion and proprioception. J Bodyw Mov Ther. 2011;15(1):114-124.doi:10.1016/j.jbmt.2009.06.003. 



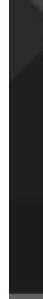



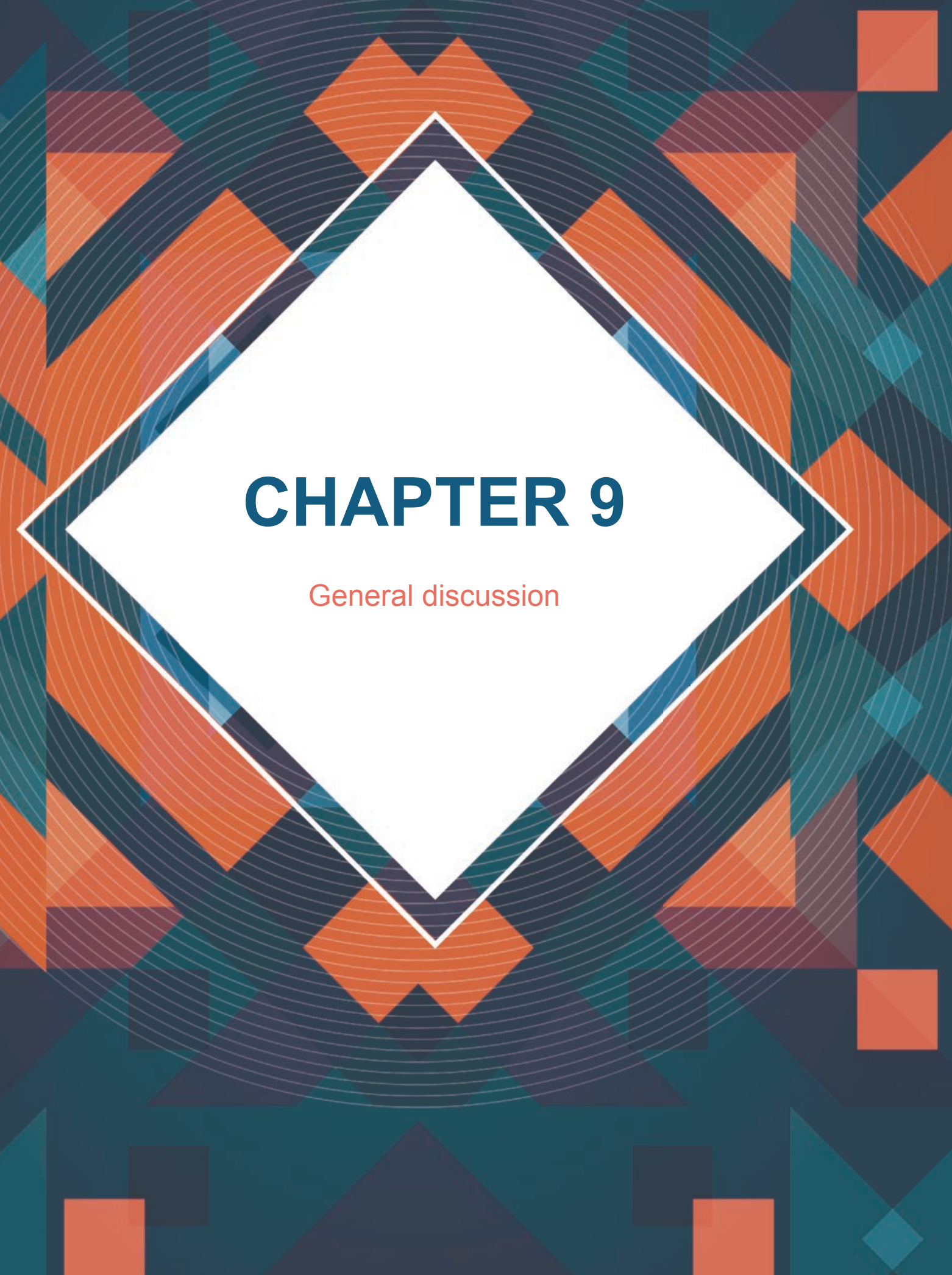

The aim of this chapter is to present the main findings of this thesis in reference to previous studies and to enter them into the current knowledge about neck pain, ist prognosis, its treatment, and the presently used outcome measures. I have presented the main outcomes and findings of the different studies in this thesis and then discussed them with reference to previously mentioned aspects. The first study investigated the prognostic factors that might influence the recurrence of neck pain in a sample of 545 patients. Patients were followed for a period of one year and then data were analyzed. It was found that an age above 45 years and a previous history of neck pain might be associated with the recurrence of neck pain ${ }^{1}$. Although further statistical analyses revealed that both the factors are poor predictors, the findings might help in the treatment of neck pain. The findings can be used to set patient expectations and needs into the right perspective. Furthermore, these findings might help patients understand that these factors could be part of the problem if there is relapse or prolonged recovery. Neither age nor a previous episode of neck pain can be influenced. The findings of this study and the possible solutions for the problems are well aligned with the findings in later chapters of this thesis, with regard to patient perspective. Therefore, it might be reasonable to help patients adjust their perspective and provide them with a realistic view on what they might expect and how they can deal with their complaint. The study investigated possible prognostic factors, and it became clear that there is a need to focus on healthrelated, patient-reported outcome measures (HR-PROs) in patients with neck pain, as limited information is available in German. A protocol for a randomized clinical trial was developed ${ }^{2}$. The goal was to evaluate a newly developed device that applied electromechanical manipulations of the thoracic spine to relieve neck pain ${ }^{2}$. In a subsequent pilot study, it was revealed that

these approaches of manipulations, in combination with exercise, can influence neck pain positively ${ }^{3}$. Additionally, patients who received electromechanical manipulations appeared to benefit more with regard to disability, as measured using the neck disability index. Different questionnaires can be used to assess patients with neck problems. However, with regard to one of the most commonly used questionnaires, the Neck Disability Index (NDI-G), no official German version is available. Moreover, the Örebro Musculoskeletal Pain Questionnaire (Örebro-G) has not been translated into German, and its usability in patients with neck pain has not been assessed. These tools need to be properly translated and tested with regard to reliability and validity for use in German-speaking countries 4,5. As mentioned in the introduction chapter, there are advantages and disadvantages of questionnaires ${ }^{6,7}$. Currently used questionnaires in patients with neck pain involve a pain, multidimensional, disability, or psychological scale ${ }^{8,9}$. Furthermore, none of the 
questionnaires can capture a patient's perspective on the range of motion. Usually, a health care practitioner performs assessments of the cervical range of motion to evaluate movement restrictions. This approach can influence the measurement because the practitioner makes judgments from his/her perspective. Additionally,

questions can either influence a patient's judgment or overlook important aspects. To create a holistic picture of the patient's complaints and needs, the patient's perspective is the most important aspect ${ }^{10}$. In order to obtain the range of motion information from the patient's perspective, a new kind of questionnaire is needed.

The S-ROM-Neck questionnaire appears to be an important alternative to existing questionnaires. Patients judge the range of motion themselves and provide their impressions of the movement ${ }^{11}$. This new tool has been shown to be valid and reliable ${ }^{11}$. However, it is important to determine whether this tool adds new

information that can be considered important to healthcare practitioners. Finally, the objective and subjective perspectives were compared with regard to the range of motion. To obtain a better understanding of the patient's perspective, a mixed-methods approach was used ${ }^{12}$. The study showed that although patients had

restrictions in specific movements, there were no impairments on their activities of daily living. This brings up the question as to whether patients need to be treated if there is no impairment from possible restriction. For example, in the interviews, participants stated that they had problems with rotation to the left, which is common when switching lanes in traffic; however, they used the car mirrors instead of rotating their head. Thus, they did not have any problem while driving a car. Furthermore, patients also mentioned that they adjusted to the situation and did not feel impaired. Thus, in my opinion, healthcare practitioners should integrate the patient's needs into the clinical decision-making process and listen to the patient's complaints.

In conclusion, the importance of a realistic view on what a patient might expect and how the patient can deal with complaints is shown. The treatment of patients with neck pain can be improved by including the patient's perspective into the assessment and treatment. The new S-ROM-Neck questionnaire provides a further step to ensure that patients are better informed and understood. 


\section{Limitations}

The majority of patients participating in this thesis had chronic neck pain and had relatively low pain levels. Therefore, the results of this thesis should be applied with caution to the general population with neck pain. To extend the generalizability of the findings, a more diverse and larger sample is needed. This sample should contain more patients with acute neck pain and high pain levels. Additionally, the NDI-G and Örebro-G should be further evaluated with regard to their responsiveness. The SROM- Neck questionnaire should be used in a different setting, and psychometric properties should be evaluated in depth. Additionally, a larger sample should be used to compare the S-ROM-Neck to the cervical range of motion assessment devices (CROM). 


\section{References}

1. Langenfeld A, Humphreys BK, Swanenburg J, Peterson CK. Prognostic Factors for Recurrences in Neck Pain Patients Up to 1 Year After Chiropractic Care. J Manipulative Physiol Ther. 2015:17. doi:10.1016/j.jmpt.2015.06.014.

2. Langenfeld A, Humphreys BK, de Bie R a., Swanenburg J. Effect of manual versus mechanically assisted manipulations of the thoracic spine in neck pain patients: study protocol of a randomized controlled trial. Trials. 2015;16(1):1-10. doi:10.1186/s13063-015-0763-5.

3. Langenfeld A, Humphreys BK, de Bie RA, Swanenburg J. Comparing manual and mechnically assisted manipulations of the thoracic spine in neck pain patients: A pilot study. F1000 Res. 2018;7(156). doi:10.12688/f1000research.13780.1.

4. Swanenburg J, Humphreys K, Langenfeld A, Brunner F, Wirth B. Validity and reliability of a German version of the Neck Disability Index (NDI-G). Man Ther. 2014;19:52-58. doi:10.1016/j. math.2013.07.004.

5. Langenfeld A, Bastiaenen C, Brunner F, Swanenburg J. Validation of the Orebro musculoskeletal pain screening questionnaire in patients with chronic neck pain. BMC Res Notes. 2018;11(1):161. doi:10.1186/s13104-018-3269-x.

6. Marshall G. The purpose, design and administration of a questionnaire for data collection. Radiography. 2005;11(2):131-136. doi:10.1016/j.radi.2004.09.002.

7. Miller NJ. Questionnaires - The Handbook for Economics Lecturers. The Handbook for Economic Lecturers. http://www.economicsnetwork.ac.uk/handbook/printable/questionnaires_v5.pdf. Published 2002. Accessed December 4, 2017.

8. Schellingerhout JM, Verhagen AP, Heymans MW, Koes BW, De Vet HC, Terwee CB. Measurement properties of disease-specific questionnaires in patients with neck pain: A systematic review. Qual Life Res. 2012;21(4):659-670. doi:10.1007/s11136-011-9965-9.

9. Petala E, Kapoukranidou D, Christos K. Assessment of Patients with Neck Pain : The Most Valid Measurement Tools. Res Rev J Med Heal Sci. 2015;4(4):19-25.

10. Wiklund I. Assessment of patient-reported outcomes in clinical trials: The example of healthrelated quality of life. Fundam Clin Pharmacol. 2004;18(3):351-363.doi:10.1111/j.14728206.2004.00234.x.

11. Langenfeld A, Bastiaenen C, Sieben J, Swanenburg J. Development and validation of a selfadminstered neck mobility assessment tool (S-ROM-Neck) in chronic neck pain patients. Musculoskeletal Science and Practice (2018), https://doi.org/10.1016/j.msksp.2018.04.004

12. Langenfeld A, Bastiaenen C, Sieben J, Humphreys BK, Swanenburg J. Patient's subjective impression of cervical range of motion: A mixed-methods approach. SPINE An International Journal for the study of the spine, DOI: 10.1097/BRS.0000000000002627 



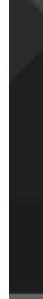



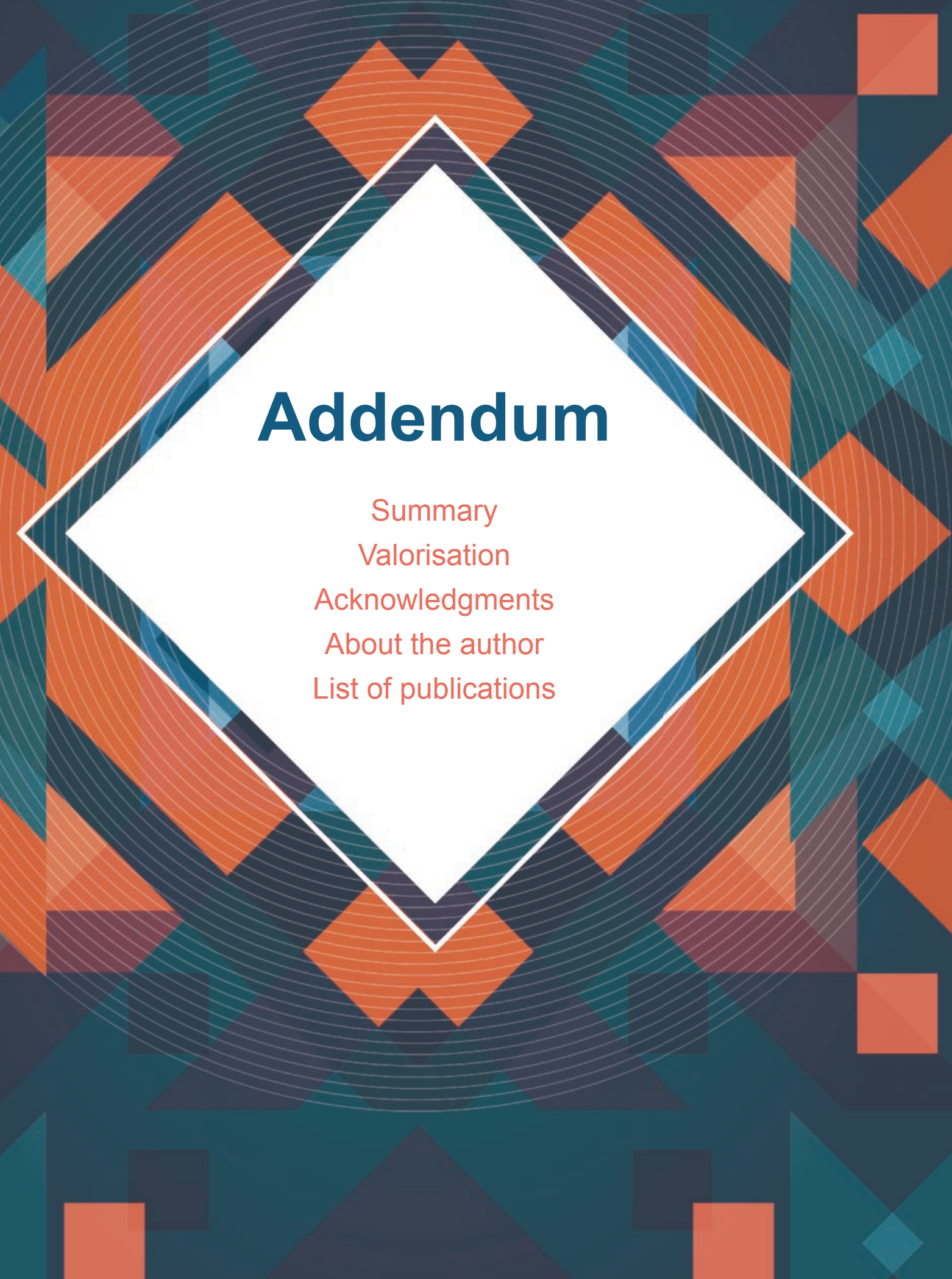



\section{Summary}

Chapter 1 introduces the theme of neck pain. Neck pain, in adjunction with low back pain, is the most common cause of disability worldwide. The prevalence is around $5 \%$ during one year globally. In general, neck pain is described as pain in the back of the neck spreading from the superior nuchal line and the spinous process of T1. However, this describes only the area where the patient perceives the pain. Neck pain usually has a multifactorial etiology and resolves within a few days in most cases.

However, the recurrence and prognostic factors of neck pain have not yet been clearly defined. There are factors that influence the onset and prognosis of neck pain. One of them is patient education. To improve the treatment outcome, current guidelines recommend a structured patient education in combination with exercises, and if the duration is less than three months, manipulation or mobilization can be considered.

Guidelines further recommend frequent reassessment of neck pain to monitor improvement or deterioration. The commonly used assessment tools for patients with neck pain are questionnaires. It is recommended that questionnaires used in the assessment of neck pain should have well confirmed psychometric properties. A novel and important assessment approach is the patient's perspective of the cervical range of motion. This assessment approach provides patient feedback and information from the patient's perspective, which may optimize the evaluation of patients with neck pain. Clinicians should obtain patient feedback and information from the patient's perspective in order to improve and target the treatment accordingly.

In Chapter 2, the findings of a study, which analyzed the data of 545 patients followed for over a year, are presented. The goal was to assess the recurrence and prognostic factors of neck pain. Information about recurrence and prognostic factors is important for patients as well as practitioners to set realistic expectations about the chances of full recovery and to reduce patient anxiety and uncertainty. Only $11 \%$ of the patients were classified as having recurrent neck pain. A logistic regression analysis was conducted to identify the possible prognostic factors. The independent variables were age, pain medication use, sex, work status, duration of neck pain, previous episodes of neck pain, and trauma onset. The analysis revealed that previous episodes of neck pain and increasing age were associated with the recurrence of neck pain. Additionally, the recurrence rate was very low. 
Chapter 3 presents the study protocol for a randomized clinical trial. Manipulations of the cervical spine have some risks for the patient being treated. Currently, the literature is equivocal, but the risk of treatment should be as limited as possible. Therefore, manipulation of the thoracic spine is a welcome alternative for patients with neck pain, and it has already been shown to be effective. The goal was to compare the short- and long-term effects of manual and mechanically assisted manipulations of the thoracic spine, in combination with a standardized exercise program in patients with neck pain. The aim was to include 54 patients with acute or chronic neck pain, without any serious pathology. Three treatment sessions were planned with a 4-day interval. Patients received either manually- or mechanically- assisted manipulations directed to the thoracic spine. The primary outcome measure was the Visual Analogue Pain Scale score. The secondary outcome measures were the German version of the Neck Disability Index (NDI-G), European Quality of Life 5 Dimensions 5 Levels, and Patient's Global Impression of Change Scale score. Both interventions were expected to improve neck pain. This treatment approach does not carry the same risks as those associated with manipulations directed to the cervical spine.

Chapter $\mathbf{4}$ describes the outcomes of a pilot study adhering to the framework as described in chapter 3 . The study included 10 patients aged over 18 years, who were able to speak and read German or English, had acute or chronic neck pain, and had not undergone manual therapy for the thoracic spine previously. Five patients received manual manipulations and five received electromechanical manipulations. Both groups showed an improvement in pain scores with no difference between the groups. There was no significant change in the secondary outcome. The electromechanical manipulation group showed a clinically relevant reduction in the NDI. Both manual and electromechanical manipulations were well tolerated, and this finding indicates that both approaches could be successful treatments for neck pain in combination with exercise. Therefore, thoracic manipulations appear to be beneficial for neck pain, while electromechanical manipulations appear to be able to reduce neck disability. The results of this study should be verified in a larger study.

In Chapter 5, the findings of a validation and reliability study conducted for the NDI-G are presented. The NDI is a well-known and widely used questionnaire and has never been translated into German and tested according to established guidelines previously. Patients with acute and chronic neck pain and healthy participants completed the questionnaire twice, within three days. The total score of the NDI showed high reliability and high Cronbach's alpha. Furthermore, the minimal detectable change and the BlandAltman plot were presented. The Kruskal-Wallis test showed significant differences in the 
total scores between acute neck pain patients and healthy participants. Factor analysis revealed a two-factor structure. The NDI-G is a valid and reliable assessment tool, and its psychometric properties are comparable with those of the original version. Thus, it can be recommended for use in German-speaking countries.

Chapter 6 presents the findings of a validation study that was conducted for the Örebro Musculoskeletal Pain Screening Questionnaire (OMPSQ). This questionnaire was primarily validated in patients with low back pain, and no long-form is available in German. Moreover, this questionnaire was not tested in patients with chronic neck pain. The questionnaire was translated into German, followed by assessment for discriminant validity between patients and healthy adults. Additionally, convergent validity was assessed by using Pearson's correlation coefficient between the ÖMPSQ-G, NDI-G, and VAS. Factor analysis, floor and ceiling effects, internal consistency, and test-retest and relative reliability were assessed. Fifty patients with chronic neck pain and 24 healthy adults participated. The Mann-Whitney $U$ test showed significant differences in OMPSQ scores between both groups at baseline and at the second time point. There were no floor and ceiling effects. Cronbach's alpha was 0.94 , and thus, OMPSQ-G showed high reliability. The Bland-Altman plot indicated no systematic error. OMPSQ-G showed good validity and reliability in patients with neck pain. Thus, OMPSQ-G can be used in patients with chronic neck pain.

Chapter 7 presents the findings of a validation study for a newly developed assessment tool. The patient's perspective of the cervical range of motion is considered. The cervical range of motion is commonly assessed during the first appointment of patients with neck pain. The measurement is often limited by the approach used by the clinician. However, integrating patient perceptual feedback can optimize and personalize treatment. This aspect appears to be lacking in previous studies and has therefore been developed. The aim was to develop and validate a questionnaire (S-ROM-Neck) for evaluating cervical range of motion from the patient's perspective. The assessment tool was developed and optimized during pretest sessions. The reliability and construct validity of the questionnaire were tested. Fifty participants aged over 18 years, with neck pain for over 90 days were enrolled. Only patients who were able to speak, read, and write German fluently were included. The exclusion criterion was the presence of any condition that could limit manual therapy to the cervical spine. Participants completed S-ROM-Neck twice within seven days, along with the VAS for pain intensity and NDI-G. Relative reliability, internal consistency, and absolute reliability were analyzed. Bland-Altman plots were generated. Construct validity was established by correlating the total score of S-ROM-Neck with the scores of 
VAS and NDI-G based on pre-set hypotheses. S- ROM-Neck demonstrated moderate reliability. There were medium negative correlations between VAS and S-ROM-Neck and between NDI-G and S-ROM-Neck. The tool provides patient feedback and information on the patient's perspective, which may optimize the assessment of patients with neck pain.

Chapter 8 presents the association between objective and subjective cervical range of motion among patients with neck pain, and the awareness of impairments has been assessed. The goal was achieved using a mixed-methods approach.

In chapter 7, the new S-ROM-Neck has been described. This tool provides information on personal feelings with regard to the range of motion. However, it does not provide information on whether the patient experiences impairments because of possible reduction in the range of motion.

It is important to know what the patient expects from the treatment and whether the patient feels impaired. Expectations can have profound effects on treatment outcomes and patient satisfaction. A cervical range of motion instrument (CROM), the NDI, and the S-ROMNeck were used. Ten patients participated in semi- structured interviews. Correlations were analyzed using Spearman's rank order correlations $\left(r_{s}\right)$. The Mann-Whitney $U$ test evaluated differences between the patient and assessor. Qualitative data were analyzed by content analysis. Thirty participants were included. Qualitative analysis revealed that patients had general restrictions in daily life and with specific movements, but they adjusted their behavior to avoid impairment. There was a significant correlation between patient and therapist ratings for cervical spine mobility. Although patients experienced restriction while moving and were impaired with regard to specific activities, they adjusted their lifestyle to accommodate their limitations.

In Chapter 9, important and new information with regard to patients experiencing neck pain has been presented. Age and a previous episode of neck pain may influence the recurrence of neck pain. Furthermore, manually and/or electromechanically applied manipulations are successful treatment options for patients with neck pain, with regard to pain and disability. Optimally, they should be combined with exercise. All questionnaires presented in this thesis were found to be valid and reliable for use in chronic neck painspecific treatment, and they were translated into German and evaluated by current standards for the first time. Additionally, there is now a tool that can capture the patient's perspective on the range of motion, and this can aid in the evaluation of patients with neck 
pain. Furthermore, it is important to mention that the patient's perspective on cervical spine range of motion and perceptual disability are important aspects for appropriately addressing the patient's needs. 



\section{Valorisation}

\section{Relevance}

Neck pain is a musculoskeletal condition that affects many people. Current treatment options are targeted at pain and disability, and most available questionnaires are in English. One aspect that can be considered missing is the patient's perspective of cervical range of motion. A patient-centered treatment approach should be the highest goal of any healthcare practitioner. This avoids "seeing" something with regard to the patient's problem and making the patient's problem more severe than it actually is. Additionally, this approach could help with a more targeted treatment and therefore may reduce the cost by focusing on the patient's goals. Additionally, this might support the patient's motivation for, and adherence to, the treatment, as the patient will feel accepted and integrated into the treatment.

\section{Target groups}

The target groups are patients, healthcare practitioners (physical therapists, medical doctors, and chiropractors), and healthcare insurance providers. The findings of this thesis can support healthcare practitioners in their assessments of patients with neck pain, as the thesis provides well-known and globally used questionnaires in German, which may be used in Austria, Germany, and Switzerland. In total, around 160.000 physical therapists in these three countries can use the platform. This approach can make the treatment outcome more comparable to outcomes of international standard. Insurance providers could benefit, as the treatment might be more specific to the patient's needs and therefore may reduce the cost.

\section{Activities/products}

Based on the findings of my thesis, either an application or internet platform (Neck Pain Network ${ }^{\odot}$ ), which provides all relevant questionnaires for the assessment, evaluation, and follow-up of patients with neck pain, is required. For patients, a cut- off value should be provided to suggest a visit to a clinician. For clinicians, the platform could be used to allow the patient to fill out the required questionnaires before the first appointment by embedding it into the home page on the clinician's website. This will provide an impression of the main problems before assessment for the first time. This approach will save the clinician's time and the costs for the patient 
and insurance company. Furthermore, clinicians can use the questionnaires for follow-up to reassess their patients on a scientific basis. Therefore, the approach will help transfer research into practice by providing reliable and valid tools in a single database. From the data, it would be possible to evaluate the clinician's performance with regard to the treatment of neck pain. Additionally, the clinician could use the data to prove that he/she is the most appropriate person to visit for neck pain. Based on this platform, a network of neck-pain specialists could be developed, and this network could provide information to the patient and, if needed, refer the patient directly to a physical therapist, medical doctor, or chiropractor. This network and the data may furthermore support healthcare practitioners in their negotiations with insurance companies, as the findings can be used to show the progress of patients under their care. Finally, the data could be used for further research in the field of neck pain.

The Neck Pain Network ${ }^{\odot}$

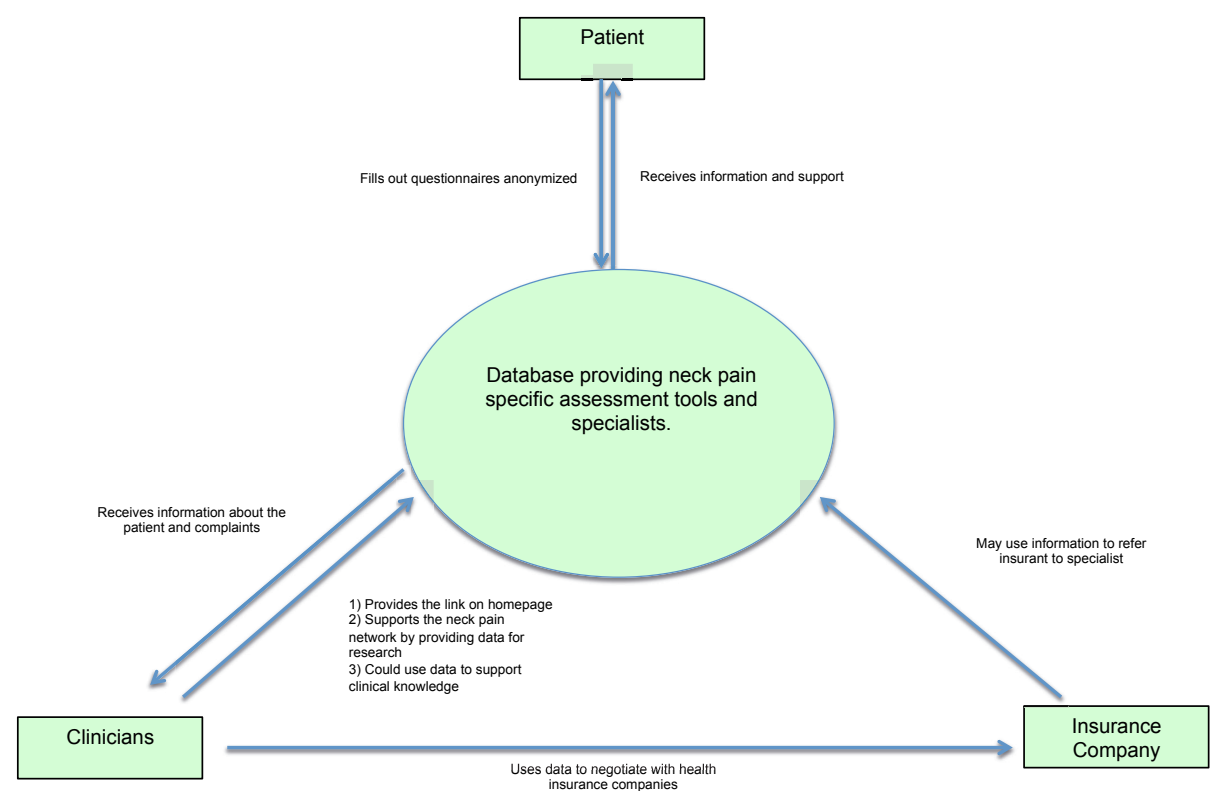

\section{Innovation}

The assessments used in this thesis were not available in German previously. However, they are now available. Furthermore, a completely new tool was developed. It provides a new perspective of neck pain and might change the treatment approach by focusing more 
on the patient's needs and by incorporating the patient's perspective with regard to the complaint.

\section{Schedule}

The first step is to obtain funding for building a minimum viable product. The product should then be evaluated and tested for its functionality, and assessments should be performed to determine whether the target group would accept it. Possible funding sources are the Swiss National Fund (SNF), Pain Research Fund (PRF), and other societies focusing on neck pain research. After funding for the minimum viable product is received, IT specialists need to be hired to program the product (IT Master's/PhD students). Subsequently, the platform needs to be presented and promoted at congresses, which are attended by clinicians working with neck pain patients. The possible risks that should be dealt with include the inaccessibility of some questionnaires in German. Furthermore, clinicians may not accept the tool because they might be afraid of being controlled via the platform or challenged with regard to medical knowledge. Therefore, it is important to mention that every group participating in the platform assessment will be anonymized and that informed consent will be required. The goal is to present the product in the clinician community as a new platform that could help with their clients and support their field of practice. Another goal is to use the platform in all German-speaking countries, and thus, collaboration of the German, Austrian, and Swiss Organizations of Physical Therapists could be useful. Later, extension to other countries is possible after making the questionnaires available in the appropriate languages. 



\section{Acknowledgments}

First of all I would like to thank everybody involved in helping me complete my PhD program.

It has always been my dream to earn a PhD degree. When I first started my research, I had already been working as a physical therapist for three years, but my impression was that I was missing out on important knowledge. Therefore, I completed my Bachelor's degree and eventually started to love scientific work. While pursuing my Master's degree, I got in contact with Prof. em. Kim Humphreys, who thought that I would be a potential PhD candidate and supported me during my application period. Therefore, my heartfelt thanks goes to him for being the first person to believe in me. Thanks a lot Kim!

Through Prof. Humphreys, I then met Dr. Jaap Swanenburg. He has played an important part in my $\mathrm{PhD}$ studies. He believed in me and supported me. He has always been understanding and encouraging. I do not know how he does it, but he has the gift of making all problems seem less formidable and big. This has been something I admire, because this is something that I lack. If there was a chance of me freaking out because something did not work the way I wanted it to, he was relaxed and put everything in the right perspective. You often saved me a lot of trouble! Thank you cordially!

Through him, I got to know Prof. Rob de Bie. After I first met him, Rob accepted me as an external PhD student at CAPHRI, and I could start my research. Rob's input has always been important and has added a new perspective to my studies and my knowledge. Thank you for everything!

I then met Dr. Carolien Bastiaenen and Dr. Judith Sieben. Both were irreplaceable. Their feedback and opinions helped to troubleshoot some harsh reviewers' opinions and extended my research knowledge immensely. Also, I thank them for the extra meetings via skype and in person. They are highly appreciated! Thank you Judith for supporting me during my defense as one of my paranymphs!

I also thank Bernadette Tobler - Ammann and Corinne Ammann - Reiffer! You both were a big support in sharing your experiences and opinions. I always liked our meetings! Thank you Bernadette for being one of my paranymphs! 
Eveline Della Casa and Vladimir Miluntinovic helped me in recruiting participants. Thanks a lot for being reliable and interested in my work. Special thanks to Eveline for traveling to conferences with me!

Last but not least, I have to thank my family: my husband Jens, who supported me during my Bachelors, Masters, and PhD degrees. So far, no further degrees. I promise (;); my mother, who always believed in me and listened to my worries; and my brother Timm, who put a lot of things into the right perspective.

My friends: Helena Breitmaier, Korina Stockmann, and Nadine Köster-Schubring! Thank you for listening, understanding, and supporting me throughout the years!

I would also like to thank the reading committee members of my thesis, and the members of the corona, for their interest in my work and the time spent on reading it: Prof. Dr. A.E. Boonen, Prof. Dr. A.F. Lenssen, Prof. Dr. B. Koes, Dr. B. Staal, and Dr. P.C. Willems. 




\section{About the author}

Anke Langenfeld Sickendieck was born in Osnabrueck, Germany on February 22, 1980. She completed her secondary school at the Graf-Stauffenberg-Gymnasium Osnabrueck, Germany and qualified as a physiotherapist in 2002 at Prof. Grewe Schule, Bad Iburg, Germany. She then started working at Klinik Muensterland, Bad Rothenfelde, Germany with a specialization in rehabilitation of musculoskeletal disorders. In 2005, she participated in a post-graduate program, and she became a trained physical therapist in proprioceptive neuromuscular facilitation (PNF) at Kaiser Permanente Foundation Rehab Centre, Vallejo, USA. Here she worked with patients having neurological disorders, such as paraplegia. Later, she returned to Germany and started working in a private physiotherapy practice focusing on musculoskeletal disorders. Simultaneously, she studied physical therapy at the University of Applied Studies Osnabrueck, Osnabrueck, Germany and earned her Bachelor's Degree in 2008. Later, she moved to Zurich, Switzerland and worked in a private practice for physical therapy focusing on musculoskeletal disorders until 2015. Simultaneously, she continued her studies and earned her Master's Degree in 2011 from Danube University, Krems, Austria. Additionally, she underwent specialized training to become an OMT-therapist. Since 2012, she worked at the Care and Health Research Institute (CAPHRI) at Maastricht University as an external PhD student. Since 2015, she has been managing a practice for musculoskeletal physical therapy in Zurich, Switzerland, and she is part of the Integrative Spinal Research [ISR] team at Balgrist University Hospital, Zurich, Switzerland. She is married and lives in Zug, Switzerland. 



\section{Publications}

1. J. Swanenburg, M. L. Meier, A. Langenfeld, P. Schweinhardt, and B. K. Humphreys. Spinal Stiffness in Prone and Upright Postures During 0-1.8 g Induced by Parabolic Flight. Aerospace Medicine and Human Performance. 2018 June 6;89(6): 563-568

2. Tschopp M, Swanenburg J, Wertli MW, Langenfeld A, McCabe CS, Lewis J, Baertschi E, Brunner F. The German version of the Bath Body Perception Disturbance Scale (BBPDS-D) : Translation, cultural adaptation and linguistic validation on patients with complex regional pain syndrome. Schmerz. 2018 May 7. doi: 10.1007/s00482-0180294-6.

3. Langenfeld A, Bastiaenen C, Sieben J, Humphreys BK, Swanenburg J. Patient's subjective impression of cervical range of motion: A mixed-methods approach. SPINE An International Journal for the study of the spine, doi:10.1097/ BRS.0000000000002627

4. Langenfeld A, Bastiaenen C, Sieben J, Swanenburg J. Development and validation of a self-adminstered neck mobility assessment tool (S-ROM-Neck) in chronic neck pain patients. Musculoskeletal Science and Practice (2018), https://doi.org/10.1016/j. msksp.2018.04.004

5. Langenfeld A, Bastiaenen C, Brunner F, Swanenburg J. Validation of the Orebro musculoskeletal pain screening questionnaire in patients with chronic neck pain. BMC Res Notes. 2018;11(1):161. doi:10.1186/s13104-018-3269-x.

6. Langenfeld A, Humphreys BK, de Bie RA, Swanenburg J. Effect of manual versus mechanically assisted manipulations of the thoracic spine in neck pain patients: study protocol of a randomized controlled trial. Trials 2015a;16:1-10. doi:10.1186/s13063015-0763-5.

7. Langenfeld A, Humphreys BK, Swanenburg J, Peterson CK. Prognostic Factors for Recurrences in Neck Pain Patients Up to 1 Year After Chiropractic Care. J Manipulative Physiol Ther 2015b:1-7. doi:10.1016/j.jmpt.2015.06.014. 
8. Swanenburg J, Humphreys K, Langenfeld A, Brunner F, Wirth B. Validity and reliability of a German version of the Neck Disability Index (NDI-G). Man Ther 2014;19:52-8. doi:10.1016/j.math.2013.07.004.

\section{Presentations}

1. Poster presentation at WCPT 2017, Cape Town, SA:

Development of a self-administered neck mobility assessment tool (S-ROM-Neck) in chronic neck pain patients: A prospective cohort study. Langenfeld A, Bastiaenen C, Sieben J, Swanenburg J, Musculoskeletal Science and Practice (2018)

Cervical spine disability in correlation with subjective voice handicap in patients with voice disorders: A cross-sectional study. Langenfeld A, Bohlender JE, Swanenburg J, Brockmann-Bauser M

2. Poster presentation at WIP 2014, Maastricht, NL and oral presentation at the svomp Symposium 2015, Winterthur, $\mathrm{CH}$

Prognostic factors for recurrences in neck pain patients up to 1 year after chiropractic care. Anke Langenfeld, B. Kim Humphreys, Jaap Swanenburg, Cynthia Peterson. J Manipulative Physiol Ther, Sept 2015

3. Poster presentation at the EFIC 2013, Florence, IT and oral presentation at the svomp Symposium 2013, Winterthur, $\mathrm{CH}$ :

Validity and reliability of a German Version of the Neck Disability Index (NDI-G) by Jaap Swanenburg, Kim Humphreys, Anke Langenfeld, Florian Brunner, Brigitte Wirth. Manual therapy. 2013

4. Poster presentation at the IFOMPT Congress 2012, Quebec, CA:

Low back pain patient's self-report of pain and disability compared to pressure pain algometry: A pilot study. Langenfeld A and Humphreys BK 